\title{
Standoff Chemical Detection Using Laser Absorption Spectroscopy: A Review
}

\author{
Jinyi $\mathrm{Li}^{1,2, *}$, Ziwei $\mathrm{Yu}^{1}$, Zhenhui $\mathrm{Du}^{3}{ }^{3}$, Yue Ji ${ }^{1}$ and Chang Liu ${ }^{2}{ }^{(1)}$ \\ 1 Key laboratory of Advanced Electrical Engineering and Energy Technology, Tiangong University, \\ Tianjin 300387, China; 1831045359@stu.tjpu.edu.cn (Z.Y.); jiyue@tiangong.edu.cn (Y.J.) \\ 2 School of Engineering, the University of Edinburgh, Edinburgh EH9 3JL, UK; c.liu@ed.ac.uk \\ 3 State Key Lab of Precision Measuring Technology and Instruments, Tianjin University, Tianjin 300072, China; \\ duzhenhui@tju.edu.cn \\ * Correspondence: lijinyi@tiangong.edu.cn
}

Received: 21 July 2020; Accepted: 24 August 2020; Published: 26 August 2020

\begin{abstract}
Remote chemical detection in the atmosphere or some specific space has always been of great interest in many applications for environmental protection and safety. Laser absorption spectroscopy (LAS) is a highly desirable technology, benefiting from high measurement sensitivity, improved spectral selectivity or resolution, fast response and capability of good spatial resolution, multi-species and standoff detection with a non-cooperative target. Numerous LAS-based standoff detection techniques have seen rapid development recently and are reviewed herein, including differential absorption LiDAR, tunable laser absorption spectroscopy, laser photoacoustic spectroscopy, dual comb spectroscopy, laser heterodyne radiometry and active coherent laser absorption spectroscopy. An update of the current status of these various methods is presented, covering their principles, system compositions, features, developments and applications for standoff chemical detection over the last decade. In addition, a performance comparison together with the challenges and opportunities analysis is presented that describes the broad LAS-based techniques within the framework of remote sensing research and their directions of development for meeting potential practical use.
\end{abstract}

Keywords: laser absorption spectroscopy; remote sensing; standoff detection; non-cooperative target; mid-infrared

\section{Introduction}

Standoff detection of chemical species (e.g., some atmospheric constituents, explosive, toxic, or hazardous gases), where both the personnel and the detection system are at some distance from the object being measured to realize chemical detection, is a highly sought-after capability for a wide range of applications [1]. Especially in some practical scenarios, remote detection, identification of chemicals, and quantification of chemical concentrations from a safe standoff distance is required. Specific applications include, but are not limited to, the following aspects. (1) Detecting chemical warfare agents (CWAs) and explosives in the public palaces or even on the battlefield [2-4]. A recent solicitation for the US Department of Defense expected to develop field diagnostic capabilities for CWAs detection [5]. (2) Greenhouse gas (GHG) measurement and environmental monitoring [3]. The temporal and spatial distribution of greenhouse gases, such as $\mathrm{CO}_{2}, \mathrm{CH}_{4}, \mathrm{O}_{3}$, etc., is of great concern to those who study climate change. Moreover, very typical applications also involve detection of exhaust emissions from vehicles and industries, as well as monitoring some other atmospheric constituents $\left(\mathrm{NH}_{3}, \mathrm{NO} \ldots\right.$ ), which is necessary for environmental assessment and protection. (3) Industrial leak detection. For petroleum and petrochemical industry, remote sensing, and automatic inspection of leak gases (mostly combustible and toxic) in the whole plant area have always been a very strong demand [6]. 
It can be extended to oil field exploitation, storage and transportation, refining and chemical production, and has important significance for safety. In addition, the related applications include safety inspections in public places, such as station and airports.

Although the precise requirements vary with specific applications, the key common requirements are summarized by N. Macleod and D. Weidmann for standoff chemical detection [7], including multi-species detection, high detection sensitivity, large dynamic range, flexible standoff detection ranges, rapid temporal response, eye-safe laser operation, compact and rugged design, as well as cost-effectiveness. Obviously, these requirements put forward a formidable challenge to detection technology.

Laser absorption spectroscopy (LAS) employs a laser as the spectroscopic light source, and measures the chemical concentration-based on the detection of a variation of laser beam intensity after transmission along the optical path, or based on detection of the acoustic waves caused by laser-radiation absorption of target chemicals. LAS is proven one of the most sensitive technologies for quantitative measurement of gas-phase chemicals because nearly every molecule possesses a unique spectroscopic "fingerprint" in the infrared spectral region [8]. Compared with conventional absorption spectroscopy using broadband incoherent radiation sources, LAS-based chemical sensing offers a highly desirable combination of high-sensitivity and high-speed detection, and the collimated laser source with high brightness allows beam propagation over large distances. Therefore, it not only can easily be configured with a cooperative target (e.g., corner-cube, retroreflector) for open-path detection, but more importantly can be used for true standoff sensing with non-cooperative targets (e.g., diffusely scattering topographic) for more flexible and diverse applications. This is an advantage of LAS over other optical sensing techniques with non-laser light sources [9], such as differential optical absorption spectroscopy (DOAS) [10,11], Fourier transform infrared (FTIR) spectroscopy [12,13], etc. Due to the low power of the thermal radiation sources employed in FTIR, open-path FTIR systems usually require long integration times to collect a spectrum. This is especially the case when trace compounds have to be detected, which only show up in tiny spectral signatures in the spectra. In addition, thanks to the use of laser source, LAS-based standoff technology has good features of improved spectral selectivity or resolution, high selectivity, good spatial resolution and high spatial coherence [14], which help it meet the aforementioned requirements of remote detections to the greatest extent and make it one of the most promising solutions for highly efficient and sensitive standoff chemical detection.

On the other hand, although many laser diagnostic technologies have their own applications and characteristics [15], LAS can easily meet the requirement of human eye-safe operation, due to less demanding of laser power, when compared with other standoff laser spectroscopic technologies that are not based on absorption spectroscopy, such as laser-induced fluorescence (LIF) [16], laser-induced breakdown spectroscopy (LIBS) [17] and coherent anti-Stokes Raman spectroscopy (CARS) [18]. While in LIBS, LIF or CARS, a laser is transmitted into the open air, and these techniques may help capable to approach the required sensitivity levels but generally fail to meet the eye-safe criteria or selectivity [19]. Although Raman spectroscopy can achieve standoff chemical detection using eye-safe laser radiation [20], the small Raman cross-section limits the SNR and the sensitivity [21]. However, it should be noted that line-of-sight is necessary for optical measurement. Once the light path is blocked by obstacles in standoff measurement, it will cause the measurement failure. Therefore, special attention should be paid to this challenge in the actual remote sensing applications using LAS technology.

LAS technology for local measurements has been comprehensively reviewed recently, which are typically used in the fields of combustion diagnosis [22,23] and breath analysis [24]. While LAS-based standoff detection technology has been extensively studied, especially in the past decade, and can be implemented in various system configurations using different spectroscopic methods. These LAS-based techniques include differential absorption LiDAR (DIAL), tunable diode laser absorption spectroscopy (TDLAS), laser photoacoustic spectroscopy (LPAS), dual-comb spectroscopy (DCS), laser heterodyne radiometry (LHR) and active coherent laser absorption spectroscopy (ACLaS). The straightforward 
solution of standoff LAS systems is to arrange a laser transmitter and receiver face to face or both at the same end and with a retroreflector at the distal end. The latter is more common in remote detection applications because of its more practical characteristics. The advantage of this scheme is that the detector can receive very strong laser energy, which ensures a high signal-to-noise ratio (SNR) and a long detection range. Therefore, almost all LAS methods can use this configuration to realize open-path detection. On the other hand, another way of standoff detection is achieved by detecting the backscattered light from a distant hard target or topographic target (namely non-cooperative target), which is the true standoff detection and more attractive in practical applications. Both standoff detections, with a cooperative target and with non-cooperative target, have been developed, and even widely applied in the past decade. Furthermore, some LAS-based techniques have been used for quantitative measurement of liquids, solids or plasma apart from detection of gases or vapors. Therefore, it is necessary to summarize these LAS-based standoff detection technologies in principles of operation, critical enabling technology, advantages and limitations. Unfortunately, there is no comprehensive review of the development of this direction in recent years to our best of knowledge.

Based on a brief overview of the principle of LAS for quantitative measurement, the aforementioned LAS-based techniques for standoff-detection were reviewed one by one in this paper, covering their principles, system components, characteristics, and state-of-the-art. In view of the urging demands in both the use and development of standoff chemical detection technology, a goal of this manuscript is to provide a comprehensive understanding and an overview of the related laser spectroscopic techniques and a reference for future research and development in this field.

\section{Basic Principle}

When a beam of light, either monochromatic or composite, passes through the target gas, the absorption spectrum is generated if the molecule of the irradiated sample gas selectively absorbs some frequency bands of the radiated light. The fundamentals of molecular absorption spectroscopy have been elaborated in detail $[25,26]$. According to the theory of the electromagnetic spectrum, the mechanism of spectrum generation in different regions are different, and corresponds to different energy level transitions. From near-infrared (NIR) to mid-infrared (MIR), the absorption spectra are mainly caused by vibrational and rotational transitions of molecules, which is the main concern of this paper. Almost all chemical species have their unique absorption spectra in the IR region. The specific position, shape and intensity of the absorption line carry the characteristic information of the absorbent. Coupled with HITRAN database [27] with line-by-line parameters, GEISA spectroscopic database [28] or PNNL database [29], it forms the basis for gas-phase species detection.

The fundamental theory lying behind absorption spectroscopy is the Beer-Lambert law, which describes the relationship between the transmitted intensity $I_{t}$ and the incident intensity $I_{0}$ through the gas medium. Its expression is presented in Equation (1) with multiple forms [30]:

$$
\begin{aligned}
I_{t}(v) \quad & =I_{0}(v) \exp \left(-\alpha_{v}\right) \\
& =I_{0}(v) \exp \left(-k_{v} L\right) \\
= & I_{0}(v) \exp \left(-n \sigma_{v} L\right) \\
= & I_{0}(v) \exp \left(-S \varphi_{v} P \chi_{i} L\right)
\end{aligned}
$$

where $\alpha_{v}$ is the spectral absorbance, $k_{v}\left[\mathrm{~cm}^{-1}\right]$ is the spectral absorption coefficient, $L[\mathrm{~cm}]$ is the absorption pathlength, $n$ [molecule/ $\mathrm{cm}^{3}$ ] is the number density of the absorbing species, $\sigma_{v}\left[\mathrm{~cm}^{2} /\right.$ molecule] is the absorption cross-section, $S\left[\mathrm{~cm}^{-2} / \mathrm{atm}\right]$ is the absorption linestrength of an individual transition line, $\varphi_{v}[\mathrm{~cm}]$ is the frequency-dependent lineshape function, $P[\mathrm{~atm}]$ is the total gas pressure, and $\chi_{i}$ is the mole fraction of the absorbing species $i$. The subscript $v$ denotes the spectral dependence of the parameter on the light frequency $v$.

Different forms in Equation (1) express the gradual expansions of the total absorbance $\alpha_{v}$. The first three forms are applicable to absorption spectroscopic measurements in general. When knowing the 
absorption cross-section $\sigma_{v}$, one can obtain the number density of the absorbing species according to the third expression. However, the last form is more demanding because it contains a lineshape function. Therefore, it is suitable for the measurement of small gas molecules with narrow absorption features, which can be described by an analytical expression. The narrow spectral lines can be obtained by wavelength scanning of tunable lasers with a rather narrow linewidth, so that quantitative measurements are performed to determine the chemical concentration of interest via the measured ratio $I_{0}(v) / I_{t}(v)$.

It is more challenging for practical standoff detection in the open atmosphere. In the laboratory, the intensities $I_{t}(v)$ and $I_{0}(v)$ can be determined by measurements with and without the absorber in the light beam, which is easily implemented in sampling measurement with a gas cell. However, $I_{0}(v)$ is difficult to determine in the open-path standoff detection applications, as it would involve removing the air, or more precisely the absorbing gas, from the atmosphere. On the other hand, when the laser beam passes through the atmosphere, its intensity decreases, due to the absorption of a target gas. Besides that, it also suffers extinction owing to absorption by other trace gases in the atmosphere, and scattering by air molecules and aerosol particles. In addition, the transmissivity of the instrument (mirrors, windows, retroreflectors, grating, etc.) will also reduce the light intensity. Moreover, atmospheric turbulence can cause fluctuations in both the intensity and the phase, as well as widen the light beam, due to variations of the refractive index along the transmission path caused by inhomogeneities in the temperature and pressure of the atmosphere [31]. Therefore, the laser power collected by the receiver would also decrease. As a result, various factors affecting the light intensity should be taken into account by a formula that includes the absorption of various trace gases with concentration $n_{j}$ and absorption cross-sections $\sigma_{j}(v)$, Rayleigh and Mie extinction, $\varepsilon_{R}(v)$ and $\varepsilon_{M}(v)$, as well as the instrumental effects and turbulence $A(v)$, to deduce an expanding Beer-Lambert law [11]:

$$
I_{t}(v)=I_{0}(v) \cdot \exp \left[-L \cdot\left(\sum_{j}\left(n_{j} \cdot \sigma_{j}(v)\right)+\varepsilon_{R}(v)+\varepsilon_{M}(v)\right)\right] \cdot A(v)
$$

It is difficult or even not achievable in practical terms to determine the multiple factors affecting the light intensity in the atmosphere. However, note that aerosol extinction processes, the effect of turbulence, and many trace gas absorptions show very broad or even smooth spectral characteristics [11], so these effects can collectively be regarded as background variations. For the case where the target absorbers and their cross-sections are known, and the absorbers are narrow, it is possible to calculate the baseline to remove these background variations [32]. Another solution is measuring the difference between the absorptions at two different but near wavelengths, i.e., so-called 'differential' absorption. This approach benefits from the cancellation of common-mode terms, due to the background that is nearly identical at both wavelengths. Alternatively, one can employ the signal processing method of differential optical absorption spectroscopy (DOAS) to separate broad- and narrowband spectral structures in an absorption spectrum in order to eliminate the influence of background and isolate the target gas absorptions [11,33].

The performance of LAS-based sensors is commonly evaluated through the detection limit, which can be assessed by the noise-equivalent absorbance (NEA) or the minimal detectable concentration (e.g., in ppm) [30]. In standoff detection, the optical pathlength depends on the standoff distance that is usually variable in real-world applications, and hence, the performance is often quantified using the pathlength-integrated unit of ppm.m [9]. Further normalization with bandwidth renders a detection limit in the unit of $\mathrm{ppm} \cdot \mathrm{m} \cdot \mathrm{Hz}^{-1 / 2}$ to account for the SNR improvement with averaging in the domain that white noise dominates [7].

\section{Differential Absorption LiDAR (DIAL)}

The methodology of Differential Absorption LiDAR (DIAL) has been developed in the 1960s. DIAL was first employed in 1966 for remote measurement of water vapor [34], which made it the 
earliest laser absorption-based technique to be used for remote atmospheric-sounding. The IR region, particularly over the range of $1.0-16.0 \mu \mathrm{m}$ is the most commonly used band for DIAL sounding applications [3], in which a large number of strong absorption lines of nearly every atmospheric gas and pollutant are located. Moreover, it is in the spectral region that extensive absorption bands of most CWAs and toxic industrial chemicals (TICs) are situated [3]. Although it is usually impractical to detect light directly scattered from the plume itself, due to low molecular (Rayleigh) scattering efficiency in the IR spectral region, DIAL can use the aerosol particulates contained in the plume with a corresponding high Mie scattering cross-section or a hard surface located behind the plume to scatter or reflect laser light back to the detector. Therefore, two ways are executable for atmospheric sounding with the DIAL method in practice, namely, the LiDAR approach and integrated path differential absorption (IPDA) approach [3], respectively. The former method is usually referred to in literature as a "range-resolved DIAL (RR-DIAL)", as shown in Figure 1a. This mode remotely measures the gaseous impurity profiles via backscattered light by atmospheric aerosol with space resolution $\Delta R$. The spatial resolution is limited by laser pulse width $\tau(\Delta R=c \tau / 2)$, but the real value depends on the counting rate $\left(S_{c r}\right)$ or the dwell time $\left(1 / S_{c r}\right)$ if photon counting mode is employed $\left(\Delta R=c / 2 S_{c r}\right)$. While for IPDA approach, it provides a method to detect a signal reflected or diffusely reflected from different topographic surfaces, as shown in Figure 1b. This method ensures a highly sensitive determination of average concentrations of gaseous impurities along optical paths in directions corresponding to the azimuth of topographic targets.
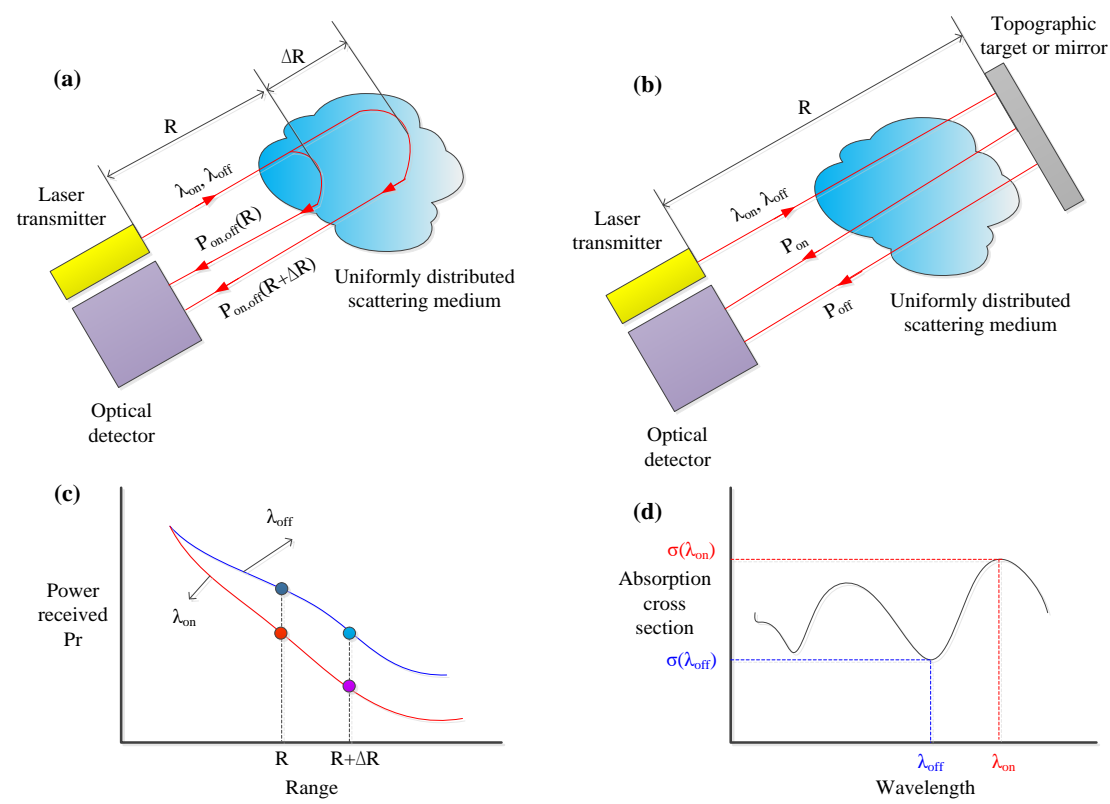

Figure 1. Differential Absorption LiDAR (DIAL) concept (a) range-resolved DIAL detection approach, (b) IPDA approach, (c) signal-reflection powers at wavelengths $\lambda_{\text {on }}, \lambda_{\text {off }}$ and (d) absorption cross-section at wavelengths $\lambda_{\text {on }}, \lambda_{\text {off. }}$.

The principle of DIAL is shown in Figure 1. A dual-wavelength laser pulse is sent in the direction of a target to realize an absorption measurement. One wavelength is tuned to a strong absorption feature of the gas of interest, often referred to as the "on" wavelength $\left(\lambda_{o n}\right)$ and the other is set at a nearby wavelength with weak absorption by the target gas, generally called the "off" wavelength $\left(\lambda_{\text {off }}\right)$, as shown in Figure 1d. A sensitive photodetector detects the light backscattered by particles at the two different wavelengths. The average gas concentration, $N_{A}$, within the range interval $\Delta R$, can be calculated from the ratio of the backscattered LiDAR signals at $\lambda_{\text {on }}$ and $\lambda_{\text {off }}[4,35]$ :

$$
\left.N_{A}=\frac{1}{2 \cdot \Delta R \cdot\left[\sigma\left(\lambda_{o n}\right)-\sigma\left(\lambda_{\text {off }}\right)\right.}\right] \ln \left[\frac{P_{\text {ron }}(R) \times P_{\text {roff }}(R+\Delta R)}{P_{\text {roff }}(R) \times P_{\text {ron }}(R+\Delta R)}\right] \text {, }
$$


where, $\sigma\left(\lambda_{o n}\right)$ and $\sigma\left(\lambda_{\text {off }}\right)$ are the absorption cross-sections at $\lambda_{\text {on }}$ and $\lambda_{\text {off }}$ and $P_{\text {ron }}(R)$ and $P_{\text {roff }}(R)$ are the received light powers from range $R$ at the on and off wavelengths, respectively, as shown in Figure 1c. As can be seen from Equation (3), the calculation after the measurement process is simplified, due to the use of a differential approach.

There have been several review articles with respect to DIAL and its applications [4,36]. DIAL has the advantages of high temporal and spatial resolution, as well as high detection sensitivity. However, the system design is relatively complicated, and especially the high quality and high-power laser source is a key component. DIAL systems are usually divided into two design categories based on their transmitter characteristics [37], i.e., using high-power tunable dye lasers and fixed-wavelength lasers, respectively. The former system is extremely versatile, but is relatively large with high power consumption, and thus, is limited to large aircraft platforms, which are costly to operate. While the latter can be made more compact for operation on smaller aircrafts, but cannot be optimized to maximize the temporal and spatial resolution and minimize undesired interferences. Progress in tunable solid-state laser technology have bridged the gap between these two approaches [38,39]. DIAL has been recently extended to multi-species measurements by using tunable broadband optical parametric oscillators $[40,41]$. A summary about representative DIAL detections is shown in Table 1 with the different species, the wavelength used and the detection capacities. As can be seen in Table 1 , DIAL systems can also be classified based on the wavelengths utilized, including UV, visible, NIR, MIR, and THz. Many combinations are possible in practical applications. For example, a DIAL system has been developed by the National Physical Laboratory with the capability of measuring a wide range of species in the UV and IR spectral regions [42,43], in which two synchronized continuum Nd-YAG lasers were used to provide pump energies for the frequency conversion stages, running at $10 \mathrm{~Hz}$ and $\sim 8 \mathrm{~ns}$ pulse duration. A Sirah dye laser is also employed to provide narrowband tunable radiation that is either frequency-doubled to give UV output, or converted into IR by different frequency-mixing and optical parametric amplification using the tangential phase-matching scheme. The DIAL system can be used to monitor atmospheric pollutants remotely, at ranges of up to $1 \mathrm{~km}$, including methane, ethane, ethene, ethyne, general hydrocarbons (HCs, e.g., petroleum and diesel vapors), $\mathrm{HCl}, \mathrm{NO}, \mathrm{NO}_{2}$, $\mathrm{SO}_{2}$, benzene and toluene [44].

Improving the detection SNR of DIAL has always been a relentless pursuit of researchers, because the weak echo signal received by the photodetector is mixed with the background noise and the detector noise. Detailed sensitivity analysis has been made for DIAL measurements [45,46], which laid the foundation for SNR improvement. Most recently, an upconversion detector (UCD)-a combination of an optical upconverter that efficiently translates infrared signals to the visible region and a visible detector that has high detectivity - has been used for $\mathrm{CO}_{2}$ [47] and $\mathrm{CH}_{4}$ DIAL [48]. Benefiting from the SNR improvement compared with direct detection by InGaAs based detector, the system possessed the ability to measure the differential absorption optical depths between 3 and $9 \mathrm{~km}$ with relative errors less than $11 \%$ [49]. On the other hand, numerous signal processing and denoising methods have been proposed to improve SNR and performance of DIAL. A method of wavelets based on a soft threshold was demonstrated that it could effectively denoise the noisy LiDAR signals in strong background light and achieve improvement in the signal to noise ratio of the system [50]. A lifting wavelet transform denoising method was also presented to obtain the high-quality signal of ground-based $\mathrm{CO}_{2}$-DIAL [51]. A universal multi-event locator, as an original automatic detection tool, was demonstrated to improve the measurements of LiDAR and DIAL systems, benefiting from manifold advantages of the technique in detecting backscattering peaks [49]. The method was also very effective in improving the detection of single events buried in a quite high level of noise. In addition, neural networks have been used for columnar $\mathrm{CO}_{2}$ retrieval, which allowed one to involve additional a priori information and to couple different input and output data [52]. The involvement of a priori data on the pressure profile significantly increases the retrieval accuracy. The temperature data increases the accuracy, but by less than 0.2-0.4 ppm [53]. A detailed error budget analysis has been presented for the multi-frequency DIAL measurements, which provided an important reference for SNR improvement [40]. 
Table 1. Summary about DIAL detection with the different species, the wavelength used and the detection capacities.

\begin{tabular}{|c|c|c|c|c|c|c|c|c|}
\hline Species & Strategy & Test Environment * & Detection Limits & Precision & Detection Time & Resolution & Detection Range & Ref. \\
\hline $\mathrm{NH}_{3}$ & RR-DIAL, OPG/OPA 211-215 nm & Laboratory & $40 \mathrm{ppm}$ & - & $2.5 \mathrm{~min}$ & $16 \mathrm{~cm}$ & $2 \mathrm{~m}$ & [54] \\
\hline Ozone & RR-DIAL, $283-310 \mathrm{~nm}$ & Actual & $2 \mathrm{ppb}$ & - & $10 \mathrm{~s}$ & $90 \mathrm{~m}$ & $400 \mathrm{~m}$ & [37] \\
\hline $\mathrm{NO}_{2}$ & $\begin{array}{l}\text { RR-DIAL, } 1.6 \mathrm{~W} 450 \mathrm{~nm} \mathrm{CW} \\
\text { LD }\end{array}$ & Actual & $\begin{array}{l}0.9 \mathrm{ppbv} \\
1.5 \mathrm{ppbv} \\
2.4 \mathrm{ppbv}\end{array}$ & - & $15 \mathrm{~min}$ & $\begin{array}{c}700 \mathrm{~m} \\
1 \mathrm{~km} \\
1 \mathrm{~km}\end{array}$ & $\begin{array}{l}0.3-1 \mathrm{~km} \\
1-2 \mathrm{~km} \\
2-3 \mathrm{~km}\end{array}$ & [55] \\
\hline $\mathrm{CH}_{4}, \mathrm{H}_{2} \mathrm{O}$ & IPDA, $1646 \mathrm{~nm}$ & Actual & - & $3 \sim 11 \%$ & $15 \mathrm{~min}$ & - & $3-9 \mathrm{~km}$ & [48] \\
\hline $\mathrm{CH}_{4}, \mathrm{CO}_{2}$ & 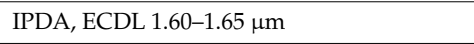 & Actual & - & $3 \%, 1 \%$ & $30 \mathrm{~s}$ & - & $2.75 \mathrm{~km}$ & [56] \\
\hline $\mathrm{H}_{2} \mathrm{O}, \mathrm{CO}_{2}$ & RR-DIAL, $1602.2 \mathrm{~nm}, 7 \mathrm{MJ}$ pulse energy & Actual & - & $11 \%, 1.5 \%$ & $10 \mathrm{~min}$ & $250 \mathrm{~m}$ & $1 \mathrm{~km}$ & [40] \\
\hline $\mathrm{CO}_{2}$ & RR-DIAL, $2.05 \mu \mathrm{m}$ band & Actual & - & $3 \%$ & $40 \mathrm{~s}$ & $270 \mathrm{~m}$ & $8-11 \mathrm{~km}$ & [57] \\
\hline $\mathrm{CH}_{4}, \mathrm{H}_{2} \mathrm{O}$ & IPDA, 3.1-3.5 $\mu \mathrm{m}$, average power $>300 \mathrm{~mW}$ & Laboratory & $595 \mathrm{ppb} \cdot \mathrm{m}$ & - & - & - & $70 \mathrm{~m}$ & [41] \\
\hline $\mathrm{CH}_{4}$ & RR-DIAL, 3.3-3.4 $\mu \mathrm{m}$ & Actual & $50 \mathrm{ppb}$ & - & $1-2 \mathrm{~min}$ & $10-30 \mathrm{~m}$ & $1 \mathrm{~km}$ & [43] \\
\hline $\mathrm{CH}_{4}$ & RR-DIAL, 3.3-3.5 $\mu \mathrm{m}$ OPO $6 \mathrm{MJ}$ pulsed laser & Laboratory & - & $8-13 \%$ & $6.4 \mathrm{~s}$ & $100 \mathrm{~m}$ & $800 \mathrm{~m}$ & [58] \\
\hline $\begin{array}{c}\mathrm{NO}, \mathrm{NO}_{2}, \mathrm{SO}_{2} \\
\text { Benzene, Toluene }\end{array}$ & RR-DIAL, UV and Visible & Actual & $20,50,10,10,10 \mathrm{ppb}$ & - & - & $10-30 \mathrm{~m}$ & $500,500,1000,600,600$ & [44] \\
\hline $\begin{array}{l}\mathrm{CH}_{4}, \mathrm{C}_{2} \mathrm{H}_{6}, \mathrm{C}_{2} \mathrm{H}_{4}, \\
\mathrm{C}_{2} \mathrm{H}_{2}, \mathrm{HCs}, \mathrm{HCl}\end{array}$ & RR-DIAL, MIR 3.3-3.4 $\mu \mathrm{m}$ & Actual & $80,20,130,30,30,15 \mathrm{ppb}$ & - & - & $10-30 \mathrm{~m}$ & $600,600,600,600,600,800 \mathrm{~m}$ & [44] \\
\hline $\mathrm{H}_{2} \mathrm{O}$ & IPDA, $1.0-3.5 \mathrm{THz}$ & Laboratory & - & - & - & - & tens of meters & [59] \\
\hline
\end{tabular}

${ }^{*}$ Test environment denotes that the performance evaluation of the corresponding detection was conducted under laboratory or actual environment. 
RR-DIAL can achieve spatially resolved measurement by collecting light backscattered from different ranges. However, this atmospheric scattering has about 1 million times lower reflectance than the cooperative corner cubes. The extremely weak echoes cause conventional RR-DIAL systems to be more complex and to require higher laser power, larger optics, and speciality detectors. Dobler et al. have developed an improved system, named greenhouse gas laser imaging tomography experiment (GreenLITE TM), for two-dimensional (2D) GHG spatial distribution measurement on local scales [60]. Two fiber-coupled DFB lasers are employed to generate an online with strong absorptions at $1571.112 \mathrm{~nm}$ and an offline with significantly lower absorptions at $1571.061 \mathrm{~nm}$ for $\mathrm{CO}_{2}$ detection and 2D mapping. Different from the traditional DIAL, GreenLITE uses intensity-modulated continuous wave semiconductor lasers as the light source and retroreflectors at the far end as the cooperative targets. Benefiting from the use of lock-in processing technique and retroreflectors, the detection SNR (typically $>3000$ ) can be improved greatly. A measurement precision ranges from 0.5 to $2.3 \mathrm{ppm}$, which depends on the distance and the environment. Two or more scannable transceivers and tens of retroreflectors are arranged such that the lines (or chords) between the two transceivers and each retroreflector generate a grid of interweaved segments. Computer tomography (CT) algorithm is used to reconstruct the $2 \mathrm{D}$ spatial distribution of $\mathrm{CO}_{2}$ concentration by means of the measured integrated $\mathrm{CO}_{2}$ column concentration along each horizontal chord. Field tests show that an accuracy of source localization is better than $11 \mathrm{~m}$ on a $0.2-\mathrm{km}^{2}$ grid, while in the presence of ambient $\mathrm{CO}_{2}$ concentrations and prevailing local wind. Field deployments demonstrate GreenLITE's capability for many applications ranging from continuous remote monitoring of ground carbon storage/sequestration facilities to the real-time measurement and assessment of subscale GHG events within complex open-air environments [61-63].

In addition, in order to use for the ground-based remote sensing, DIAL systems have been equipped on various platforms to expand the applications from local point measurement to large-scale regional detection and even global observation [64]. Common platforms include, but are not limited to, vehicles, uncrewed aerial vehicles (UAVs), aircrafts and satellites. Vehicle-based DIALs are usually used to monitor the emission flux of areas of interest, e.g., industrial complexes and urban sectors emission, with simultaneously measuring the atmospheric temperature, atmospheric pressure, wind speed, and wind direction $[64,65]$. Recently, a compact and movable ozone DIAL based on an all-solid-state and tuning-free laser source has been developed and deployed as vehicle-borne detection for regional $\mathrm{O}_{3}$ pollution monitoring [66]. The development of airborne DIAL began in the late 1970s and early 1980s [67]. In airborne monitoring, IPDA approach is generally exploited for gas column measurement of interest. An airborne prototype prior to the GreenLITE system has been demonstrated and used in a number of field campaigns for high-precision $\mathrm{CO}_{2}$ column measurements $[68,69]$. Other airborne $\mathrm{CO}_{2}$ DIALs have also been developed and applied based on absorptions at either $1.57 \mu \mathrm{m}$ [70] or $2 \mu \mathrm{m}[71,72]$. Water vapor in the atmosphere can be simultaneously measured with $\mathrm{CO}_{2}$ by using an airborne triple-pulsed $2 \mu \mathrm{m}$ IPDA [73,74]. Additionally, airborne DIALs have been developed for simultaneous measurement of ozone and water vapor profiles in the tropopause region [75] and for $\mathrm{CH}_{4}$ observations [76-78]. Not only have airborne DIAL systems provided a wealth of information about atmospheric chemistry and dynamics during the past 40 years, but also their development and deployment provide a good foundation upon which to base designs for space-based DIAL systems $[46,79,80]$. Employing an IPDA LiDAR instrument, the methane remote sensing LiDAR mission (MERLIN) aims at demonstrating the spaceborne active measurement of atmospheric methane, with a launch currently scheduled for the timeframe 2021/22 [81,82]. Spaceborne DIAL for atmospheric gas traces sensing will certainly help for climate monitoring and to predict the importance of global climate changes.

In summary, DIAL technology can be applied from local to global scale depending on the objectives of the measurements. Specific applications include but are not limited to global measurement of atmospheric constituents, detection and measurement of chemical warfare agents, detection and measurement of a pollutant over urban areas, validation or calibration of models, use of high-resolution Doppler LiDAR as a complementary tool, which has been reviewed in detail in Reference [49]. 
Furthermore, it is noteworthy that one of the advantages in the use of RR-DIAL is the obtainment of spatial distributions of chemical vapors. Because the knowledge of chemical vapor spatial distributions is important to separate and independently quantify emissions from multiple sources and to discriminate between the chemical source and the background. The spatial resolution of the technique is usually on the order of several meters or more, as shown in Table 1 for general DIALs. However, an alternative to the IPDA approach, referred to as backwards transient absorption spectroscopy (BTAS) has been presented to be able to reach millimeter scale spatial resolution [83]. In BTAS, a UV (195 nm) pump and an NIR probe pulsed laser beams illuminate the same spot on a topography target located behind the gas to be measured, and the NIR backscattered photons are utilized to acquire transient absorption spectra of Rydberg state excited by the UV pump laser. The spatial resolution of the technique is determined by the laser pulse duration (15 ps) and the lifetime of the Rydberg state (3.2 ps). This BTAS technique is expected to bring new applications of ultrahigh spatial resolution detection. In addition, LiDAR techniques have also been demonstrated for combustion diagnostics recently. A centimeter-scale range resolution for a collection distance of $2.5 \mathrm{~m}$ and a detection limit of 30 ppm for measurement of potassium chloride $(\mathrm{KCl})$ in a large-scale boiler were achieved by a picosecond DIAL [84]. A portable Scheimpflug LiDAR system was developed and used for large-scale ( 1-20 m) combustion diagnostics [85]. Most recently, a DIAL based on a broadband supercontinuum laser has been reported for temperature measurement in combustion power plants [86].

\section{Tunable Diode Laser Absorption Spectroscopy (TDLAS)}

Tunable diode laser absorption spectroscopy (TDLAS), employs a tunable diode laser (TDL) with a very narrow linewidth to obtain gas absorption lines at very high spectral resolution by current or thermal tuning the emission wavelength. TDLAS is one of the most promising and widely used techniques for gas detection. Especially the development of MIR semiconductor lasers recently, e.g., quantum cascade lasers (QCLs) and interband cascade lasers (ICLs), enhances the vitality of TDLAS [8]. It can reach ppm level or even lower detection limit with long optical path length, due to the advantages of high sensitivity, good selectivity and fast response. There have been many comprehensive reviews about TDLAS and its applications [30,87]. Here in this section, we focus on the standoff TDLAS detection and try to bring this research direction up to date with recent developments. Other open-path systems that use open-path gas cells are beyond the scope of this section.

\subsection{TDLAS with Retroreflectors}

A simple standoff open-path TDLAS can be realized by means of a transceiver coupled with a retroreflector, which retrieves path-averaged gas concentrations by a long-path transmission measurement. A schematic diagram is shown in Figure 2 to describe typical TDLAS systems with three different modes of operation, i.e., direct absorption spectroscopy (DAS), wavelength modulation spectroscopy (WMS) and frequency modulation spectroscopy (FMS). DAS is the simplest one, where a tunable laser is a wavelength scanned by a ramp signal to cover the absorption of the target gas. The optical signal absorbed by the gas is directly collected through the photodetector and then processed by the computer, as shown in Figure 2a. DAS relies on a measurement of a small change of a signal on top of a large background. Any noise introduced by the light source or the optical system will deteriorate the detectability of the technique. The sensitivity of DAS techniques is often limited to an absorbance of $\sim 10^{-3}$, and it is vulnerable to the effects of background noise. Therefore, DAS is seldom used for many standoff detection applications.

Alternatively, modulation techniques are widely used to improve SNR by encoding and detecting the absorption signal at a high frequency, where the noise level is low. In modulation spectroscopy, the laser is modulated by a sinusoid injection current signal with high-frequency $f$ superimposed on the ramp that makes wavelength continuously scanned across the absorption profile. As shown in Figure $2 b$, WMS is characterized by the use of a large modulation depth generating a large number of sidebands, and a modulation frequency is much smaller than the linewidth of the target gas 
$(f<1 \mathrm{MHz})$. The modulated laser is then collimated and passes through a gaseous medium through an off-axis parabolic mirror (OAPM) with a small hole and then illuminates onto an opposite optical reflector. The reflected laser propagates back to the gaseous medium and is concentrated by the OAPM onto a photodetector. The detector signal is demodulated in two lock-in amplifiers (LIAs), respectively, with reference-in signals of one- and two-times modulation frequency. The first (1f) and second harmonic (2f) signals are obtained simultaneously and then processed in a computer or an embedded processor for WMS-2f/1f calibration-free measurement to avoid the influence of light intensity fluctuations in open-path detection. While in the case of FMS, the modulation depth is small, but the frequency is very high $(f>100 \mathrm{MHz})$, which is the same magnitude as the line width of the target gas. Therefore, a radio frequency (RF) signal generator is usually utilized to generate such a high modulation signal, and a bias tee is used to superimpose the RF signal with the scanning signal to drive the laser, as shown in Figure 2c. The frequency modulated laser reflected by the mirror at a far end carries both absorption and dispersion information of the target gas, which is detected by a high-speed detector. The detector signal is sent to an RF-LIA. The absorption component and dispersion component are obtained by in-phase and quadrature-phase demodulation in the RF-LIA, respectively, to retrieve gas concentration [88]. Although FMS has lower $1 / f$ noise, it has a higher cost of a lock-in amplifier and other optoelectronic devices than WMS as a result of the requirement of higher modulation frequency. Therefore, WMS techniques are most widely used in TDLAS for standoff gas detection. Owing to the suppression of noise, the sensitivity of modulation spectroscopy can be brought into the $10^{-5}-10^{-6}$ range or even better [89].

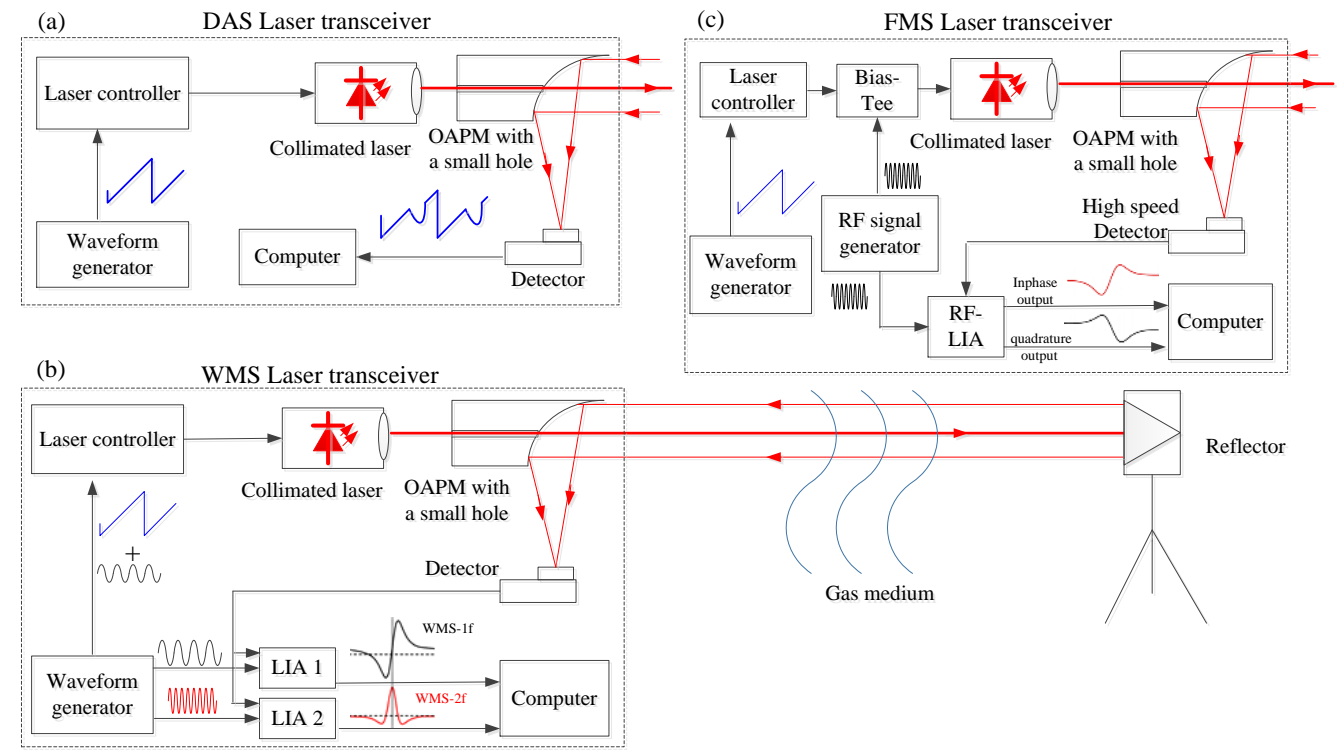

(c) FMS Laser transceiver

Figure 2. Three schemes of tunable diode laser absorption spectroscopy (TDLAS) systems for open-path standoff detection with an optical reflector with direct absorption spectroscopy (DAS)

(a) wavelength modulation spectroscopy (WMS) (b) and frequency modulation spectroscopy (FMS)

(c) RF, radio frequency, LIA, lock-in amplifier, OAPM, off-axis parabolic mirror.

It can be seen that this scheme is similar to the TDLAS with a gas cell system, except that the open-path is used to replace the multipath gas absorption cell. Moreover, there is almost no extra loss in detection capability compared with the latter, due to the use of optical reflectors. A broadly-tunable ECQCL operating at $20 \mathrm{~Hz}$ spectral sweep rate and spectral resolution of $4 \mathrm{~cm}^{-1}$ was used for standoff gas-phase chemical detection over 300-600 m distances using a corner-cube retroreflector, from which noise equivalent concentration length (NECL) values as low as $0.75 \mathrm{ppm} \cdot \mathrm{m}$ in $2-5 \mathrm{~s}$ averaging times were estimated for strongly absorbing chemicals [90]. The main application scenarios include measurement of greenhouse gas emissions [91], hazardous gas detection in underground coal mines [92], atmospheric 
composition monitoring [93-95], leak detection in petroleum storage tanks [87], standoff detection of alcohol vapors exhaled by humans [96], etc. Most recently, it has been utilized for food volatiles detection and handheld TDLAS sensor to detect meat spoilage [97].

It is noteworthy that a system concept called LaserWarn ${ }^{\mathrm{TM}}$ [98] can be established by the system shown in Figure 2 for protection of outdoor facilities, such as for leakage detection and warning in the oil depot. The LaserWarn transceiver is directed in sequence to inexpensive retroreflectors placed at opposite ends of the facility and measures the transmittance along each of the optical paths, as shown in Figure 3. Conjointly, these laser beam paths form an "optical fence" around the facility. If a threat cloud crosses the "optical fence", the LaserWarn system will detect its presence. In addition to sequentially interrogating multiple-beam paths, it is also practicable to configure a system of mirrors such that the laser beam crisscrosses the facility in such a way that the transceiver does not require to move [90]. Moreover, the LaserWarn system is suitable for the protection of large indoor areas, such as airports. Advantages of this method include the capability of detecting a diversity of gases with high sensitivity over large distances (several kilometers). Furthermore, the system needs no consumables and leads to low maintenance compared to a network of point sensors. Recent advances in TDLAS standoff detections with retroreflectors are summarized in Table 2.
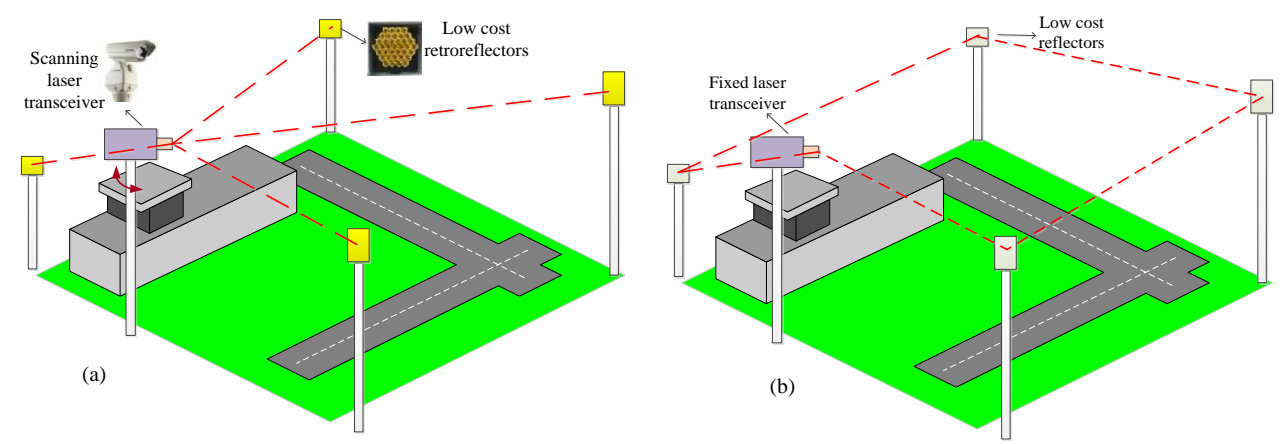

Figure 3. LaserWarn system [98] for threat cloud detection and facilities protection by constructing an "optical fence" with (a) laser transceiver scanning mode and (b) laser transceiver fixed mode.

Note that the WMS signal is intensity-dependent and requires normalization by the received power, which especially in low-light conditions might be a source of a significant measurement error. In order to mitigate this limitation of WMS, Wysocki and Weidman introduced a novel technique, named chirped laser dispersion spectroscopy (CLaDS) [99], for quantitative trace gas detection based on molecular dispersion measurements. Rather than measuring absorption, ClaDS detects refractive index changes that occur in the vicinity of a molecular transition. The essence of phase-detection makes it highly immune to amplitude noise and transmission fluctuations, which means ClaDS particularly suitable for open-path remote or standoff sensing. The performance of ClaDS sensor for open-path sensing has been demonstrated by standoff $\mathrm{N}_{2} \mathrm{O}$ detection using a $4.53 \mu \mathrm{m}$ QCL [100]. A detection limit down to the single-ppbv level is achieved. Subsequently, the same research group used ClaDS based on a $1.65 \mu \mathrm{m}$ DFB LD for standoff remote $\mathrm{CH}_{4}$ detection both in the laboratory [101] and in the field [102]. Furthermore, standoff $\mathrm{H}_{2} \mathrm{~S}$ detection using $\mathrm{ClaDS}$ was reported, and the minimum detection limit of $255 \mathrm{ppm} \cdot \mathrm{m}$ was obtained at an averaging time of $1 \mathrm{~s}$ [103]. These detection results are also summarized in Table 2. Although ClaDS has shown advantages in standoff detection, the ultra-high modulation and demodulation frequency (hundreds of $\mathrm{MHz}$ to $\mathrm{GHz}$ level) makes its cost and complexity greater than that of WMS, which possibly limits its application. 
Table 2. Recent advances in TDLAS standoff detections with retroreflectors.

\begin{tabular}{|c|c|c|c|c|c|c|}
\hline Species & Strategy & Test Environment & Detection Limits & Detection Time & Distance & Ref. \\
\hline HF & $1284 \mathrm{~nm}$ & Laboratory & $1 \mathrm{ppb}$ & $0.1 \mathrm{~s}$ & $25 \mathrm{~m}$ & {$[104]$} \\
\hline \multirow{4}{*}{$\mathrm{CH}_{4}$} & $1.6 \mu \mathrm{m}$ WMS & Actual & $2 \mathrm{ppb}$ & $60 \mathrm{~s}$ & $2.6 \mathrm{~km}$ & [105] \\
\hline & $1.65 \mu \mathrm{m}, 200-\mathrm{mm}$ Fresnel lens & Actual & $1.1 \mathrm{ppm} \cdot \mathrm{m} / \mathrm{Hz}^{1 / 2}$ & - & $1-2 \mathrm{~km}$ & [92] \\
\hline & 1653.7 & Laboratory & $1 \mathrm{ppm}$ & $2 \mathrm{~s}$ & $100 \mathrm{~m}$ & [87] \\
\hline & $1.65 \mu \mathrm{m}, \mathrm{ClaDS}$ & Actual & $1.7 \mathrm{ppm} \cdot \mathrm{m} / \mathrm{Hz}^{1 / 2}$ & $1 \mathrm{~s}$ & $20 \mathrm{~m}$ & [102] \\
\hline $\mathrm{C}_{2} \mathrm{H}_{2}$ & $1531.6 \mathrm{~nm}$ & Laboratory & $0.4 \mathrm{ppm}$ & $2 \mathrm{~s}$ & $100 \mathrm{~m}$ & [87] \\
\hline $\mathrm{C}_{2} \mathrm{H}_{4}$ & $1621.4 \mathrm{~nm}$ & Laboratory & $0.5 \mathrm{ppm}$ & $2 \mathrm{~s}$ & $100 \mathrm{~m}$ & [87] \\
\hline \multirow{3}{*}{$\mathrm{H}_{2} \mathrm{~S}$} & $1.58 \mu \mathrm{m}, 200$-mm Fresnel lens & Actual & $15 \mathrm{ppm} \cdot \mathrm{m} / \mathrm{Hz}^{1 / 2}$ & - & $1-2 \mathrm{~km}$ & [92] \\
\hline & $1.574 \mu \mathrm{m}, \mathrm{ClaDS}$ & Laboratory & $225 \mathrm{ppm} \cdot \mathrm{m} / \mathrm{Hz}^{1 / 2}$ & $1 \mathrm{~s}$ & $18 \mathrm{~m}$ & [103] \\
\hline & $1.6 \mu \mathrm{m}$ WMS & Actual & $20 \mathrm{ppm}$ & $20 \mathrm{~s}$ & $2.6 \mathrm{~km}$ & [105] \\
\hline \multirow[t]{2}{*}{$\mathrm{CO}_{2}$} & 2004 nm WMS & Actual & - & - & $7.2 \mathrm{~m}$ & [94] \\
\hline & $2.05 \mu \mathrm{m}$ DAS & Laboratory & $36 \mathrm{ppm}$ & - & $15 \mathrm{~m}$ & [93] \\
\hline \multirow{2}{*}{$\mathrm{NH}_{3}$} & $1103.4 \mathrm{~cm}^{-1}$ & Laboratory & $0.46 \mathrm{ppb}$ & $2 \mathrm{~min}$ & $60 \mathrm{~m}$ & [95] \\
\hline & LaserWarn ${ }^{\mathrm{TM}}$ & Calculated & $80 \mathrm{ppb}$ & - & $25 \mathrm{~m}$ & {$[90]$} \\
\hline $\mathrm{NO}$ & $1900 \mathrm{~cm}^{-1}$ & Laboratory & $0.4 \mathrm{ppb}$ & $2 \mathrm{~min}$ & $60 \mathrm{~m}$ & [95] \\
\hline \multirow{2}{*}{$\mathrm{NO}_{2}$} & $1600 \mathrm{~cm}^{-1}$ & Laboratory & $0.4 \mathrm{ppb}$ & $2 \mathrm{~min}$ & $60 \mathrm{~m}$ & [95] \\
\hline & $4.53 \mu \mathrm{m}, \mathrm{ClaDS}$ & Actual & $1.2 \mathrm{ppm} \cdot \mathrm{m} / \mathrm{Hz}^{1 / 2}$ & $10 \mathrm{~s}$ & $17 \mathrm{~m}$ & [100] \\
\hline \multirow{2}{*}{$\mathrm{O}_{3}$} & $1031.2 \mathrm{~cm}^{-1}$ & Actual & $0.3 \mathrm{ppm} \cdot \mathrm{m}$ & $18 \mathrm{~s}$ & $2.9 \mathrm{~km}$ & [106] \\
\hline & 9.3 to $9.81 \mu \mathrm{m}$ & Actual & $<10 \mathrm{ppb}$ & $8 \mathrm{~min}$ & $38 \mathrm{~m}$ & [107] \\
\hline $\mathrm{SO}_{2}$ & LaserWarn TM & Calculated & $2.4 \mathrm{ppm}$ & - & $25 \mathrm{~m}$ & [90] \\
\hline $\mathrm{HNO}_{3}$ & LaserWarn TM & Calculated & $0.15 \mathrm{ppm}$ & - & $25 \mathrm{~m}$ & [90] \\
\hline HCLO & LaserWarn ${ }^{\mathrm{TM}}$ & Calculated & $0.26 \mathrm{ppm}$ & - & $25 \mathrm{~m}$ & [90] \\
\hline Freon-134a & 2 Mini-QCLs, $780-1330 \mathrm{~cm}^{-1}, 50-\mathrm{mm}$-diameter receive aperture & Actual & $3 \mathrm{ppb}$ & $5 \mathrm{~s}$ & $155 \mathrm{~m}$ & [90] \\
\hline Freon-152a & ditto & Actual & - & $2 \mathrm{~s}$ & $281 \mathrm{~m}$ & [90] \\
\hline
\end{tabular}




\subsection{TDLAS with Non-Cooperative Target}

Although the TDLAS systems that deploy retroreflectors or other cooperative targets can achieve open-path detection, they are not ideal for mobile or multidirectional measurements. This is because the direction of the beam is defined by the system layout, and has to be realigned when the system is moved. In the last decade, special attention has been devoted to the research and development of a real standoff sensing with backscattered light with non-cooperators, called backscatter-TDLAS [108]. Here in this section, we focus on this kind of standoff open-path system that retrieves path-averaged gas concentrations by collecting the backscattered light from a distant non-cooperative topographic target.

In backscatter-TDLAS, a transceiver projects the laser beam onto a remote non-cooperative surface instead of an optical reflector, as shown in Section 4.1, and only receives a fraction of the passively scattered laser light returned from the surface [109]. The biggest challenge of this technique is the collection of weak backscattered light to ensure adequate detection SNR. The commonly used optical structure for backscatter-TDLAS can be generally divided into two categories. The first approach uses a large-diameter Fresnel lens [110-112], as shown in Figure 4a. The simple structure is conducive to integrate a compact, lightweight and low-cost handheld system for short path standoff detection. A $5 \mathrm{~cm}$ diameter receiver is adequate to collect sufficient scattered light for $\sim 10 \mathrm{~m}$ distance standoff detection [108]. The second approach, which utilizes a large-aperture telescope [6,113], as shown in Figure $4 \mathrm{~b}$, can be used for long-range standoff detection. On the other hand, the overall performance of the instrument greatly depends on the optical properties of the backscattering target $[114,115]$. Most recently, backscattering properties and hemispherical reflectance of some common topographic targets have been measured in the visible, NIR, and MIR spectral ranges [116], which is useful for optimizing active standoff TDLAS detection and DIAL with hard-target, as well as for increasing their overall efficiency.
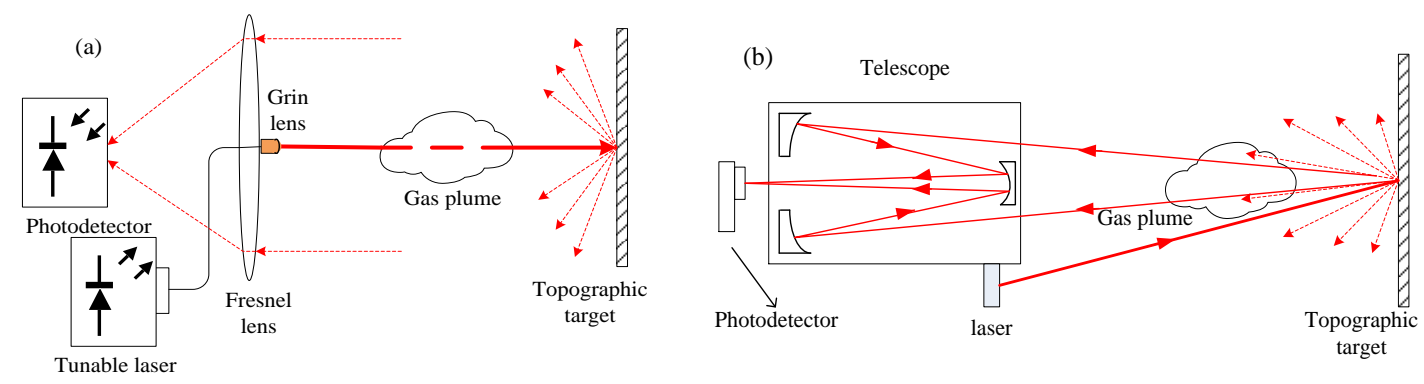

Figure 4. Typical transceiver units of the TDLAS system with the non-cooperative target (a) with a single Fresnel lens, and (b) with a large-aperture telescope.

Natural gas leak detection in the pipeline has been the most widely reported application by using this TDLAS technique. The $1.65 \mu \mathrm{m}$ band is a superior choice for commercial $\mathrm{CH}_{4}$ sensor development and application, because of the rugged and easy to align fiber-coupled DFB laser diode, the low-cost optical components commercially available in optical communication and the field-tested durability. M. B. Frish et al. developed a handheld Remote Methane Leak Detector (RMLD) that employed a $10 \mathrm{~mW}$ scale laser and was capable of detecting a few ppm-m methane at a $30 \mathrm{~m}$ range [117]. By inserting an erbium-doped fiber amplifier (EDFA) that boosts the laser output power $\sim 500 \times$ to the $5 \mathrm{~W}$ scale, and increasing the telescope diameter, they have extended the standoff distance to $3000 \mathrm{~m}$ (increased the standoff range by approximately two orders of magnitude) [118]. Then, they provided relatively low-cost lightweight and battery-powered aerial leak sensors. A miniaturized ultra-lightweight TDLAS sensor flies aboard a small quad-rotor uncrewed aerial vehicle (UAV) for landfill methane monitoring [118] less than $1 \mathrm{~W}$ of electrical power. Additionally, they presented measured range limits from a variety of common tomographic targets (as many as 22 different surfaces). They listed some representative hazardous gases and relative detection limits for the NIR region. The latest progress is that a miniaturized, downward-facing RMLD mounted on a small UAV has 
been developed to investigate natural gas fugitive leaks [119] and further to localize the leakage, as well as quantify the emission rate [120]. Recently, QCL has become a reliable MIR light source for a variety of trace gas sensing applications either in pulsed or continuous mode. QCLs can work at room temperature with a high output optical power, are relatively compact, and can address mid- to long-wave infrared spectral range applications where many trace gases exhibit significant absorption features. Consequently, QCLs have been successfully used for many standoff detection applications [121,122]. Adrian Diaz et al. presented a standoff detection of $\mathrm{CH}_{4}$ and $\mathrm{N}_{2} \mathrm{O}$ leaks with a $7.7 \mu \mathrm{m}$ pulsed QCL that retrieves path-averaged concentrations by collecting the backscattered light from a distant hard target. They achieved an uncertainty of $3.1 \%$ and normalized sensitivity of $3.3 \mathrm{ppm} \cdot \mathrm{m} \mathrm{Hz}^{-1 / 2}$ for $\mathrm{N}_{2} \mathrm{O}$ and $9.3 \%$ and normalized sensitivity of $30 \mathrm{ppm} \cdot \mathrm{m} \mathrm{Hz}^{-1 / 2}$ for $\mathrm{CH}_{4}$ at a standoff range of $45 \mathrm{~m}$ [123]. Moreover, QCLs have been widely used for standoff explosives detection [124-126]. In realistic scenarios, explosives are usually concealed, and their detection mostly relies on the sensing of evaporated substance in the surrounding air. Peroxide-based explosives like triacetone triperoxide (TATP) possess a much higher vapor pressure (7 Pa with an equilibrium concentration of $\sim 70 \mathrm{ppm}$ ) [125], making direct LAS detection using QCLs possible. However, for the nitrogen-based explosives, the concentrations of evaporated molecules are only in the range of ppb to ppt level because of the very low vapor pressure [125]. It is extremely difficult to directly detect this type of explosives. This difficulty can be circumvented by the combination of TDLAS with pulsed laser fragmentation (PLF) [126-128]. PLF is used to produce a measurable concentration of decomposition products (e.g., $\mathrm{NO}$ and $\mathrm{NO}_{2}$ ) that are subsequently detected by synchronized MIR laser absorption spectroscopy. TDLAS standoff detection (based on MIR QCLs with a non-cooperative target) is not only employed to detect chemicals in gas phase, but is also used as a powerful method to identify bulk materials and trace contaminants on surfaces [98]. Most recently, a TDLAS system with three MIR QCLs has been reported for detection and quantification of explosives in soils at a distance of $15 \mathrm{~cm}$ [129]. Using multivariate analysis and artificial intelligence techniques, the system is capable of distinguishing between soils contaminated with DNT, TNT, or RDX and uncontaminated soils with 0.997 accuracy.

The concept, based on TDLAS standoff detection with non-cooperative targets, has also been employed for in situ measurement of combustion diagnosis. Ze Wang and S. T. Sanders first developed a single-ended laser-absorption-spectroscopy (SE-LAS) sensor that uses return scattering from native surfaces, such as the piston of an automotive engine, which benefits of ease of installation and mitigates the invasive drawbacks [130]. The SE-LAS sensor can collect $10 \mu \mathrm{W}$ backscatter through a 2-mm-diameter aperture in the case of a $20 \mathrm{~mW}$ DFB laser as the light source. Afterwards, the authors demonstrated the feasibility of spatially resolved measurements of gas properties using a SE-LAS sensor in conjunction with two-line thermometry [131]. A 1-D distribution of $\mathrm{H}_{2} \mathrm{O}$ mole fraction and temperature with a spatial resolution of $5 \mathrm{~mm}$ were obtained. The method can be extended to measurements for other species' distribution and 2-D scanning. SE-LAS MIR sensors based on QCLs have also been developed for simultaneous in situ measurements of $\mathrm{H}_{2} \mathrm{O}, \mathrm{CO}_{2}, \mathrm{CO}$, and temperature in combustion flows [132]. Most recently, C. S. Goldenstein has designed and demonstrated a compact SE-LAS sensor for measuring temperature and $\mathrm{H}_{2} \mathrm{O}$ in high-temperature combustion gases by collecting laser light backscattered off native surfaces [133]. The SE-LAS sensor achieved an optical collection efficiency and provided a measurement accuracy and precision that is similar to or better than the conventional line-of-sight-based LAS sensor.

In practical remote detection by standoff WMS with a non-cooperative target, the received light energy varies, due to the variation of the scattering surface characteristics, as well as the change of the distance between the sensor and the tomographic surface. Therefore, measures should be taken to eliminate the fluctuation of the light intensity detected, among which the most commonly used effective method is using the first harmonic (1f) signal to normalize the second harmonic (2f) signal, namely, WMS-2f/1f technique [134]. In addition, there are several methods to realize the calibration-free measurement [30]. Wuwen Ding et al. put forward a measurement scheme, called 'Baseline-offset' 
WMS, which means the zero response of the detector has been offset by a reference cell inserted into the measuring optical path. This scheme inherits the merits of WMS and can achieve high SNR, especially in a low concentration environment [135].

This type of standoff detection has great potential in applications of atmospheric environmental monitoring, leak detection and security early-warning, benefiting from great robustness and flexibility. The current performance of this technique is summarized in Table 3. However, as we can see, the detection distance of TDLAS with non-cooperative target ranges only from a few meters to tens of meters. Although it can be extended by approximately two orders of magnitude via utilizing a fiber-amplified source and increasing the telescope diameter [108], standoff range improvement needs to be compromised with human eye safety in practical applications. Another research direction is to develop chip-scale low-power integrated-optic gas-phase chemical sensors based on TDLAS [136], which are beneficial towards robot-assisted gas remote sensing [137] and leak rate quantification and localization with small UAVs $[108,138]$.

Table 3. Recent advances in TDLAS standoff detections with non-cooperators.

\begin{tabular}{|c|c|c|c|c|c|c|}
\hline Species & Strategy & $\begin{array}{c}\text { Test } \\
\text { Environment } \\
\end{array}$ & Detection Limits & $\begin{array}{l}\text { Detection } \\
\text { Time }\end{array}$ & Distance & Ref. \\
\hline $\mathrm{H}_{2} \mathrm{O}$ & $\begin{array}{l}1392 \text { and } 1343 \mathrm{~nm} \text { DFB LD, } 6 \mathrm{~mm} \text { diameter } \\
\text { antireflection-coated lens }\end{array}$ & Laboratory & $\begin{array}{c}\text { Precision } 26 \mathrm{~K} \text { for } \\
\text { temperature } \\
\text { measurement@25 kHz } \\
\text { bandwidth }\end{array}$ & - & $\mathrm{Up}$ to $50 \mathrm{~cm}$ & [133] \\
\hline $\mathrm{H}_{2} \mathrm{~S}$ & $\begin{array}{l}1575 \mathrm{~nm} \text {, a small telescope (primary mirror with a } \\
\text { diameter of } 75 \mathrm{~mm} \text { ) }\end{array}$ & Laboratory & $200 \mathrm{ppm} \cdot \mathrm{m}$ & $>0.05 \mathrm{~s}$ & $9 \mathrm{~m}$ & [6] \\
\hline \multirow{4}{*}{$\mathrm{CH}_{4}$} & NIR1.65 $\mu \mathrm{m}, 150 \mathrm{~mm}$ Fresnel lens & Actual & $10 \mathrm{ppm} \cdot \mathrm{m}$ & $0.3 \mathrm{~s}$ & $5 \mathrm{~m}$ & {$[111]$} \\
\hline & NIR1.65 $\mu \mathrm{m}, 100 \mathrm{~mm}$ Fresnel lens & Laboratory & $50 \mathrm{ppm} \cdot \mathrm{m}$ & - & $20 \mathrm{~m}$ & [112] \\
\hline & $\begin{array}{l}1651 \mathrm{~nm} \text {, a small telescope (primary mirror with a } \\
\text { diameter of } 75 \mathrm{~mm} \text { ) }\end{array}$ & & $10 \mathrm{ppm} \cdot \mathrm{m}$ & $>0.05 \mathrm{~s}$ & $10 \mathrm{~m}$ & [6] \\
\hline & NIR1.65 $\mu \mathrm{m}, \mathrm{UAV}$ & Actual & $50 \mathrm{ppm} \cdot \mathrm{m}$ & - & $10 \mathrm{~m}$ & [113] \\
\hline $\mathrm{MeOH}$ EtOH & $\begin{array}{l}9.4 \text { to } 10.8 \mu \mathrm{m} \text { ECQCL, } 50-\mathrm{mm} \text { diameter off } \\
\text { axis parabola }\end{array}$ & Actual & $\begin{array}{l}0.13 \mathrm{ppm} \cdot \mathrm{m} \cdot \mathrm{Hz}^{-1 / 2} \\
1.2 \mathrm{ppm} \cdot \mathrm{m} \cdot \mathrm{Hz}^{-1 / 2}\end{array}$ & $1 \mathrm{~s}$ & $10 \mathrm{~m}$ & [121] \\
\hline $\begin{array}{l}{ }^{14} \mathrm{NH}_{3}, \\
{ }^{15} \mathrm{NH}_{3} \\
\end{array}$ & $10 \mu \mathrm{m}$ ECQCL, 50-mm diameter off axis parabola & Actual & $\begin{array}{c}150 \mathrm{ppb} \cdot \mathrm{m} \\
10 \mathrm{ppb} \cdot \mathrm{m}\end{array}$ & $\begin{array}{c}0.05 \mathrm{~s} \\
10 \mathrm{~s}\end{array}$ & $10 \mathrm{~m}$ & [122] \\
\hline Silicone & $10 \mu \mathrm{m}$ QCL & Actual & a few $\mu \mathrm{g} / \mathrm{cm}^{2}$ & - & $15 \mathrm{~cm}$ & [98] \\
\hline
\end{tabular}

\section{Laser Photoacoustic Spectroscopy (LPAS)}

Like TDLAS, laser photoacoustic spectroscopy (LPAS) is a chemical sensing method that employs a tunable laser as the light source and needs to modulate the laser. Differently from TDLAS, LPAS is an indirect absorption spectroscopy - which applies a photoacoustic (PA) cell as the signal receiver. After absorption of the target gas in the PA cell, the modulated optical signal is transformed into sound pressure, due to the PA effect, which is subsequently converted to an electric signal by a microphone. However, most of the demonstrated PA detections are localized and require the chemical samples to be contained in a PA cell. Since the 21st century, LPAS has been gradually used in open-path detection, but it was subjected to the large size, heavy-weight, MIR laser sources, i.e., high power $\mathrm{OPO}$ or $\mathrm{CO}_{2}$ lasers, etc. $[139,140]$. With the development of laser technology in recent years, especially the availability of commercialized QCLs and ECQCLs, LPAS has been becoming a research hotspot to achieve standoff measurement by using QCL/ECQCL as a light source and deforming traditional measurement structures [141]. It is a sensitive technique that can be used to evaluate the chemical composition of solids, liquids, and gases. One of the key advantages of PA standoff detection is the $1 / r$ (where $r$ is the radius) detection-distance dependence rather than a $1 / r^{2}$ dependence like other energy-detecting techniques, due to the fact that the microphone detects acoustic wave amplitude instead of energy. According to the different detection methods for photoacoustic signal, standoff 
LPAS can be currently divided into three categories, i.e., LPAS with sound reflector and microphone, laser interferometer-based LPAS and standoff quartz-enhanced photoacoustic spectroscopy (QEPAS).

\subsection{Standoff LPAS with Microphones}

$X$. Chen et al. from the University of Maryland demonstrated standoff PA detection of isopropanol (IPA) vapor and TNT in solid phase using pulse QCLs operated at $7.9 \mu \mathrm{m}(<40 \mathrm{~mW})$ and $7.35 \mu \mathrm{m}$ $(\sim 50 \mathrm{~mW})$, respectively. Their experimental setups are shown in Figure 5, in which an ultra-sensitive microphone with 1 inch diameter and a parabolic reflector with a diameter of 1.5 feet were employed for efficient collection of the acoustic signal [142,143]. By means of the sound reflector, filters, and amplifiers, the standoff range can be extended up to 41 feet and 8 feet for IPA and TNT detection, respectively. Subsequently, the research group demonstrated a signal-enhancement and noise-reduction approach experimentally by means of acoustic beam-former technology with multiple microphone/reflector system, as well as with an array of multiple microphones and one reflector [144,145]. A standoff detection distance of 41 feet in an outdoor setting has been achieved for safely detecting chemicals, such as IPA, RDX, and TNT, with high signal sensitivity [146]. Most recently, Ramesh C. Sharma et al. developed a QCL based standoff LPAS with for detection of hazardous molecules contaminants/adsorbed on surfaces, such as plastic and cloth, from short standoff distances [147]. The pulsed QCL is modulated at $25 \mathrm{kHz}$ and $42 \mathrm{kHz}$ frequency, and the PA signal is detected by two commoditized ultrasonic piezo microphones that have a narrow bandwidth response centered at $\sim 25 \mathrm{kHz}$ and $\sim 42 \mathrm{kHz}$, respectively. This modulation frequency settings avoid interference of audio frequency ( $20 \mathrm{~Hz}$ to $20 \mathrm{kHz}$ ) and bright sunlight ingeniously. In addition, two cylindrical acoustic resonators are designed as an acoustic amplifier and then coupled with the microphones for standoff detection of molecules by matching their Eigen frequencies with modulation frequencies of the laser. Sensitivities of 5 and $10 \mu \mathrm{g} / \mathrm{cm}^{2}$ of the hazardous chemicals, such as acetic acid, PETN (pentaerythritol tetranitrate), and DPA (dipicolinic acid), are achieved with frequencies of $25 \mathrm{and} 42 \mathrm{kHz}$, respectively, at a distance of $0.5 \mathrm{~m}$. The technique has great potential for screening of suspicious objects for security check and forensic applications.

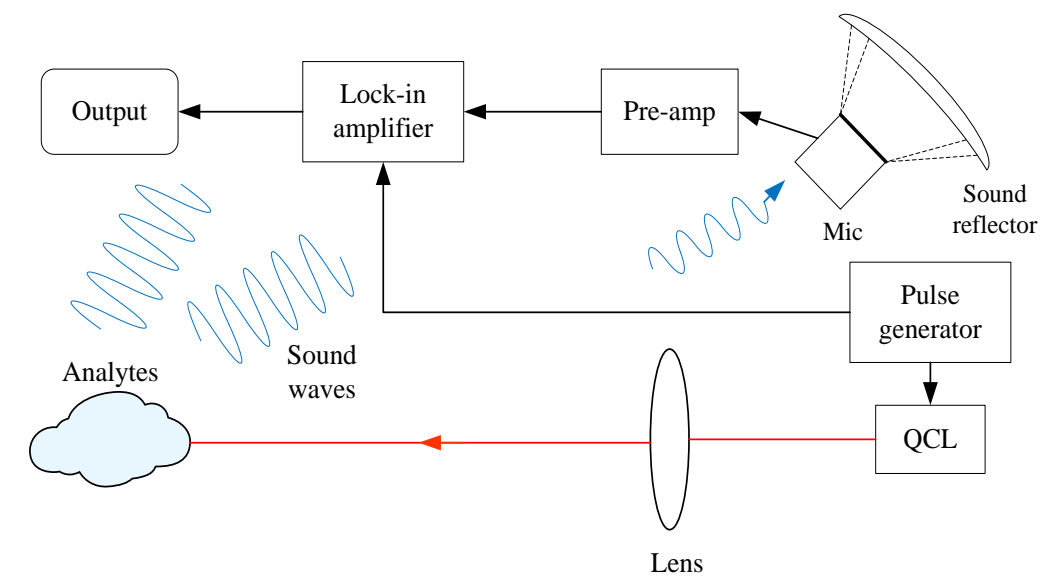

Figure 5. Experimental setup for standoff laser photoacoustic spectroscopy (LPAS) with microphone [142].

Noting that many explosives have strong absorption at deep ultraviolet (UV) band [148], Alyssa B. Zrimsek et al. have demonstrated deep UV PAS of trace explosives using a sensitive microphone at meter standoff distances [149]. Different from most studies using QCLs as laser sources, they directly detect $10 \mu \mathrm{g} / \mathrm{cm}^{2}$ of pentaerythritol tetranitrate (PETN), 2,4,6-trinitrotoluene (TNT), and ammonium nitrate (AN) by using a $213 \mathrm{~nm}$ laser with $1 \mathrm{~s}$ accumulations from a $3 \mathrm{~m}$ standoff distance. Their study also showed that production of gaseous species during photolysis of AN can enhance the PAS signal strength, but the PAS signal would disappear, due to completely photolyzed of AN with continued UV 
irradiation. Therefore, the response time should be one of the key considerations when UV-PAS is used for standoff detection of some explosives.

It is not hard to find that standoff LPAS with microphones is a simple variant of traditional PAS with the absence of the PA cell. It has the advantages of simplicity and ease of implementation, as well as no need for back reflection surfaces. However, acoustic waves spread, broadening their already minimal energy below the detection limits of acoustic detectors because of the absence of a sealed PA cell. The detection sensitivity and distance require improvement. Additionally, it is difficult for using a microphone to directly detect acoustic signal in the atmospheric environment as a result of the influence of wind effects, such as air turbulence or constant winds [150].

\subsection{Standoff Laser Interferometer-Based LPAS}

Laser interferometer-based PAS is an attractive alternative, since it can provide high sensitivity over long distances $(>300 \mathrm{~m})$ and maintain eye safety [150]. Rather than detecting the acoustic wave directly by a microphone, an interferometer is used to measure the physical response of the excited system at a standoff distance.

A research group at the U.S. Army Research Laboratory (ARL) has been focused on the research of laser interferometer-based PAS sensor used for standoff hazardous materials detection [150-153]. The simplified schematic diagram of their PAS sensor setup is shown in Figure 6, the components remain basically the same with the exception of a laser Doppler vibrometer (LDV) that replaces the traditional microphone. The LDV can be regarded as a variant of a Michelson interferometer that responds to the PA excitation by measuring the total change in optical path length of a coherent light source (usually a HeNe laser) reflected from the surface of the sample [151]. Using a broadly tunable, quasi-continuous wave (QCW) EC-QCL as the excitation source, the ARL group measured the concentration of RDX $\left(500 \mu \mathrm{g} / \mathrm{cm}^{2}\right)$, PETN $\left(150 \mu \mathrm{g} / \mathrm{cm}^{2}\right)$, and TNT $\left(500 \mu \mathrm{g} / \mathrm{cm}^{2}\right)$, with each of these explosive materials deposited on an $\mathrm{Al}$ substrate from a standoff distance of $1 \mathrm{~m}[150,151]$. The explosive samples were prepared using a drop-on-demand inkjet printer to ensure uniformity. The measurement results were very comparable to the Fourier-transform infrared (FTIR) measurements [151]. Y. H. El-Sharkawy and S. Elbasuney also developed a laser interferometer-based PAS to detect explosive material, including TNT, RDX, and HMX with a Q-switched Nd:YAG laser [154]. The He-Ne laser interferometer was employed to determine the time delay between the optical pulse and the detected photoacoustic response, which depends on the elastic properties of the material under test. The logarithm of photoacoustic signal amplitude is proportional to the reduced time with a slope of multiplication of sound speed of the sample and its absorption coefficients. The LPAS sensor provided standoff detection capabilities $(10 \mathrm{~cm})$, rapid response, high sensitivity $\left(200 \mathrm{ng} / \mathrm{m}^{3}\right)$, and enhanced SNR. Yu Fu and his colleagues have also established the capability of the photovibrational technique to detect chemicals in powder state and liquid phase in the near field [155]. After preliminary testing at long standoff distances of the technique [156,157], the research group has demonstrated an in-house-developed laser Doppler vibrometer to be able to detect the vibration amplitude and frequency of trace explosives at long standoff distances of $100 \mathrm{~m}$ in an open environment [158]. Three explosives (TNT, PETN and their mixture) with a concentration of $10 \mu \mathrm{g} / \mathrm{mm}^{2}$ were detected, and the photo-vibrational spectrum obtained by scanning the emission wavelength of the QCL through the MIR range, is consistent with the corresponding spectrum measured by using an FTIR spectroscopy.

Although the use of LDV increases the system complexity and cost, the standoff laser interferometer-based PAS has shown the capability in remote detection of explosives with long-distance and non-cooperative targets. However, there is still a long way to go to make full use of its application potential. Substrate interaction, background noise reduction and minimization of air turbulence effect are needed to be further investigated to increase the sensitivity and standoff range. 


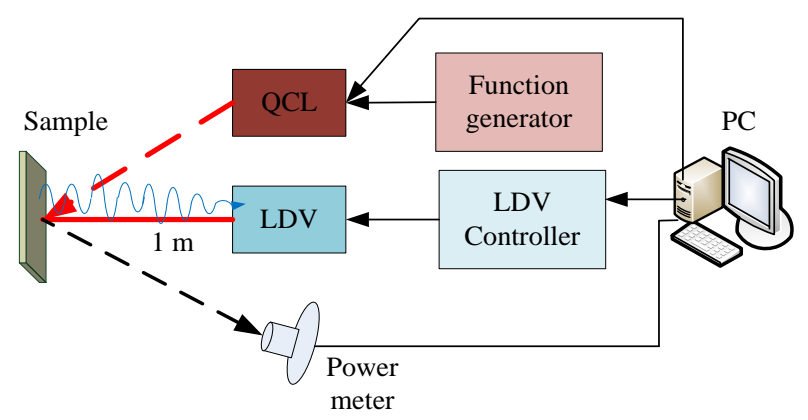

Figure 6. Schematic diagram of laser interferometer-based photoacoustic spectroscopy (PAS) sensor setup for the standoff detection of explosives at $1 \mathrm{~m}$ [151]. QCL, quantum cascade laser; LDV, laser Doppler vibrometer.

\subsection{Standoff Quartz-Enhanced Photoacoustic Spectroscopy}

In 2002, an improved technique called quartz-enhanced photoacoustic spectroscopy (QEPAS) was developed [159], which used a commercially available millimeter-sized piezoelectric element quartz-crystal tuning fork (QCTF) as an acoustic wave transducer. The QCTF detector not only has a very narrow resonance width of less than $1 \mathrm{~Hz}$ to immune to background acoustic noise, but also can response an extremely broad wavelength ranging from ultraviolet to terahertz without any cooling requirements. Benefiting from the advantages of high sensitivity, good selectivity, low cost, compact structure, as well as large dynamic range, QEPAS sensors have been widely used in chemical detection [160].

The groundwork in standoff QEPAS is the study by C. W. Van Neste et al. in 2008 [161], who presented a variation of QEPAS for standoff detection of surface adsorbed chemicals. The schematic diagram of the experimental setup is shown in Figure 7a. A QCL with a wavelength tuning range of 9257.98 to $9804.07 \mathrm{~nm}$ was employed as the optical source to for illuminating a stainless-steel target surface located $0.5-20 \mathrm{~m}$ away. The target surface was coated with varying amounts of chemical residue and several explosive samples, including TBP, RDX, TNT, and PETN, were chosen to test in their experiments. The light reflected/scattered off the target was collected near the source using a spherical mirror and focused onto a QCTF. The tuning fork signal was detected by a lock-in amplifier and then further processed by a computer to obtain the spectroscopic information of the chemicals. A detection limit on the order of $100 \mathrm{ng} / \mathrm{cm}^{2}$ and a standoff detection distance of $20 \mathrm{~m}$ was achieved for their work, which laid a foundation for standoff chemical sensing. Furthermore, by using multiple QCLs and a QCTF array, it is possible to scan large spectral windows for molecular identification [162]. However, their technique relies on good surface reflection to provide sufficient photons for photo-thermal generation and quartz tuning fork excitation. Another drawback of the technique is that the background spectrum of a clean target surface needs to be taken initially, which also limits its expansion to non-cooperative target applications.
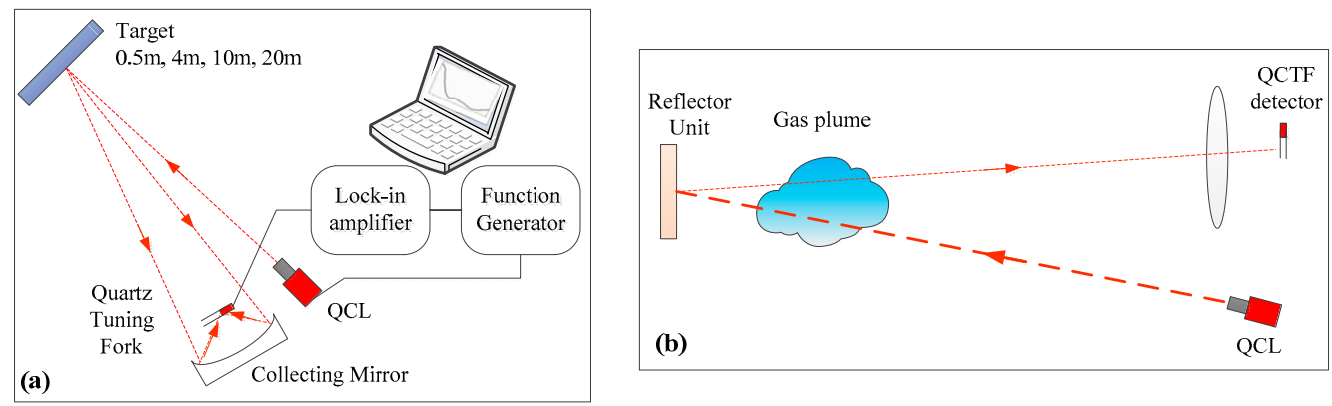

Figure 7. Diagram of the experimental setup variation of QEPAS for standoff detection of (a) surface adsorbed chemicals [161,162]; (b) gas plume [163,164]. 
Standoff QEPAS technique has also been used for the open-path determination of gaseous species by means of the transceiver configuration, as shown in Figure $7 \mathrm{~b}$. Kumar D et al. used EC-QCLs to achieve open-path QEPAS measurements of methane and ozone for a distance up to $25 \mathrm{~m}$ with a sensitivity $\sim 10 \mathrm{ppbv}$ at ambient temperature and humidity [165]. Jingsong Li and his group developed a QEPAS sensor for standoff detection of volatile organic compounds (VOCs) for a distance up to $40 \mathrm{~m}$ with a pulsed, broadband EC-QCL [163]. A multiple linear regression (MLR) algorithm, as shown in Figure 8, was developed to realize the composition identification and concentration quantification of ethanol, acetone and diethyl ether. The subsequent laboratory results showed great potential for remote detection of VOCs at a distance of over $100 \mathrm{~m}$ [164]. Afterwards, the research group verified experimentally that the results detected by QCTF with much lower cost were slightly better than that by a commercial infrared MCT detector. Furthermore, they also investigated the effect of incident light beam excitation position related to QCTF on signal amplitude and Q-factor, as well as the impact of incident light intensity and pressure on the intrinsic property of QCTF, in order to explore and demonstrate the capabilities of this technique [166].

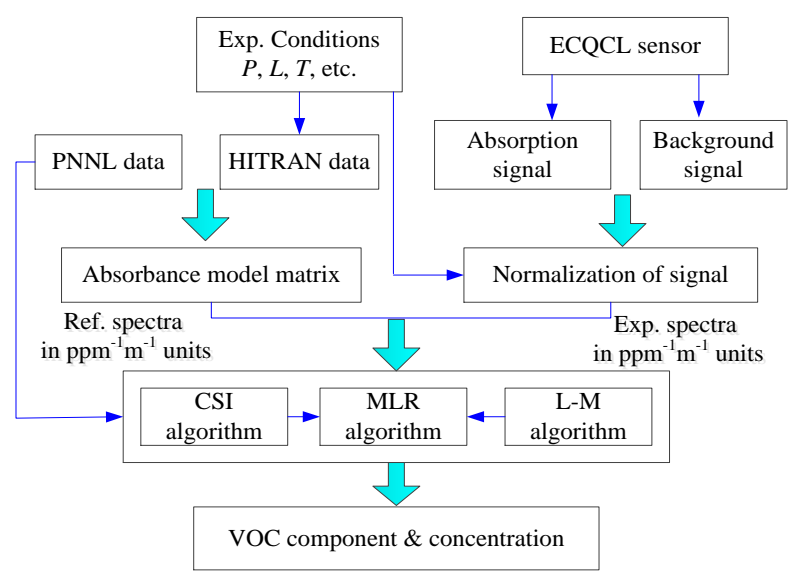

Figure 8. Flowchart of the spectral analysis model for volatile organic compounds (VOCs) spectral analysis [164].

In order to expand standoff QEPAS to non-cooperative target applications, Ramesh C. Sharma et al. theoretically calculated the laser power reaching at the QCTF detector for standoff setup similar to Figure 2 [167]. The results show that powers received from a distance of $10 \mathrm{~m}$ are $\sim 0.1 \mu \mathrm{W}$ and $0.4 \mu \mathrm{W}$ for wood and aluminum sample, respectively, in the case of a transmitter power of $12 \mathrm{~mW}$. They evaluated that a $0.1 \mu \mathrm{W}$ signal resulted in an LPAS signal of $\sim 0.2 \mathrm{nA} / \mathrm{Hz}^{1 / 2}$ and noise floor of QCTF detector was calculated to be $1.32 \times 10^{-11} \mathrm{~A} / \mathrm{Hz}^{1 / 2}$. Therefore, $10 \mathrm{~m}$ standoff signal can be detected with a high SNR of 15. This study provides a reference for the design and detection capability evaluation of standoff QEPAS system. Z. Zhang et al. studied the dynamics of QCTF force both theoretically and experimentally in standoff photoacoustic detection [168]. Their study shows that the resonance amplitude of the tuning fork caused by the electromagnetic radiation pressure of the laser can reach $0.22 \mathrm{pm}$ with a laser power of $40 \mathrm{~mW}$ and a standoff detection distance of $0.5 \mathrm{~m}$. Moreover, both the electromagnetic radiation pressure and resonance amplitude exponentially decreased, with the distance between the tuning fork and detected objects. Therefore, in spite of the advantages of simplicity and low cost, standoff QEPAS would encounter many challenges when used for non-cooperative target remote sensing.

To summarize, standoff LPAS technology has demonstrated the ability to detect chemicals in gas, vapor, liquid, and solid-state, as well as absorbed materials on the surface or any kind of hazardous substance. The properties of these three modalities for standoff LPAS technique are summed up, as shown in Table 4. The current standoff LPAS studies focus on explosives related detection, due to the urgent requirements of security and anti-terrorism. With increasing knowledge of physical and 
chemical properties of explosives [141], as well as the development of LPAS technique, it is believed that mature instruments will be available for on-site security inspection in the near future.

Table 4. Comparison of the three modalities of standoff LPAS technique.

\begin{tabular}{|c|c|c|c|c|c|c|}
\hline Chemical Species & Standoff LPAS Modality & Absorption Band & $\begin{array}{l}\text { Detection } \\
\text { Limits }\end{array}$ & Detection Time & Distance & Ref. \\
\hline $\mathrm{AN}$ & LPAS with microphones & $213 \mathrm{~nm}$ & $\sim 10 \mu \mathrm{g} / \mathrm{cm}^{2}$ & $1 \mathrm{~s}$ & $3 \mathrm{~m}$ & [149] \\
\hline TNT & laser vibrometry-based LPAS & $1324-1451 \mathrm{~cm}^{-1}$ & $10 \mu \mathrm{g} / \mathrm{mm}^{2}$ & $2 \mathrm{~s}$ & $100 \mathrm{~m}$ & [158] \\
\hline \multirow[t]{3}{*}{ PETN } & LPAS with microphones & $\begin{array}{c}213 \mathrm{~nm} \\
1286 \mathrm{~cm}^{-1} \\
1276 \mathrm{~cm}^{-1}\end{array}$ & $\begin{array}{l}\sim 10 \mu \mathrm{g} / \mathrm{cm}^{2} \\
\sim 4.0 \mu \mathrm{g} / \mathrm{cm}^{2} \\
\sim 2.5 \mu \mathrm{g} / \mathrm{cm}^{2}\end{array}$ & $\begin{array}{c}1 \mathrm{~s} \\
10 \mathrm{~ms} \\
10 \mathrm{~ms}\end{array}$ & $\begin{array}{c}3 \mathrm{~m} \\
0.5 \mathrm{~m} \\
0.5 \mathrm{~m}\end{array}$ & $\begin{array}{l}{[149]} \\
{[147]} \\
{[147]}\end{array}$ \\
\hline & laser vibrometry-based LPAS & $1176-1307 \mathrm{~cm}^{-1}$ & $10 \mu \mathrm{g} / \mathrm{mm}^{2}$ & $2 \mathrm{~s}$ & $100 \mathrm{~m}$ & [158] \\
\hline & QEPAS & $800-1400 \mathrm{~cm}^{-1}$ & $\sim 5.0 \mu \mathrm{g} / \mathrm{cm}^{2}$ & $2 \mathrm{~s}$ & $12 \mathrm{~m}$ & [167] \\
\hline DPA & LPAS with microphones & $1311 \mathrm{~cm}^{-1}$ & - & $10 \mathrm{~ms}$ & $0.5 \mathrm{~m}$ & [147] \\
\hline Acetic acid & LPAS with microphones & $1294 \mathrm{~cm}^{-1}$ & $\sim 2.0 \mu \mathrm{L}$ & $10 \mathrm{~ms}$ & $0.5 \mathrm{~m}$ & [147] \\
\hline
\end{tabular}

\section{Dual-Comb Spectroscopy (DCS)}

As a radically new laser technology, optical frequency combs (OFCs) appeared and finally won the Nobel Prize in physics in 2005 [169]. Frequency combs enable the first direct and phase coherent links between the measurable radio frequencies and quasi-optical/optical frequencies ( $10^{12}$ to $\left.10^{15} \mathrm{~Hz}\right)$, offering an innovative way to conduct broadband absorption spectroscopy. Frequency-comb-based absorption spectroscopy, especially in the molecular fingerprint part of the MIR spectral region, has great potential for remote chemical detection, due to massive parallelism of data acquisition [170].

Dual-comb spectroscopy (DCS) provides one approach for the detection of multiple species and broadband spectra with high spectral resolution and high time-resolution [171-177]. The key idea of DCS is that one can use two broadband frequency combs with slightly different repetition rates to naturally down convert absorption features with a fast detector from optical frequencies to the RF regime. This method shows at least two major improvements compared with the conventional way like FTIR. First, it abandons the moving component, which holds back the resolution and requisition time. Second, after the signal is down converted to RF regime, mature signal amplification, and digital data requisition/analysis technologies can help to boost its SNR. Moreover, DCS has enormous advantages for standoff detection [32], including broadband spectral coverage for multi-species detection, a bright diffraction-limited source for high SNR over multikilometer ranges, a rapid update rate for immunity to turbulence-induced optical intensity fluctuations, and high-accuracy spectra through sampling the transmission on a comb tooth-by-tooth basis. An excellent review of DCS has been presented by Ian Coddington et al. in 2016 [174], which provides a detailed reference for DCS researchers. Here, we focus on the standoff applications by means of DCS. The schematic diagram of a typical DCS standoff detection is shown in Figure 9. It is noteworthy that the variations in the comb spectrum must be effectively normalized so that only the response of the sample is measured.

As early as 2005, a frequency comb FTIR spectrometer that employed a laser-like infrared probing beam generated from two 10-fs Ti: sapphire lasers was demonstrated to overcome the limitations of traditional FTIR in rapidity and standoff distance [176]. A DCS based remote sensing of greenhouse gases was developed to achieve a precision of $\sim 0.86 \mathrm{ppm}$ for $\mathrm{CO}_{2}$ and $\sim 2.3 \mathrm{ppb}$ for $\mathrm{CH}_{4}$ with a $\sim 2.2 \mathrm{~km}$ air path and $\sim 5 \mathrm{~min}$ integration time [32]. The interferogram for a single spectrum can be obtained in a few milliseconds, which effectively reduces the influence of intensity-modulation on the experimental data caused by atmospheric turbulence. Moreover, it has been used for the detection of methane leaks in the field [178]. Furthermore, a quantitative intercomparison between two open-path 
DCS instruments, which were operated across adjacent 2-km open-air paths over a two-week period, was presented [179]. Afterwards, the standoff distance was extended to $5.8 \mathrm{~km}$ (round trip $11.6 \mathrm{~km}$ ) for city-scale open-path greenhouse gas monitoring [180]. Subsequently, the research group demonstrated DCS to a retroreflector that is mounted on a small uncrewed aircraft system (sUAS) to scan horizontal and vertical paths and retrieve the column integrated mixing ratios of $\mathrm{H}_{2} \mathrm{O}, \mathrm{CO}_{2}$, and $\mathrm{CH}_{4}$ [181]. Most recently, an MIR DCS with a broad comb spectrum ranging from $2750 \mathrm{~cm}^{-1}$ to $3150 \mathrm{~cm}^{-1} \mathrm{was}$ developed for VOCs detection over up to $1 \mathrm{~km}$ long open-air paths [182]. Both combs were combined before propagation through the turbulent air path, and therefore, turbulence-induced phase front distortions are common mode. For this reason, the phase noise caused by turbulence can be eliminated, and high heterodyne mixing efficiency between the combs can be maintained. In addition to being used for environmental monitoring, DCS has also been applied to combustion diagnosis [183]. Although DCS is able to provide broadband and fast measurements, it requires expensive laser equipment and data acquisition electronics. In addition, because of the massively broadband nature, standoff DCS usually requires a reflector at the far end of the path to ensure sufficient SNR and long detection distance [181]. Encouragingly, Joel M. Hensley et al. demonstrated the standoff detection ability with non-cooperative targets by a developed QCL based DCS system against diffusely scattering surfaces at a distance up to $1 \mathrm{~m}$ [184]. However, the measurement SNR was limited by measurement fluctuation and self-mixing interference, due to diffusely scattering. The standoff detection achievements for DCS are summarized in Table 5. Note that the detection time shown in Table 5 were generally set to be the optimal averaging time period, according to the timescale of the atmospheric fluctuations in practical measurements [32]. A large averaging time (tens of seconds to minutes) helps improve measurement sensitivity, which is allowable for long-period (hours to days) time-resolved measurements. However, DCS can also be used for real-time open-path measurement with $1 \mathrm{~s}$ resolution [172] or even ultrafast time-resolved measurements for combustion diagnosis [185]. Most recently, a field-deployed MIR DCS system, based on QCLs, has been demonstrated for remote detection of chemicals for the first time [186]. Covering a wavelength band from 975 to $1010 \mathrm{~cm}^{-1}$ and cooperating with a retroreflector far away, the QCL-based DCS is used for standoff detection of methanol, R134a, ethanol, acetic acid, and isopropanol alcohol. The robust construction and suitability for field deployments have been verified. The compact system design provides a reference for miniaturized and portable applications of DCS.

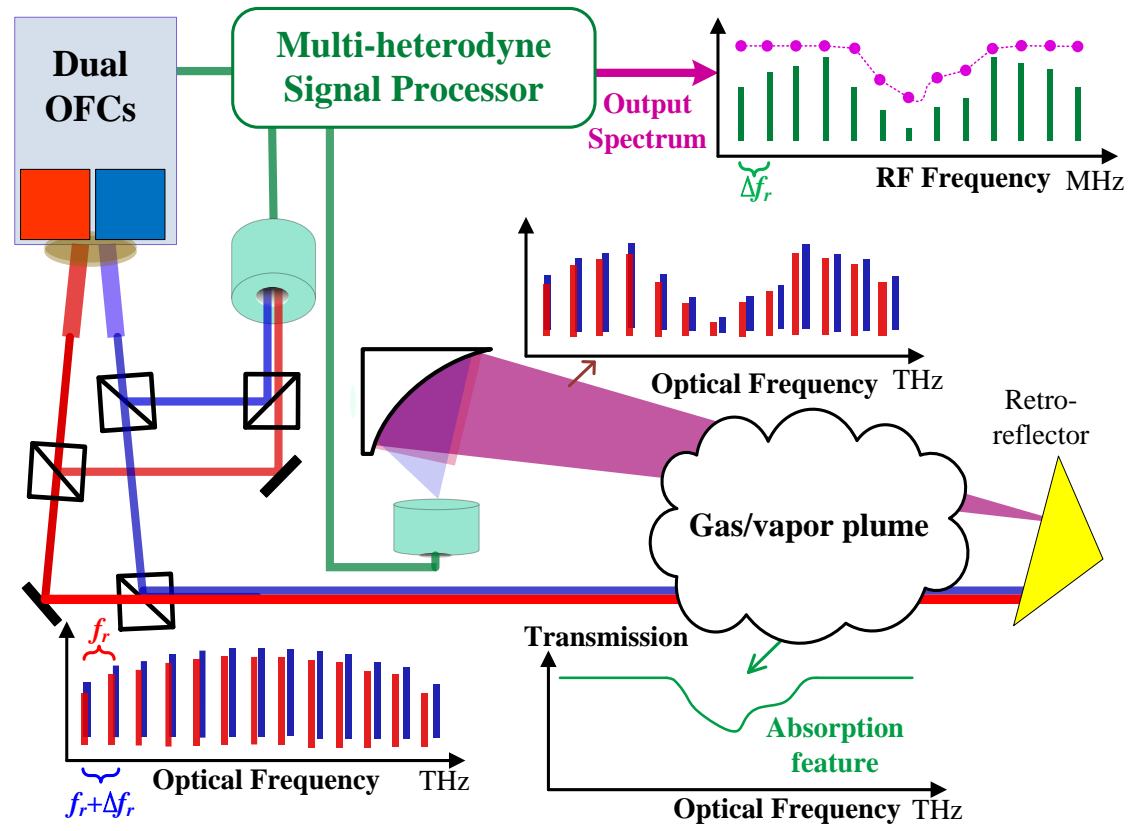

Figure 9. The schematic diagram for standoff gas sensing through dual-comb spectroscopy. 
Table 5. Performance of reported dual-comb spectroscopy (DCS) standoff detection for chemical sensing.

\begin{tabular}{ccccccc}
\hline Molecule & $\begin{array}{c}\text { Absorption } \\
\text { Band }\end{array}$ & Detection Limit & $\begin{array}{c}\text { Test } \\
\text { Environment }\end{array}$ & Detection Time & Distance & Ref. \\
\hline $\mathrm{CO}_{2}, \mathrm{CH}_{4}$ & $1568-1660 \mathrm{~nm}$ & $0.24 \mathrm{ppm}, 2.1 \mathrm{ppb}$ & Actual & $5 \mathrm{~min}$ & $1 \mathrm{~km}$ & {$[179]$} \\
\hline $\mathrm{CH}_{4}, \mathrm{CO}_{2}$ & $1.57-1.66 \mu \mathrm{m}$ & $6.0 \mathrm{ppb}, 0.6 \mathrm{ppm}$ & Actual & $100 \mathrm{~s}$ & $1 \mathrm{~km}$ & {$[181]$} \\
\hline $\mathrm{CO}_{2}, \mathrm{CH}_{4}$ & $1.57-1.69 \mu \mathrm{m}$ & $5 \mathrm{ppm}, 0.2 \mathrm{ppm}$ & Actual & $3 \mathrm{~min}$ & $5.8 \mathrm{~km}$ & {$[180]$} \\
\hline $\mathrm{CO}_{2}, \mathrm{CH}_{4}$ & $1600-1670 \mathrm{~nm}$ & $<1 \mathrm{ppm},<3 \mathrm{ppb}$ & Actual & $5 \mathrm{~min}$ & $1 \mathrm{~km}$ & {$[32]$} \\
\hline $\mathrm{CH}_{4}$ & $1.62-1.69 \mu \mathrm{m}$ & $2 \mathrm{ppb}$ & Actual & $100 \mathrm{~s}$ & $1 \mathrm{~km}$ & {$[178]$} \\
\hline $\mathrm{CO}_{2}$ & $1.63-2.14 \mu \mathrm{m}$ & $2.8 \mathrm{ppm} \cdot \mathrm{km} / 0.1 \mathrm{ppm} \cdot \mathrm{km}$ & Laboratory & $1 \mathrm{~s} / 13 \mathrm{~min}$ & $1 \mathrm{~km}$ & {$[172]$} \\
\hline $\mathrm{CH}_{3} \mathrm{COCH}_{3}, \mathrm{C}_{3} \mathrm{H}_{8} \mathrm{O}, \mathrm{C}_{2} \mathrm{H}_{6}$ & $2750-3150 \mathrm{~cm}^{-1}$ & $\begin{array}{c}5.7 \mathrm{ppm} \cdot \mathrm{m}, 2.4 \mathrm{ppm} \cdot \mathrm{m}, \\
0.4 \mathrm{ppb}\end{array}$ & Actual & $60 \mathrm{~s}$ & $1 \mathrm{~km}$ & {$[182]$} \\
\hline
\end{tabular}

It is worth noting that DCS can measure not only the absorption spectrum, but also the phase spectrum, which also contains the equivalent information of the target sample like the former. Unlike both combs are transmitted through the sample, as shown in Figure 9, if a single OFC is sent through the sample and combined with the local oscillator OFC immediately prior to the detector, then both phase and absorption can be measured [175,187]. Phase spectroscopy of $\mathrm{CO}_{2}, \mathrm{CH}_{4}$ and $\mathrm{H}_{2} \mathrm{O}$ has been demonstrated across a 2-km long atmospheric path by using a $7 \mathrm{THz}$ bandwidth DCS [187]. However, phase-sensitive measurement in the open atmosphere is subject to turbulence which adds significant phase noise to the transmitted light. Therefore, phase correction is usually necessary to reduce phase noise and obtain a high-SNR spectrum.

In brief, DCS is a very promising candidate for standoff detection with intermediate resolutions at the 1-10 km scale, due to the merits of high sensitivity, wide spectral coverage, high spectral resolution and fast time response. However, current DCS systems are complex and expensive because of the requirement for two fully stabilized OFCs with slightly different comb spacing. Note that DCS is an emerging new technology and also an extremely active area of research, consequently, many new developments are emerging to improve DCS performance, simplify its composition, and reduce its size $[173,175,188-194]$. As a result, we fully believe that DCS will become more and more mature and may surpass traditional broadband spectroscopy for a wide range of applications.

\section{Laser Heterodyne Radiometry (LHR)}

Laser heterodyne radiometry (LHR) is a remote laser spectroscopic technique which offers the potential to develop a compact ground or satellite-based radiometer for Earth observation and astronomy. LHR systems have numerous advantages, including high sensitivity, ultra-narrow optical resolution, very confined field-of-view (FOV), as well as a great potential for ruggedization and miniaturization [195] owing to low component count, reduced cost and high reliability.

Unlike other methods introduced in this review, LHR is a passive measurement approach and has remained substantially unchanged, since the very first demonstrations carried out by Menzies and Shumate [196] in the early 1970s. The system configuration of a typical traditional LHR is shown in Figure 10a. A sun tracker is used to actively track the apparent location of the sun and capture the solar radiation with a narrow FOV. After transferring through an optical filter, the remaining radiation is modulated by a chopper and then directed to a beam splitter (BS). The transmission is superimposed with the local oscillator ( $\mathrm{LO}$ ) beam from a linear tuning laser, and then the combined beam is detected on a high-speed photo mixer (PM) to obtain heterodyne signal. A part of the laser beam passing through the BS is guided a F-P etalon for frequency calibration. The solar radiation transmitted through the Earth's atmosphere contains information about absorbing constituents. The heterodyne process downconverts the spectral information from the infrared to the RF domain. The AC output of the PM offers the spectral information, while the DC output provides an approach to monitor the LO power. The RF signal is amplified and then detected by a zero-bias Schottky diode. Its output is demodulated by a lock-in amplifier at the chopper frequency to obtain the absorption spectra of the 
target gas/gases. The acquired high resolution spectral data can be retrieved by an algorithm, named optimal estimation method (OEM), for vertical profiling of atmospheric constituents [197].

LHR's capabilities have been proven to depend in part on the performance of the laser source providing the LO [198]. With the help of the development of semiconductor lasers, QCLs especially EC-QCLs have become the ideal MIR LO light source of LHR, due to their high optical power, narrow linewidth, and broad tuning range. QCL based LHR has been widely used for atmospheric sounding [198-202]. A $3.53 \mu \mathrm{m}$ ICL, moreover, has been employed as the LO source to retrieve the concentration of $\mathrm{H}_{2} \mathrm{O}$ and $\mathrm{CH}_{4}$ column recently $[89,203]$. However, NIR DFB-LD based LHR still has great research value and significance, because it provides a low-cost, miniaturized and robust strategy [204-208].

In contrast to aforementioned developments concentrated on the utilization of higher-performing components, wavelength modulation laser heterodyne radiometry (WM-LHR) [209], has been recently put forward as a new LHR spectral interrogation procedure to enhance the LHR performance. As shown in Figure 10b, WM-LHR is based on the use of a wavelength-modulated LO laser, in which the detection principle is similar to the widely used WMS technique, as described in Section 4 . Both NIR LD-based [209] and MIR QCL-based WM-LHR [195] were recently demonstrated a very promising improvement in performance and consistency. In comparison to the traditional LHR method, WM-LHR provides a superior SNR and reduces the requirements on the quality of the components [195].

In short, LHR has become a powerful optical sounding tool for atmospheric measurements [200,203-208] and planetary observations [210,211] nowadays. The up to date results of LHR detection are summarized, as shown in Table 6. However, passive LHS derives its sensitivity from thermal contrast when used in transmission mode, which limits its ability to provide ppb level detection in any realistic standoff detection configuration [7]. Because of its passive nature, LHR is not sensitive enough for terrestrial remote detection of trace chemical plumes over distances of tens to hundreds of meters. Besides, its application is currently limited to atmospheric sounding.

Table 6. Detection error and detection limit of passive laser heterodyne spectrum.

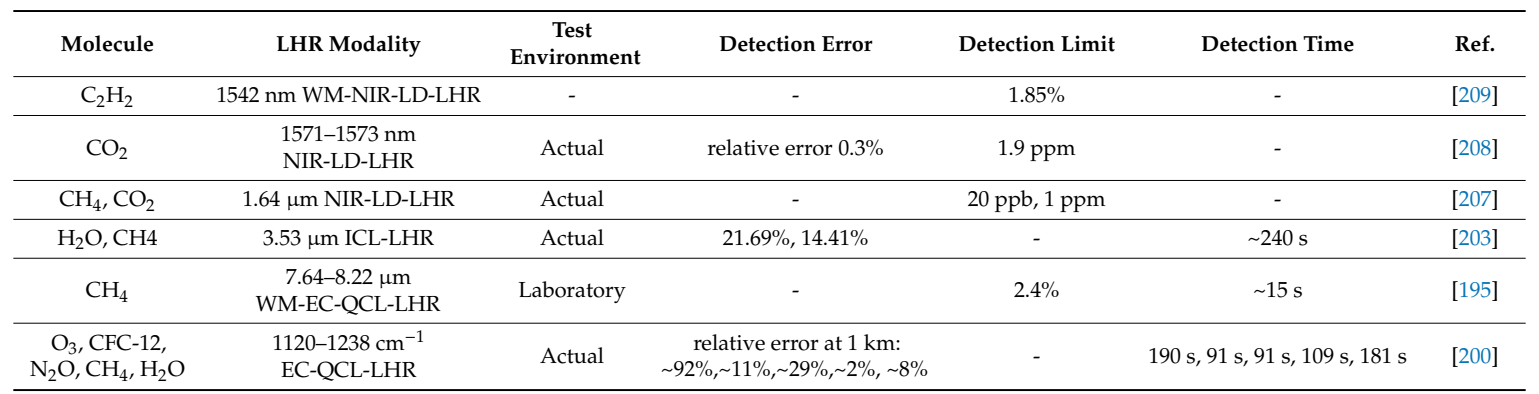

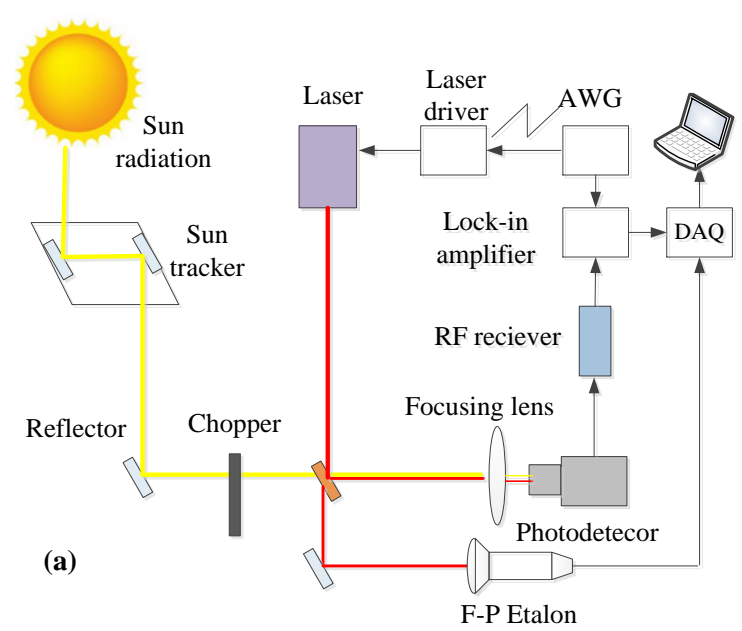

Figure 10. Cont. 


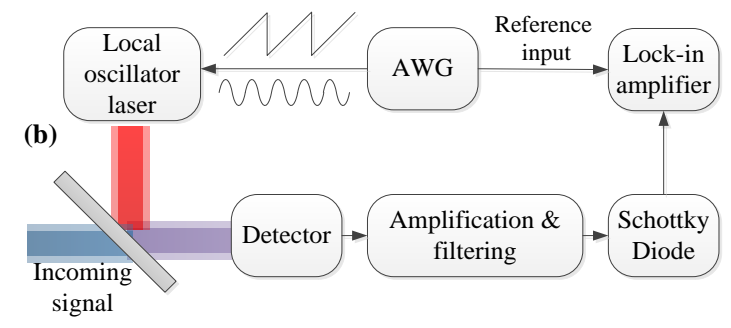

Figure 10. Schematic diagram of typical system configuration for (a) traditional LHS and (b) WMS-LHS.

\section{Active Coherent Laser Absorption Spectrometry (ACLaS)}

Inspired by LHR, Neil A. Macleod and Damien Weidmann of Rutherford Appleton Laboratory proposed an Active Coherent Laser Spectrometer (ACLaS) for remote detection and identification of chemicals in 2012 [19]. Rather than passive capture of solar radiation in LHR, ACLaS provides active eye-safe illumination of a topographic target and subsequent spectroscopic analysis through optical heterodyne detection of the diffuse backscattered field.

The simplified optical structure of the ACLaS has been exhibited in their publications [19,212], which is redrawn here, as shown Figure 11. A MIR QCL is preferred to use as the optical source for high sensitivity. The collimated QCL radiation is directed to an R90/T10 beam splitter (BS1). The transmitted part of the optical power is used as the LO for heterodyne, while the reflected portion of the beam passes through a germanium acousto-optic frequency shifter. The unshifted zeroth-order output light is transferred through an etalon for relative frequency calibration of the laser. In comparison, the first-order diffracted beam is used as a signal light for transmission toward a distant topographic target. A small fraction of the signal light backscattered by the target is collected by the ACLaS receiver mirror, and adjusted to be superimposed with the LO field on a high bandwidth photodetector. A beat frequency signal caused by the interference is obtained, which contains the information of the tested chemicals, and the signal is then detected in the manner similar to the LHR system shown in Figure 10a.

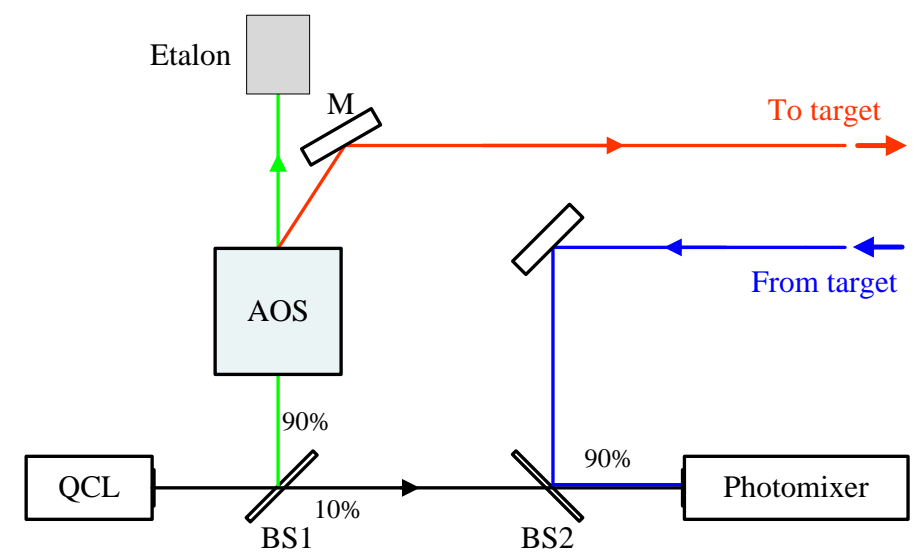

Figure 11. Optical layout of the ACLaS. M, mirror; BS, beam splitter; AOS, acousto-optic shifter [212].

According to the working principle of the ACLaS, a forward model has been established to describe the relationship between the directly measured spectral signal and the unknown state vector of molecular mixing ratios, with consideration of instrument parameters [213]. The OEM algorithm originally used in LHR was adapted to retrieve mixing ratios using the synthetized spectral trace calculated by the forward model as input $[7,213]$. A "cost" function is defined in OEM consisting of weighted differences between the measured data and the simulated data by the forward model, and between the current state vector and the a-priori vector. The solution minimizing the cost function is output as the optimal solution. In addition, the OEM also enables full error propagation analysis to estimate the level of confidence and further detection sensitivities [7]. 
A $7.85 \mu \mathrm{m}$ DFB QCL was employed at first to demonstrate the ACLaS method experimentally [19]. Standoff detection of numerous chemical species, including hydrogen peroxide, nitrous oxide, methane, water and acetylene, was carried out with topographic targets at distances of up to $30 \mathrm{~m}$. Normalized detection sensitivities range between 14 and $0.3 \mathrm{ppm} \cdot \mathrm{m} \cdot \mathrm{Hz}^{-1 / 2}$ were achieved. Afterwards, an EC-QCL with large tuning range was used for detection of vapor phase molecules with broadband features, such as dichloroethane (DCE), ethylene glycol dinitrate (EGDN), and tetrafluoroethane (HFC-134a) [213]. Not limited to gas and vapor detection, ACLaS has also been demonstrated the capability of detection of condensed phase compounds, e.g., 4-nitroacetanilide (4NA), deposited onto surfaces [213]. The measured and extrapolated limits of detection for a range of gases and explosive related molecules have been summarized in References [213] and [7], as shown here in Table 7. Note that the extrapolated values according to the cross-section of the species and the chemical vapor pressure are marked as "calculated" in the second column of the table.

Table 7. The detection performance of active coherent laser absorption spectrometry.

\begin{tabular}{|c|c|c|c|c|c|c|}
\hline Molecule & $\begin{array}{l}\text { Absorption } \\
\text { Band }\left(\mathrm{cm}^{-1}\right)\end{array}$ & $\begin{array}{c}\text { Test } \\
\text { Environment }\end{array}$ & $\begin{array}{l}\text { Detection Limit } \\
\left(\mathrm{ppm} \cdot \mathrm{m} \cdot \mathrm{Hz}^{-1 / 2}\right)\end{array}$ & $\begin{array}{l}\text { Detection } \\
\text { Time }\end{array}$ & Distance & Ref. \\
\hline $\mathrm{N}_{2} \mathrm{O}$ & 1278 & Laboratory & $10-15$ & - & $30 \mathrm{~m}$ & [7] \\
\hline $\mathrm{H}_{2} \mathrm{O}_{2}$ & 1277 & Laboratory & 1.1 & $1 \mathrm{~s}$ & $7 \mathrm{~m}$ & [7] \\
\hline $\mathrm{H}_{2} \mathrm{O}$ & 1277 & Laboratory & 2605 & $1 \mathrm{~s}$ & $2.89 \mathrm{~m}$ & [213] \\
\hline $\mathrm{CH}_{4}$ & 1277 & Laboratory & 7.3 & $1 \mathrm{~s}$ & $5.5 \mathrm{~m}$ & [212] \\
\hline DCE & 1292 & Laboratory & 128 & $1 \mathrm{~s}$ & $2.89 \mathrm{~m}$ & [213] \\
\hline EGDN & 1280 & Laboratory & 0.69 & $1 \mathrm{~s}$ & $2.89 \mathrm{~m}$ & [213] \\
\hline HFC-134a & 1300 & Laboratory & 10.5 & $1 \mathrm{~s}$ & $2.89 \mathrm{~m}$ & [213] \\
\hline 4NA & $1275-1310$ & Laboratory & - & $1 \mathrm{~s}$ & $3 \mathrm{~m}$ & {$[7]$} \\
\hline Nitromethane (NM) & - & Calculated & 1.13 & $1 \mathrm{~s}$ & $2.89 \mathrm{~m}$ & [213] \\
\hline Nitroglycerine (NG) & 1277 & Calculated & 0.25 & $1 \mathrm{~s}$ & $>1 \mathrm{~m}$ & {$[7]$} \\
\hline Diacetone diperoxide (DADP) & 1207 & Calculated & 0.345 & $1 \mathrm{~s}$ & $>1 \mathrm{~m}$ & [7] \\
\hline Triacetone triperoxide (TATP) & 1194 & Calculated & 0.23 & $1 \mathrm{~s}$ & $>1 \mathrm{~m}$ & [7] \\
\hline Sarin $(\mathrm{GB})$ & 1020 & Calculated & 0.317 & $1 \mathrm{~s}$ & $>1 \mathrm{~m}$ & [7] \\
\hline Soman (GD) & 1010 & Calculated & 0.29 & $1 \mathrm{~s}$ & $>1 \mathrm{~m}$ & [7] \\
\hline Tabun (GA) & 1020 & Calculated & 0.55 & $1 \mathrm{~s}$ & $>1 \mathrm{~m}$ & [7] \\
\hline
\end{tabular}

ACLaS is a very promising technique benefiting from its high detection sensitivity, high spectral resolution induced good selectivity, and efficient background noise rejection. This technique has shown a high level of performance in remote chemical detection of multifarious species, including atmospheric constituents, explosives, as well as industrial gases. However, the detecting capability of current ACLaS is far away from the absolute ideal shot noise limit allowed by heterodyne detection, due to the limitation of the speckle noise and excess noise. The standoff detection distance and the miniaturization design of the instrument also have much room for improvement. Furthermore, the OEM algorithm needs to be improved for accurate inversion of liquids or solids deposited onto the surfaces.

\section{Benchmarking, Challenges and Opportunities}

\subsection{Benchmarking}

Overall performance comparison of the presented LAS-based standoff detection techniques is further summarized, as shown in Table 8, according to the comprehensive requirements proposed for standoff chemical detection by N. A. Macleod and D. Weidmann [7] as aforementioned in Section 1. In order to quantify the comparison of detection sensitivity, we reviewed the typical results reported recently for $\mathrm{CH}_{4}$, which has been measured as a target gas by all these techniques. These values of detection sensitivity may be obtained at different absorption bands, so they are transformed to equivalent values measured at $1.654 \mu \mathrm{m}$ according to the absorption cross-section. The original absorption bands used for $\mathrm{CH}_{4}$ measurements are marked in the note below the table. Furthermore, the equivalent detection sensitivities are all normalized to a $1 \mathrm{~m}$ optical path and $1 \mathrm{~s}$ integration time in unit of $\mathrm{ppm} \cdot \mathrm{m} \cdot \mathrm{Hz}^{-1 / 2}$. It is noteworthy that the sensitivity will decrease with increasing of standoff 
distance, due to the reduction of SNR. Here the sensitivity values are given at the typical detection distance of each technique, which is also described in the note below the table. The analysis of currently available methods of remote monitoring shows that the general requirements for operation under actual conditions, such as real-time monitoring, high sensitivity (at the maximum concentration limit level), ease of control, low level of false alarms, etc., can be satisfied to the utmost by the LAS-based methods because of the absorption of light in the IR, visible, and UV ranges by the molecules of interest.

Table 8. Performance comparison of LAS-based standoff detection techniques.

\begin{tabular}{|c|c|c|c|c|c|c|c|}
\hline Technique & $\begin{array}{l}\text { Sensitivity for } \mathrm{CH}_{4} \\
\left(\mathrm{ppm} \cdot \mathrm{m} \cdot \mathrm{Hz}^{-1 / 2}\right)\end{array}$ & Multi-Species (g) & Selectivity/Precision & Real Time & $\begin{array}{c}\text { Standoff Range with } \\
\text { Non-Cooperative } \\
\text { Target }\end{array}$ & Complexity/Size/Cost & $\begin{array}{l}\text { Eye-Safe } \\
\text { Operation }\end{array}$ \\
\hline DIAL & 106 (a) [42] & $1-3$ & Intermediate & Yes & Tens of kilometers & Intermediate to High & No \\
\hline DCS & 80 (d) [179] & Yes & Intermediate to high & Yes & Meters & High & Yes \\
\hline LHR & $1000(\mathrm{~g})[205]$ & $1-5$ & Intermediate & Not yet & Tens of kilometers & Intermediate to high & Yes \\
\hline ACLaS & 87 (f) [212] & $1-4$ & High & Yes & Tens of meters & Intermediate to high & Yes \\
\hline
\end{tabular}

Note: The detection sensitivities have been transformed to equivalent values measured at $1.654 \mu \mathrm{m}$ and then normalized to a $1 \mathrm{~m}$ optical path and $1 \mathrm{~s}$ integration time. The original absorption bands and some explanations are as follows. (a) Absorption band 3.3-3.4 $\mu \mathrm{m}$, at a range of $200 \mathrm{~m}$, see detail in Reference [45]; (b) Absorption band $1.654 \mu \mathrm{m}$, standoff distance $10 \mathrm{~m}$; (c) Absorption band 1300-1310 $\mathrm{cm}^{-1}$, standoff QEPAS with an aluminum mirror at a distance of $25 \mathrm{~m}$; (d) Absorption band $1.6 \mu \mathrm{m}\left(6047 \mathrm{~cm}^{-1}\right)$, standoff detection with reflector with a range of $1000 \mathrm{~m}$; (e) Absorption band $1.6 \mu \mathrm{m}\left(6047 \mathrm{~cm}^{-1}\right)$, optical path the whole distance of vertical atmosphere is assumed to be $1000 \mathrm{~km}$; (f) Absorption band $7.832 \mu \mathrm{m}\left(1276.8 \mathrm{~cm}^{-1}\right)$, standoff distance $5.5 \mathrm{~m}$. (g) Multi-species column indicates the number of gases that can be detected simultaneously according to reported literature. For the DCS, a "Yes" denotes the great potential for multi-species measurement, due to the broad spectral coverage (up to $1000 \mathrm{~cm}^{-1}$ ).

Although the standoff detection techniques herein we reviewed are all based on the principle of absorption spectroscopy, their performances and application fields are different, due to the use of different laser sources, detectors, and detection methods. The detection sensitivity is intently related to the magnitude of absorption cross-section of the measured substance, which is a function of wavelength. In addition, the power of the laser and the detection capability of the receiver determines the distance of remote detection.

For DIAL, solid-state lasers with pulsed high-power emission are mainly used to realize remote sensing. DIAL is good at measuring vertical profile (by using RR-DIAL) or column concentration (by using IPDA) of the atmospheric constituents. DIAL has mostly been applied to the detection of GHGs with small molecules, such as $\mathrm{H}_{2} \mathrm{O}, \mathrm{CO}_{2}, \mathrm{CH}_{4}$, etc., as well as aerosols and wind velocity. The detection range can reach tens of kilometers or even more. Hence, it can be widely used for ground-based, vehicle-based, airborne or even spaceborne measurements. Moreover, DIAL appear to be the most promising approach for landfill fugitive methane measurement [43].

TDLAS employs a TDL as a light source, which is a key factor affecting system performance. Generally, the tuning range of an NIR TDL is small $(\sim 1 \mathrm{~nm})$, which can cover one complete absorption line or at most two separate lines of small molecules. With the maturity of mid-infrared (EC) QCL and ICL, the performance of TDLAS has been greatly improved. Not only can the wavelength tuning range be expanded for large molecules (e.g., VOCs) detection, but also the detection sensitivity can be improved by at least an order of magnitude compared to NIR detection. TDLAS is particularly suitable for low-power miniaturized handheld or portable standoff gas-sensitive detection with non-cooperators applications, with standoff distance ranging from meters to tens of meters. Not only that, small size and lightweight TDLAS sensors can also be mounted on mobile robots or UAVs for intelligent leak inspection and localization.

LPAS also uses a TDL as the light source, but it measures the photoacoustic signal transformed by the modulated laser light after absorbed by the object to be measured. Compared with TDLAS, standoff LPAS is more preferred to measure certain solid powder or liquid substance, such as some explosives, beyond a certain distance. Standoff distance has been demonstrated to be from meters to tens of meters as well. 
DCS employs two broadband frequency combs with slightly different repetition rates as laser sources to down convert absorption features with a fast detector from optical frequencies to the RF regime. Its prominent advantages of broadband spectra (hundreds $\mathrm{cm}^{-1}$ ) and high spectral resolution (typically a few $\mathrm{kHz}$ to $\mathrm{MHz}$ ) make DCS more suitable for the detection of multi-species or large molecules with broadband features. On the other hand, DCS system is naturally complex and high cost, and it usually requires cooperation with a reflector for standoff detection applications.

LHR is a passive measurement, which measures the absorption of solar radiation in the field of view by the target gas along the transmission path. From a strict perspective, it cannot be counted as LAS. However, LHR uses a TDL as a LO source for heterodyne detection of gas absorption. The detection depends on the tuning range of the TDL and absorption lines of atmospheric molecules are measured similarly to LAS. Information on the concentration of atmospheric constituents is obtained from the depth and shape of the absorption lines. Therefore, LHR is a powerful optical sounding tool suitable for measuring the vertical profiles of gas molecules in the atmosphere.

ACLaS can be regarded as the combined product of TDLAS and LHR, with alterations of passive measurement of LHR to active measurement, and of the direct detection in TDLAS to heterodyne detection. The SNR of heterodyne detection systems is usually 3-4 orders of magnitude higher than that of direct detection systems [214], which means ACLaS is able to detect weak echo signals with picowatt level. Therefore, a much longer standoff distance than TDLAS can be achieved under the same conditions theoretically. With ECQCL as the light source, ACLaS has been used not only for standoff detection of small molecule gases, but also for large molecules with broadband features. Not limited to gas and vapor detection, ACLaS has also been demonstrated the capability of detection of condensed phase compounds deposited onto surfaces.

Note that heterodyne or coherent technology is very important for performance improvement of remote measurement, which has been more and more used in combination with LAS-based standoff techniques, including DIAL, laser interferometer-based PAS, LHR and ACLaS. However, the detecting capability of these current techniques needs to be further improved by means of overcoming the limitation of the speckle noise and excess noise.

\subsection{Challenges}

Although LAS-based methods have realized successful measurements of chemical species in trace amounts, some challenges of chemical standoff detection with these techniques address various issues still to be solved.

An imminent challenge at present is the specification and classification of data on the absorption spectra of medium-to-high molecular weight species with broadband absorption feature, such as CWA and TIC vapors. The complexity of obtaining these spectra depends not only upon the high toxicity of these substances, but also on the fact that many CWAs and TICs contain process-related impurity vapors, which have spectral lines interfering with absorption lines of the CWA and TIC vapors under investigation [3]. In order to precisely determine the spectral absorption factor values, it is still necessary to study the absorption spectra of CWA and TIC vapors in detail in the MIR range, even though some molecular absorption data are included in PNNL database. A specialized database on CWA and TIC vapor-absorption spectra is expected to be created for the open atmosphere detection applications at various temperatures, humidity levels, etc., in the NIR and MIR ranges.

LAS gas measurements are constantly affected by the pressure and temperature of the atmospheric environment $[52,215,216]$, especially for large scale open-path measurement. Traditional methods, usually by means of installing pressure and temperature sensors on the instrument to correct the measurement results, are no longer applicable because of the non-uniform distribution of pressure and temperature along the path. On the other hand, for some remote applications, such as underground fire detection [217], it is necessary to measure the temperature at the same time together with the concentration of the target gases in order to determine the combustion location [218,219]. Currently, computer tomography (CT)-TDLAS has been developed and widely used to simultaneously measure 
2D temperature and concentration [220-226]. However, measurement of gas pressure distribution still needs to be developed for remote sensing applications. Moreover, it is still to be studied to use true standoff CT-TDLAS for large scale 2D or even 3D multi-parameters $(x, T, P)$ measurement in the atmospheric environment, which may provide a solution for underground fire detection.

According to Table 8, conventional LAS-based standoff methods can achieve multiple species detection on the strength of broadband tunable laser sources, e.g., EC-QCL, but they have been limited in either spectral scan speed or spectral resolution [121]. DCS for standoff detections of gas-phase chemicals has shown promising results in sensitivity and multi-species, but its time resolution also has been limited in tens of seconds even one minute. It is not appropriate for the detection of short-lived, transient events. Hence, LAS systems need to be improved in the future with rapid tuning rates over large wavelength ranges, high spectral resolution and excellent scan stability and reproducibility.

The standoff range with non-cooperative targets is still a challenge, especially when combined with the requirement of eye safety. Flexibility is usually needed for a fully versatile instrument used for remote chemical detection, which should be able to work at short $(<1 \mathrm{~m})$ and far standoff distances $(>1000 \mathrm{~m}$ ) [7]. Furthermore, the instrument should meet eye-safety standards for a class 1 laser and must not pose a risk of harm to the public when deployed in public open areas. Although TDLAS, LPAS and ACLaS can satisfy the latter, their detection distances have been tested in real environments to be a few meters to tens of meters. ACLaS is the most promising technology to achieve the above requirements, thanks to its coherent detection rather than a direct measurement. However, ACLaS currently is limited by speckle noise result from diffuse reflection on a rough surface of a non-cooperative hard target, which makes its sensitivity and detection range greatly restricted. Various speckle suppression techniques have been summarized in Reference [227], which include averaging over polarization, spectral channels, spatial dimensions, and/or collection angles, as well as reducing the coherence of the input laser. These speckle suppression methods may need undesirable trade-offs with other sensor parameters, such as spectral resolution, the laser fluence on the target, spatial resolution, increased thermal background collection, total collection time, and/or instrument complexity [227].

When broadband emission sources (e.g., ECQCLs and OFCs) illuminate on targets featuring particle sizes or surface roughness on the order of microns, it may produce significant spectral variability even from chemically identical materials [227]. Because the laser light can scatter from multiple surfaces, resulting in a complex combination of reflection, absorption, and transmission events that cause the spectral characteristics to become highly dependent upon the microscopic morphology of the target material. Consequently, the main challenge is to develop an advanced and robust algorithm that can not only discriminate between multiple absorbing molecules, but also account for spectral variability resulting from the rough surface by means of their different spectroscopic features.

Additionally, a miniaturized chemical sensor platform with low power consumption and small system package has been extremely desirable to fulfill the handheld or UAV borne applications. Of course, this depends on the advancement of high-performance lasers with high wall plug efficiency broad tunability, and decreased system sizes.

Finally, the effect of fluctuations in laser light intensity over long distances under different weather conditions and turbulence-induced scintillation on LAS-based standoff measurements is needed to be further evaluated.

\subsection{Opportunities}

The laser source is the key component of a LAS system. The fundamental rovibrational bands of a vast majority of chemical substances of interest in standoff detection are located in the MIR spectral region $(2.5-25 \mu \mathrm{m})$ [8]. MIR laser sources technology has undergone tremendous development in recent years [228-231], with the development of optoelectronic technology and quantum technology. Especially the continuous development of high-performance, monolithic, broadly tunable semiconductor lasers, such as QCLs [232,233], EC-QCL [234,235], QCL arrays [236-239], ICLs [240], and MIR vertical-cavity 
surface-emitting lasers [241], lays the foundation for miniaturized LAS system, due to their potential for extreme compactness, high robustness, high output power, narrow linewidth, high lifetime, and low cost.

LAS, based on MIR QCLs, has been demonstrated to be a powerful diagnostic tool for molecular plasmas, which offers some advantages of high sensitivity, good temporal resolution and multi-component detection [242]. However, the current measurements are mostly limited to the traditional DAS based on the multi-pass cell. In our opinion, single-ended LAS sensors can open up new possibilities in flexible and in situ measurements for standoff plasma diagnostic applications. Ease of installation and need for fewer windows will make SE-LAS more promising both in the laboratory and in industry. SE-LAS can provide double pass naturally, which can be conveniently used for kinetic studies in discharge tubes [243,244].

Many existing methods can be used to solve some problems in LAS-based remote sensing. With 1f normalization, the calibration-free WMS-2f/1f method can account for variations in laser intensity such as non-absorption losses, due to light scattering or beam steering [245]. As reviewed in Reference [30], there are other similar methods for calibration-free measurement, including the recovery of the absorption profile based on high order harmonic signals and DAS calibrated WMS, which can be employed to eliminate the effects of light intensity variation. Spectral analysis methods can be used for the simultaneous inversion of temperature and pressure to correct concentration measurements without additional sensors [132,246]. In addition, a spectral data processing method based on co-frequency and dual-wave has been proposed to reduce the error influence factors and the error transfer coefficient resulting from atmospheric turbulence [247,248].

The combination of LAS and other technologies offers possibilities for more sophisticated and advanced remote chemical sensing applications. A new heterodyne interferometric method for optical signal detection in photoacoustic or photothermal spectroscopy has been demonstrated and characterized recently, which enables high sensitivity and three-dimensional spatial gas distribution measurement [249]. Moreover, LAS has been combined with hyperspectral imaging, named infrared backscatter imaging spectroscopy $[250,251]$, for the detection of trace amount of hazardous materials. Like CT-TDLAS, other standoff LAS-based detection techniques can also be combined with CT technology to measure 2D or even 3D information for threat localization [252]. In contrast to absorption-based techniques, dispersion spectroscopy technology has also been developed in recent years, including CLaDS [100] as discussed in Section 4.1 and heterodyne phase-sensitive dispersion spectroscopy (HPSDS) [253], which can provide high sensitivity and large dynamic range. CLaDS has been demonstrated to be particularly suitable for remote detection, benefiting from very high immunity of the signal amplitude to power variations (e.g., due to air turbulences, environmental condition, or when detection relies on scattered radiation), baseline free nature and high dynamic range [103]. Furthermore, broadband phase spectroscopy has been proposed with a phase-sensitive DCS by executing adaptive compensation for the strong decoherence from atmospheric turbulence, which enables measurement of the full complex susceptibility even in practical open-path sensing rather than only intensity absorption [254].

\section{Conclusions and Future Outlook}

In the past few decades, numerous LAS methods have been developed and widely used. LAS-based standoff detection technology has been a powerful tool for remote chemical analysis with applications spanning from environmental monitoring, through industrial emission monitoring and process control, to leak detection for health and safety, as well as defense and security. A wide range of chemical species has become the targets for remote detection, including atmospheric compositions, hazardous or toxic industrial chemicals, explosives related substances, chemical warfare agents, etc., which cover gaseous, liquid, solid and even condensed phase. Of particular note is that some newly developed technologies in the past decade, i.e., LPAS, DCS and ACLaS, have great potential in remote sensing applications, although their performance has mainly been verified in the laboratory. Their advantages in explosive 
standoff detection, multi-species broadband absorption detection and highly sensitive measurement with non-cooperative targets, respectively, have been recognized and many laboratory demonstrations have been reported. While the traditional LAS-based techniques, i.e., DIAL, TDLAS and LHR, have been widely used in practice early, but they are still developing in terms of improving performance.

Although LAS techniques have become commonly used tools for laser spectroscopists nowadays, there is still much room for improvement, especially for remote applications. Field test and practical inspection are necessary for instrumental development of the newly developed technologies, such as LPAS, DCS, and ACLaS. Their specific implementation (or application) in the research of related engineering fields will promote the maturity of these technologies. Moreover, miniaturized and low-power LAS sensors with non-cooperative targets are worthy of focused research, because they are particularly suitable for being mounted on mobile robots or UAVs for increasing intelligent and automated applications in hazardous area inspections and other fields. This research may open up a new direction of machine olfactory. In addition, future efforts still need to be made to fill gaps between the current performance of existing instruments and stringent requirements aforementioned in Section 1, and overcome formidable challenges in practical applications. In our view, taking advantage of up-to-date laser technologies and spectral analysis methods, in combination with available and prospective measures of enhancing detection sensitivity, would enable one to perform an effective remote detection of chemicals of interest with a LAS-based standoff system.

Author Contributions: J.L. designed the paper, collected references, drafted and revised the paper; Z.Y. collected references, and contributed to the preliminary draft; Z.D. supervised the whole work and revised the draft; Y.J. collected references, and contributed to the preliminary draft; C.L. supervised the work and revised the draft. All authors have read and agreed to the published version of the manuscript.

Funding: This research was funded by National Natural Science Foundation of China (61505142); China Scholarship Council Academic Visiting Scholarship Program (201908120037); Science \& Technology Development Fund of Tianjin Education Commission for Higher Education (2017KJ085, 2017KJ086); and Program for Innovative Research Team in University of Tianjin (TD13-5036).

Conflicts of Interest: The authors declare no conflict of interest.

\section{Abbreviations}

\begin{tabular}{ll} 
LAS & Laser Absorption Spectroscopy \\
CWAs & Chemical Warfare Agents \\
DOAS & Differential Optical Absorption Spectroscopy \\
FTIR & Fourier Transform Infrared \\
LIF & Laser-Induced fluorescence \\
LIBS & Laser-Induced Breakdown Spectroscopy \\
CARS & Coherent Anti-Stokes Raman Spectroscopy \\
SNR & Signal-To-Noise Ratio \\
DIAL & Differential Absorption LiDAR \\
TDLAS & Tunable Diode Laser Absorption Spectroscopy \\
LPAS & Laser Photoacoustic Spectroscopy \\
DCS & Dual-Comb Spectroscopy \\
LHR & Laser Heterodyne Radiometer \\
ACLaS & Active Coherent Laser Absorption Spectroscopy \\
NIR & Near-Infrared \\
MIR & Mid-Infrared \\
IR & Infrared \\
HITRAN & High-Resolution Transmission Molecular Absorption \\
GEISA & Gestion Et Etude Des Informations Spectroscopiques AtmosphÉRiques \\
PNNL & Pacific Northwest National Laboratory \\
DOAS & Absorption Spectroscopy \\
NEA & Noise-Equivalent Absorbance \\
TICs & Toxic Industrial Chemicals \\
& \\
\hline
\end{tabular}


IPDA Integrated Path Differential Absorption

RR-DIAL Range Resolved Differential Absorption LiDAR

UV Ultraviolet

Nd-YAG Neodymium-Doped Yttrium Aluminum Garnet

HCs Hydrocarbons

UCD Upconversion Detector

CW Continuous Wave

GreenLITE Greenhouse gas Laser Imaging Tomography Experiment

2D Two-Dimensional

CT Computer Tomography

MERLIN MEthane Remote sensing LiDAR missioN

ECDL External-Cavity Diode Lasers

OPO Optical Parametric Oscillator

BTAS Backwards Transient Absorption Spectroscopy

TDL Tunable Diode Laser

QCLs Quantum Cascade Lasers

ICLs Interband Cascade Lasers

DAS Absorption Spectroscopy

WMS Wavelength Modulation Spectroscopy

FMS Frequency Modulation Spectroscopy

OAPM Off-Axis Parabolic Mirror

RF Radio Frequency

LIA Lock-in Amplifier

ECQCL External Cavity-Quantum Cascade Laser

CLaDS Chirped Laser Dispersion Spectroscopy

NECL Noise Equivalent Concentration Length

DFB Distributed Feedback

RMLD Remote Methane Leak Detector

EDFA Erbium-Doped Fiber Amplifier

UAV Uncrewed Aerial Vehicle

SE-LAS Single-Ended Laser-Absorption-Spectroscopy

PA Photoacoustic

QEPAS Quartz-Enhanced Photoacoustic Spectroscopy

IPA Isopropanol

DNT 2,4-dinitrotoluene

TNT Trinitrotoluene

RDX Cyclonite

PETN Pentaerythritol Tetranitrate

DPA Dipicolinic Acid

AN Ammonium Nitrate

ARL Army Research Laboratory

LDV Laser Doppler Vibrometer

QCW Quasi-Continuous Wave

FTIR Fourier-Transform Infrared

QCTF Quartz-Crystal Tuning Fork

TBP Tributyl Phosphate

VOCs Volatile Organic Compounds

MLR Multiple Linear Regression

MCT Mercury-Cadmium-Telluride

sUAS Small Uncrewed Aircraft System

FOV Field-Of-View

BS Beam Splitter

LO Local Oscillator

PM Photo Mixer

OEM Optimal Estimation Method 


$\begin{array}{ll}\text { WM-LHR } & \text { Wavelength Modulation Laser Heterodyne Radiometry } \\ \text { DCE } & \text { Dichloroethane } \\ \text { EDGN } & \text { Ethylene Glycol Dinitrate } \\ \text { OFCs } & \text { Optical Frequency Combs } \\ \text { HPSDS } & \text { Heterodyne Phase-Sensitive Dispersion Spectroscopy }\end{array}$

\section{References}

1. Bogue, R. Remote chemical sensing: A review of techniques and recent developments. Sens. Rev. 2018, 38, 453-457. [CrossRef]

2. Wallin, S.; Pettersson, A.; Ostmark, H.; Hobro, A. Laser-based standoff detection of explosives: A critical review. Anal. Bioanal. Chem. 2009, 395, 259-274. [CrossRef] [PubMed]

3. Nabiev, S.S.; Palkina, L.A. Current trends in the development of remote methods of detecting radioactive and highly toxic substances. In The Atmosphere and Ionosphere; Bychkov, V., Golubkov, G., Nikitin, A., Eds.; Springer: Cham, Switzerland, 2014; pp. 113-200.

4. Gaudio, P. Laser Based Standoff Techniques: A Review on Old and New Perspective for Chemical Detection and Identification. In Cyber and Chemical, Biological, Radiological, Nuclear, Explosives Challenges; Martellini, M., Malizia, A., Eds.; Springer: Cham, Switzerland, 2017; pp. 155-177.

5. Crowley, M.; Shang, L.J.; Dando, M. Preventing chemical weapons as sciences converge. Science 2018, 362, 753-755. [CrossRef]

6. Jaworski, P.; Stachowiak, D.; Nikodem, M. Standoff detection of gases using infrared laser spectroscopy. In Proceedings of the Optical Sensing and Detection IV, Brussels, Belgium, 3-7 April 2016; p. 98990Q.

7. MacLeod, N.A.; Weidmann, D. High sensitivity stand-off detection and quantification of chemical mixtures using an active coherent laser spectrometer (ACLaS). In Proceedings of the Chemical, Biological, Radiological, Nuclear, and Explosives (CBRNE) Sensing XVII, Baltimore, MD, USA, 18-20 April 2016; p. 98240B.

8. Du, Z.H.; Zhang, S.; Li, J.Y.; Gao, N.; Tong, K.B. Mid-Infrared Tunable Laser-Based Broadband Fingerprint Absorption Spectroscopy for Trace Gas Sensing: A Review. Appl. Sci. 2019, 9, 338. [CrossRef]

9. Hodgkinson, J.; Tatam, R.P. Optical gas sensing: A review. Meas. Sci. Technol. 2012, 24, 012004. [CrossRef]

10. Platt, U.; Perner, D. Measurements of atmospheric trace gases by long path differential UV/visible absorption spectroscopy. In Optical and Laser Remote Sensing; Springer: Berlin/Heidelberg, Germany, 1983; pp. 97-105. [CrossRef]

11. Platt, U.; Stutz, J. Differential absorption spectroscopy. In Differential Optical Absorption Spectroscopy; Platt, U., Stutz, J., Eds.; Springer: Cham, Switzerland, 2008; pp. 135-174.

12. Childs, D.T.D.; Hogg, R.A.; Revin, D.G.; Rehman, I.U.; Cockburn, J.W.; Matcher, S.J. Sensitivity Advantage of QCL Tunable-Laser Mid-Infrared Spectroscopy Over FTIR Spectroscopy. Appl. Spectrosc. Rev. 2015, 50, 822-839. [CrossRef]

13. Taslakov, M.; Simeonov, V.; van den Bergh, H. Open path atmospheric spectroscopy using room temperature operated pulsed quantum cascade laser. Spectroc. Acta Part A Mol. Biomol. Spectrosc. 2006, 63, 1002-1008. [CrossRef]

14. Tittel, F.; Lewicki, R. Tunable mid-infrared laser absorption spectroscopy. In Semiconductor Lasers; Baranov, A., Tournié, E., Eds.; Elsevier: London, UK, 2013; pp. 579-629.

15. Deguchi, Y. Industrial Applications of Laser Diagnostics; CRC Press: New York, NY, USA, 2011.

16. Farsund, O.; Rustad, G.; Kasen, I.; Haavardsholm, T.V. Required Spectral Resolution for Bioaerosol Detection Algorithms Using Standoff Laser-Induced Fluorescence Measurements. IEEE Sens. J. 2010, 10, 655-661. [CrossRef]

17. Gottfried, J.L.; De Lucia, F.C., Jr.; Munson, C.A.; Miziolek, A.W. Laser-induced breakdown spectroscopy for detection of explosives residues: A review of recent advances, challenges, and future prospects. Anal. Bioanal. Chem. 2009, 395, 283-300. [CrossRef]

18. Gares, K.L.; Hufziger, K.T.; Bykov, S.V.; Asher, S.A. Review of explosive detection methodologies and the emergence of standoff deep UV resonance Raman. J. Raman Spectrosc. 2016, 47, 124-141. [CrossRef]

19. MacLeod, N.A.; Weidmann, D. Active coherent laser spectrometer for remote detection and identification of chemicals. In Proceedings of the Optics and Photonics for Counterterrorism, Crime Fighting, and Defence VIII, Edinburgh, Scotland, 24-26 September 2012; p. 85460H. 
20. Almaviva, S.; Angelini, F.; Chirico, R.; Palucci, A.; Nuvoli, M.; Schnuerer, F.; Schweikert, W.; Romolo, F. Eye-safe UV Raman spectroscopy for proximal detection of explosives and their precursors in fingerprints concentration. In Proceedings of the Optics and Photonics for Counterterrorism, Crime Fighting, and Defence X; and Optical Materials and Biomaterials in Security and Defence Systems Technology XI, Amsterdam, The Netherlands, 7 October 2014; p. 925303.

21. Angelini, F.; di Frischia, S.; Chiuri, A.; Colao, F. Maximization of Raman signal in standoff detection under eye-safe conditions. In Proceedings of the Counterterrorism, Crime Fighting, Forensics, and Surveillance Technologies III, Strasbourg, France, 9-11 September 2019; p. 1116609.

22. Goldenstein, C.S.; Spearrin, R.M.; Jeffries, J.B.; Hanson, R.K. Infrared laser-absorption sensing for combustion gases. Prog. Energy Combust. Sci. 2017, 60, 132-176. [CrossRef]

23. Liu, C.; Xu, L.J. Laser absorption spectroscopy for combustion diagnosis in reactive flows: A review. Appl. Spectrosc. Rev. 2019, 54, 1-44. [CrossRef]

24. Henderson, B.; Khodabakhsh, A.; Metsala, M.; Ventrillard, I.; Schmidt, F.M.; Romanini, D.; Ritchie, G.A.D.; Hekkert, S.t.L.; Briot, R.; Risby, T.; et al. Laser spectroscopy for breath analysis: Towards clinical implementation. Appl. Phys. B Lasers Opt. 2018, 124. [CrossRef] [PubMed]

25. Demtröder, W. Laser Spectroscopy: Basic Concepts and Instrumentation, 3rd ed.; Mack, R., Ed.; Springer Science \& Business Media: Berlin, Germany, 2013.

26. Hanson, R.K.; Spearrin, R.M.; Goldenstein, C.S. Spectroscopy and Optical Diagnostics for Gases; Springer: Cham, Switzerland, 2016.

27. Jacquinet-Husson, N.; Armante, R.; Scott, N.A.; Chedin, A.; Crepeau, L.; Boutammine, C.; Bouhdaoui, A.; Crevoisier, C.; Capelle, V.; Boonne, C.; et al. The HITRAN2016 molecular spectroscopic database. J. Quant. Spectrosc. Radiat. Transf. 2017, 203, 3-69. [CrossRef]

28. Jacquinet-Husson, N.; Armante, R.; Scott, N.A.; Chedin, A.; Crepeau, L.; Boutammine, C.; Bouhdaoui, A.; Crevoisier, C.; Capelle, V.; Boonne, C.; et al. The 2015 edition of the GEISA spectroscopic database. J. Mol. Spectrosc. 2016, 327, 31-72. [CrossRef]

29. Sharpe, S.W.; Johnson, T.J.; Sams, R.L.; Chu, P.M.; Rhoderick, G.C.; Johnson, P.A. Gas-phase databases for quantitative infrared spectroscopy. Appl. Spectrosc. 2004, 58, 1452-1461. [CrossRef]

30. Wang, Z.H.; Fu, P.F.; Chao, X. Laser Absorption Sensing Systems: Challenges, Modeling, and Design Optimization. Appl. Sci. 2019, 9, 2723. [CrossRef]

31. Zhu, X.M.; Kahn, J.M. Free-space optical communication through atmospheric turbulence channels. IEEE Trans. Commun. 2002, 50, 1293-1300. [CrossRef]

32. Rieker, G.B.; Giorgetta, F.R.; Swann, W.C.; Kofler, J.; Zolot, A.M.; Sinclair, L.C.; Baumann, E.; Cromer, C.; Petron, G.; Sweeney, C.; et al. Frequency-comb-based remote sensing of greenhouse gases over kilometer air paths. Optica 2014, 1, 290-298. [CrossRef]

33. Cao, X.H.; Li, J.Y.; Gao, H.; Du, Z.H.; Ma, Y.W. Simultaneous Determination of Carbon Disulfide, Carbon Monoxide, and Dinitrogen Oxide by Differential Absorption Spectroscopy Using a Distributed Feedback Quantum Cascade Laser. Anal. Lett. 2017, 50, 2342-2350. [CrossRef]

34. Schotland, R.M. Errors in the lidar measurement of atmospheric gases by differential absorption. J. Appl. Meteorol. 1974, 71-77. [CrossRef]

35. Browell, E.; Ismail, S.; Grant, W. DIAL. Encycl. Atmos. Sci. 2003, 3, 1183-1193.

36. Molebny, V.; McManamon, P.F.; Steinvall, O.; Kobayashi, T.; Chen, W. Laser radar: Historical prospective-From the East to the West. Opt. Eng. 2016, 56, 031220. [CrossRef]

37. Alvarez, R.J.; Senff, C.J.; Langford, A.O.; Weickmann, A.M.; Law, D.C.; Machol, J.L.; Merritt, D.A.; Marchbanks, R.D.; Sandberg, S.P.; Brewer, W.A.; et al. Development and Application of a Compact, Tunable, Solid-State Airborne Ozone Lidar System for Boundary Layer Profiling. J. Atmos. Ocean. Tech. 2011, 28, 1258-1272. [CrossRef]

38. Coutts, D.W.; McGonigle, A.J.S. Cerium-doped fluoride lasers. IEEE J. Quantum Electron. 2004, 40, 1430-1440. [CrossRef]

39. Demirbas, U.; Uecker, R.; Klimm, D.; Wang, J. Low-cost, broadly tunable (375-433 nm \& 746-887 nm) Cr: LiCAF laser pumped by one single-spatial-mode diode. Appl. Opt. 2012, 51, 8440-8448. [CrossRef]

40. Wagner, G.A.; Plusquellic, D.F. Multi-frequency differential absorption LIDAR system for remote sensing of $\mathrm{CO}_{2}$ and $\mathrm{H}_{2} \mathrm{O}$ near $1.6 \mu \mathrm{m}$. Opt. Express 2018, 26, 19420-19434. [CrossRef] 
41. Kara, O.; Sweeney, F.; Rutkauskas, M.; Farrell, C.; Leburn, C.G.; Reid, D.T. Open-path multi-species remote sensing with a broadband optical parametric oscillator. Opt. Express 2019, 27, 21358-21366. [CrossRef]

42. Robinson, R.; Gardiner, T.; Innocenti, F.; Woods, P.; Coleman, M. Infrared differential absorption Lidar (DIAL) measurements of hydrocarbon emissions. J. Environ. Monit. 2011, 13, 2213-2220. [CrossRef]

43. Innocenti, F.; Robinson, R.; Gardiner, T.; Finlayson, A.; Connor, A.J.R.S. Differential absorption lidar (DIAL) measurements of landfill methane emissions. Remote Sens. 2017, 9, 953. [CrossRef]

44. Emission Monitoring Using Differential Absorption Lidar (DIAL). Available online: https://www.npl.co.uk/ products-services/environmental/absorption-lidar-dial (accessed on 10 May 2020).

45. Ambrico, P.F.; Amodeo, A.; Di Girolamo, P.; Spinelli, N. Sensitivity analysis of differential absorption lidar measurements in the mid-infrared region. Appl. Opt. 2000, 39, 6847-6865. [CrossRef]

46. Ehret, G.; Kiemle, C.; Wirth, M.; Amediek, A.; Fix, A.; Houweling, S. Space-borne remote sensing of $\mathrm{CO}_{2}, \mathrm{CH}_{4}$, and $\mathrm{N}_{2} \mathrm{O}$ by integrated path differential absorption lidar: A sensitivity analysis. Appl. Phys. B Lasers Opt. 2008, 90, 593-608. [CrossRef]

47. Høgstedt, L.; Fix, A.; Wirth, M.; Pedersen, C.; Tidemand-Lichtenberg, P. Upconversion-based lidar measurements of atmospheric $\mathrm{CO}_{2}$. Opt. Express 2016, 24, 5152-5161. [CrossRef] [PubMed]

48. Meng, L.; Fix, A.; Wirth, M.; Høgstedt, L.; Tidemand-Lichtenberg, P.; Pedersen, C.; Rodrigo, P.J. Upconversion detector for range-resolved DIAL measurement of atmospheric $\mathrm{CH}_{4}$. Opt. Express 2018, 26, 3850-3860. [CrossRef] [PubMed]

49. Gelfusa, M.; Gaudio, P.; Malizia, A.; Murari, A.; Vega, J.; Richetta, M.; Gonzalez, S. UMEL: A new regression tool to identify measurement peaks in LIDAR/DIAL systems for environmental physics applications. Rev. Sci. Instrum. 2014, 85, 063112. [CrossRef] [PubMed]

50. Zhou, Z.R.; Hua, D.X.; Wang, Y.F.; Yan, Q.; Li, S.C.; Li, Y.; Wang, H.W. Improvement of the signal to noise ratio of Lidar echo signal based on wavelet de-noising technique. Opt. Laser Eng. 2013, 51, 961-966. [CrossRef]

51. Xiang, C.Z.; Han, G.; Zheng, Y.X.; Ma, X.; Gong, W. Improvement of $\mathrm{CO}_{2}$-DIAL Signal-to-Noise Ratio Using Lifting Wavelet Transform. Sensors 2018, 18, 2362. [CrossRef]

52. Matvienko, G.G.; Sukhanov, A.Y. Application of Neural Networks for Retrieval of the $\mathrm{CO}_{2}$ Concentration at Aerospace Sensing by IPDA-DIAL lidar. Remote Sens. 2019, 11, 659. [CrossRef]

53. Matvienko, G.; Sukhanov, A.Y.; Babchenko, S. The Analysis of Capabilities of Neural Networks in $\mathrm{CO}_{2}$ Sounding with Spaceborne IPDA-Lidar with the Use of Different A Priori Data. Atmos. Ocean. Opt. 2019, 32, 165-170. [CrossRef]

54. Kaldvee, B.; Brackmann, C.; Aldén, M.; Bood, J.J.O.E. Highly range-resolved ammonia detection using near-field picosecond differential absorption lidar. Opt. Express 2012, 20, 20688. [CrossRef]

55. Mei, L.; Guan, P.; Kong, Z. Remote sensing of atmospheric $\mathrm{NO}_{2}$ by employing the continuous-wave differential absorption lidar technique. Opt. Express 2017, 25, A953-A962. [CrossRef] [PubMed]

56. Wagner, G.A.; Plusquellic, D.F. Ground-based, integrated path differential absorption LIDAR measurement of $\mathrm{CO}_{2}, \mathrm{CH}_{4}$, and $\mathrm{H}_{2} \mathrm{O}$ near 1.6 mum. Appl. Opt. 2016, 55, 6292-6310. [CrossRef]

57. Refaat, T.F.; Ismail, S.; Koch, G.J.; Rubio, M.; Mack, T.L.; Notari, A.; Collins, J.E.; Lewis, J.; De Young, R.; Choi, Y.; et al. Backscatter 2- $\mu \mathrm{m}$ Lidar Validation for Atmospheric $\mathrm{CO}_{2}$ Differential Absorption Lidar Applications. IEEE Trans. Geosci. Remote Sens. 2011, 49, 572-580. [CrossRef]

58. Yakovlev, S.; Sadovnikov, S.; Kharchenko, O.; Kravtsova, N. Remote Sensing of Atmospheric Methane with IR OPO Lidar System. Atmosphere 2020, 11, 70. [CrossRef]

59. Takida, Y.; Ikeo, T.; Nawata, K.; Wada, Y.; Higashi, Y.; Minamide, H. Terahertz differential absorption spectroscopy using multifurcated subnanosecond microchip laser. Appl. Phys. Lett. 2019, 115. [CrossRef]

60. Dobler, J.T.; Zaccheo, T.S.; Pernini, T.G.; Blume, N.; Broquet, G.; Vogel, F.; Ramonet, M.; Braun, M.; Staufer, J.; Ciais, P.; et al. Demonstration of spatial greenhouse gas mapping using laser absorption spectrometers on local scales. J. Appl. Remote Sens. 2017, 11, 26. [CrossRef]

61. Lian, J.H.; Breon, F.M.; Broquet, G.; Zaccheo, T.S.; Dobler, J.; Ramonet, M.; Staufer, J.; Santaren, D.; Xueref-Remy, I.; Ciais, P. Analysis of temporal and spatial variability of atmospheric $\mathrm{CO}_{2}$ concentration within Paris from the GreenLITE (TM) laser imaging experiment. Atmos. Chem. Phys. 2019, 19, 13809-13825. [CrossRef] 
62. Dobler, J.T.; Pernini, T.G.; Blume, N.; Zaccheo, T.S.; Braun, M. GreenLITE (TM): A new laser-based tool for near-real-time monitoring and mapping of $\mathrm{CO}_{2}$ and $\mathrm{CH}_{4}$ concentrations on scales from $0.04-25 \mathrm{~km}^{2}$. In Proceedings of the Lidar Remote Sensing for Environmental Monitoring 2017, San Diego, CA, USA, 8-9 August 2017.

63. Dobler, J.; Zaccheo, T.S.; Pernini, T.; Blume, N.; Braun, M. Greenlite ${ }^{\mathrm{TM}}$ : A year of carbon dioxide monitoring over paris, france, and recent progress in monitoring methane. In EPJ Web of Conferences; EDP Sciences: Les Ulis, France, 2018; p. 05013.

64. LIU, W.; CHEN, Z.; LIU, J.; XIE, P.J.C.S.B. Stereoscopic monitoring technology and applications for the atmospheric environment in China. Chin. Sci. Bull. 2016, 61, 3196-3207. [CrossRef]

65. Shi, T.; Han, G.; Ma, X.; Zhang, M.; Pei, Z.; Xu, H.; Qiu, R.; Zhang, H.; Gong, W.J.J.o.C.P. An inversion method for estimating strong point carbon dioxide emissions using a differential absorption Lidar. J. Clean. Prod. 2020, 271, 122434. [CrossRef]

66. Liu, P.; Zhang, T.S.; Sun, X.H.; Fan, G.Q.; Xiang, Y.; Fu, Y.B.; Dong, Y.S. Compact and movable ozone differential absorption lidar system based on an all-solid-state, tuning-free laser source. Opt. Express 2020, 28, 13786-13800. [CrossRef]

67. Browell, E.V.; Ismail, S.; Grant, W.B. Differential absorption lidar (DIAL) measurements from air and space. Appl. Phys. B Lasers Opt. 1998, 67, 399-410. [CrossRef]

68. Dobler, J.T.; Harrison, F.W.; Browell, E.V.; Lin, B.; McGregor, D.; Kooi, S.; Choi, Y.; Ismail, S. Atmospheric $\mathrm{CO}_{2}$ column measurements with an airborne intensity-modulated continuous wave $1.57 \mathrm{mu}$ fiber laser lidar. Appl. Opt. 2013, 52, 2874-2892. [CrossRef]

69. Lin, B.; Ismail, S.; Harrison, F.W.; Browell, E.V.; Nehrir, A.R.; Dobler, J.; Moore, B.; Refaat, T.; Kooi, S.A. Modeling of intensity-modulated continuous-wave laser absorption spectrometer systems for atmospheric $\mathrm{CO}_{2}$ column measurements. Appl. Opt. 2013, 52, 7062-7077. [CrossRef] [PubMed]

70. Abshire, J.B.; Ramanathan, A.; Riris, H.; Mao, J.P.; Allan, G.R.; Hasselbrack, W.E.; Weaver, C.J.; Browell, E.V. Airborne Measurements of $\mathrm{CO}_{2}$ Column Concentration and Range Using a Pulsed Direct- Detection IPDA Lidar. Remote Sens. 2014, 6, 443-469. [CrossRef]

71. Refaat, T.F.; Singh, U.N.; Yu, J.R.; Petros, M.; Remus, R.; Ismail, S. Double-pulse 2-mu m integrated path differential absorption lidar airborne validation for atmospheric carbon dioxide measurement. Appl. Opt. 2016, 55, 4232-4246. [CrossRef] [PubMed]

72. Singh, U.N.; Refaat, T.F.; Petros, M.; Ismail, S. Evaluation of 2-mu m Pulsed Integrated Path Differential Absorption Lidar for Carbon Dioxide Measurement-Technology Developments, Measurements, and Path to Space. IEEE J. Sel. Top. Appl. Earth Observ. Remote Sens. 2018, 11, 2059-2067. [CrossRef]

73. Refaat, T.F.; Singh, U.N.; Yu, J.R.; Petros, M.; Ismail, S.; Kavaya, M.J.; Davis, K.J. Evaluation of an airborne triple-pulsed $2 \mathrm{mu}$ m IPDA lidar for simultaneous and independent atmospheric water vapor and carbon dioxide measurements. Appl. Opt. 2015, 54, 1387-1398. [CrossRef]

74. Singh, U.N.; Petros, M.; Refaat, T.F.; Antill, C.W.; Remus, R.; Yu, J.R. Airborne lidar for simultaneous measurement of column $\mathrm{CO}_{2}$ and water vapor in the atmosphere. In Lidar Technologies, Techniques, and Measurements for Atmospheric Remote Sensing XII; Singh, U.N., Nicolae, D.N., Eds.; Spie-Int Soc Optical Engineering: Bellingham, WA, USA, 2016; Volume 10006.

75. Fix, A.; Steinebach, F.; Wirth, M.; Schafler, A.; Ehret, G. Development and application of an airborne differential absorption lidar for the simultaneous measurement of ozone and water vapor profiles in the tropopause region. Appl. Opt. 2019, 58, 5892-5900. [CrossRef]

76. Refaat, T.F.; Ismail, S.; Nehrir, A.R.; Hair, J.W.; Crawford, J.H.; Leifer, I.; Shuman, T. Performance evaluation of a 1.6-mu m methane DIAL system from ground, aircraft and UAV platforms. Opt. Express 2013, 21, 30415-30432. [CrossRef]

77. Amediek, A.; Ehret, G.; Fix, A.; Wirth, M.; Budenbender, C.; Quatrevalet, M.; Kiemle, C.; Gerbig, C. CHARM-F-a new airborne integrated-path differential-absorption lidar for carbon dioxide and methane observations: Measurement performance and quantification of strong point source emissions. Appl. Opt. 2017, 56, 5182-5197. [CrossRef]

78. Yerasi, A.; Tandy, W.D.; Emery, W.J.; Barton-Grimley, R.A. Comparing the theoretical performances of 1.65-and 3.3-mu $\mathrm{m}$ differential absorption lidar systems used for airborne remote sensing of natural gas leaks. J. Appl. Remote Sens. 2018, 12, 16. [CrossRef] 
79. Hahn, F. A deployable spaceborne lidar telescope: Concept and technology advances. In Proceedings of the Opto-Canada: SPIE Regional Meeting on Optoelectronics, Photonics, and Imaging, Ottawa, ON, Canada, 9-10 May 2002; p. 103130P.

80. Schilt, S.; Matthey, R.; Tow, K.H.; Thévenaz, L.; Südmeyer, T.J.C.S.J. All-fiber versatile laser frequency reference at $2 \mu \mathrm{m}$ for $\mathrm{CO}_{2}$ space-borne lidar applications. CEAS Space J. 2017, 9, 493-505. [CrossRef]

81. Ehret, G.; Bousquet, P.; Pierangelo, C.; Alpers, M.; Millet, B.; Abshire, J.B.; Bovensmann, H.; Burrows, J.P.; Chevallier, F.; Ciais, P.; et al. MERLIN: A French-German Space Lidar Mission Dedicated to Atmospheric Methane. Remote Sens. 2017, 9, 29. [CrossRef]

82. Bode, M.; Alpers, M.; Millet, B.; Ehret, G.; Flamant, P. Merlin: An Integrated Path Differential Absorption (IPDA) Lidar for Global Methane Remote Sensing. In International Conference on Space Optics-ICSO 2014; Sodnik, Z., Cugny, B., Karafolas, N., Eds.; Spie-Int Soc Optical Engineering: Bellingham, WA, USA, 2014; Volume 10563.

83. Rudakov, F.; Geiser, J.D.; Weber, P.M. Spatially resolved standoff trace chemical sensing using backwards transient absorption spectroscopy. Opt. Lett. 2018, 43, 1279-1282. [CrossRef]

84. Leffler, T.; Brackmann, C.; Ehn, A.; Kaldvee, B.; Alden, M.; Berg, M.; Bood, J. Range-resolved detection of potassium chloride using picosecond differential absorption light detection and ranging. Appl. Opt. 2015, 54, 1058-1064. [CrossRef] [PubMed]

85. Malmqvist, E.; Brydegaard, M.; Alden, M.; Bood, J. Scheimpflug Lidar for combustion diagnostics. Opt. Express 2018, 26, 14842-14858. [CrossRef]

86. Saleh, A.; Aalto, A.; Ryczkowski, P.; Genty, G.; Toivonen, J. Short-range supercontinuum-based lidar for temperature profiling. Opt. Lett. 2019, 44, 4223-4226. [CrossRef]

87. Cui, X.; Dong, F.; Zhang, Z.; Xia, H.; Pang, T.; Sun, P.; Wu, B.; Liu, S.; Han, L.; Li, Z. Environmental Application of High Sensitive Gas Sensors with Tunable Diode Laser Absorption Spectroscopy. In Green Electronics; Ravariu, C., Mihaiescu, D., Eds.; IntechOpen: London, UK, 2017.

88. Chen, J.; Du, Z.H.; Sun, T.; Li, J.Y.; Ma, Y.W. Self-corrected frequency modulation spectroscopy immune to phase random and light intensity fluctuation. Opt. Express 2019, 27, 30700-30709. [CrossRef]

89. Wang, F.; Jia, S.; Wang, Y.; Tang, Z.J.A.S. Recent developments in modulation spectroscopy for methane detection based on tunable diode laser. Appl. Sci. 2019, 9, 2816. [CrossRef]

90. Goyal, A.K.; Kotidis, P.; Deutsch, E.R.; Zhu, N.; Norman, M.; Ye, J.; Zafiriou, K.; Mazurenko, A. Detection of chemical clouds using widely tunable quantum cascade lasers. In Proceedings of the Chemical, Biological, Radiological, Nuclear, and Explosives (CBRNE) Sensing XVI, Baltimore, MD, USA, 21-23 April 2015; p. 94550L.

91. Ro, K.S.; Johnson, M.H.; Varma, R.M.; Hashmonay, R.A.; Hunt, P. Measurement of greenhouse gas emissions from agricultural sites using open-path optical remote sensing method. J. Environ. Sci. Health A 2009, 44, 1011-1018. [CrossRef]

92. Xia, H.; Liu, W.Q.; Zhang, Y.J.; Kan, R.F.; Wang, M.; He, Y.; Cui, Y.B.; Ruan, J.; Geng, H. An approach of open-path gas sensor based on tunable diode laser absorption spectroscopy. Chin. Opt. Lett. 2008, 6, 437-440. [CrossRef]

93. Pranovich, A.; Divoky, M.; Prochazka, I.; Mocek, T. Tunable diode laser absorption spectroscopy at 2.05 um for the $\mathrm{CO}_{2}$ concentration measurement. In Proceedings of the Optical Sensors 2015, Prague, Czech Republic, 13-16 April 2015; p. 95061S.

94. Li, J.; Du, Z.; Ma, Y.; Liu, J. Indoor carbon dioxide monitoring with diode laser absorption at $2 \mu \mathrm{m}$. In Proceedings of the Third International Symposium on Laser Interaction with Matter, Nanjing, China, 2-5 November 2014; p. 954313.

95. Yang, C.; Hu, M.; Chen, X.; Xu, Z.; Fan, X.; Liu, J.; Kan, R. Multi-QCLs based Open-path Sensor for Atmospheric $\mathrm{NO}, \mathrm{NO}_{2}$ and $\mathrm{NH}_{3} 2$ Detections. In Proceedings of the Optics and Photonics for Energy and the Environment, Leipzig, Germany, 14-17 November 2016; p. JW4A-26.

96. Mlynczak, J.; Kubicki, J.; Kopczynski, K. Stand-Off Detection of Alcohol Vapors Exhaled by Humans. Sensors 2018, 18, 1310. [CrossRef] [PubMed]

97. Dong, D.M.; Jiao, L.Z.; Li, C.X.; Zhao, C.J. Rapid and real-time analysis of volatile compounds released from food using infrared and laser spectroscopy. TrAC Trends Anal. Chem. 2019, 110, 410-416. [CrossRef] 
98. Deutsch, E.R.; Kotidis, P.; Zhu, N.; Goyal, A.K.; Ye, J.; Mazurenko, A.; Norman, M.; Zafiriou, K.; Baier, M.; Connors, R. Active and passive infrared spectroscopy for the detection of environmental threats. In Proceedings of the Advanced Environmental, Chemical, and Biological Sensing Technologies XI, Baltimore, MD, USA, 5-6 May 2014; p. 91060A.

99. Wysocki, G.; Weidmann, D. Molecular dispersion spectroscopy for chemical sensing using chirped mid-infrared quantum cascade laser. Opt. Express 2010, 18, 26123-26140. [CrossRef] [PubMed]

100. Nikodem, M.; Wysocki, G. Chirped laser dispersion spectroscopy for remote open-path trace-gas sensing. Sensors 2012, 12, 16466-16481. [CrossRef]

101. Nikodem, M.; Plant, G.; Sonnenfroh, D.; Wysocki, G. Open-path sensor for atmospheric methane based on chirped laser dispersion spectroscopy. Appl. Phys. B Lasers Opt. 2015, 119, 3-9. [CrossRef]

102. Plant, G.; Nikodem, M.; Mulhall, P.; Varner, R.K.; Sonnenfroh, D.; Wysocki, G. Field Test of a Remote Multi-Path CLaDS Methane Sensor. Sensors 2015, 15, 21315-21326. [CrossRef]

103. Nikodem, M. Chirped laser dispersion spectroscopy for laser-based hydrogen sulfide detection in open-path conditions. Opt. Express 2016, 24, A878-A884. [CrossRef]

104. Golubkov, G.V.; Grigoriev, G.Y.; Nabiev, S.S.; Palkina, L.A.; Golubkov, M.G. Use of IR Absorption Laser Spectroscopy at Nuclear Fuel Cycle Plants: Problems and Prospects (Review). Russ. J. Phys. Chem. B 2018, 12, 804-829. [CrossRef]

105. Xia, J.; Zhu, F.; Zhang, S.; Kolomenskii, A.; Dong, J.; Okada, K.; Strohaber, J.; Schuessler, H.A. Probing greenhouse gases in turbulent atmosphere by long-range open-path wavelength modulation spectroscopy. Opt. Lasers Eng. 2019, 117, 21-28. [CrossRef]

106. Taslakov, M.; Simeonov, V.; Froidevaux, M.; van den Bergh, H. Open-path ozone detection by quantum-cascade laser. Appl. Phys. B Lasers Opt. 2006, 82, 501-506. [CrossRef]

107. Michel, A.P.M.; Liu, P.Q.; Yeung, J.K.; Corrigan, P.; Baeck, M.L.; Wang, Z.F.; Day, T.; Moshary, F.; Gmachl, C.F.; Smith, J.A. Quantum cascade laser open-path system for remote sensing of trace gases in Beijing, China. Opt. Eng. 2010, 49, 111125. [CrossRef]

108. Frish, M.B. Laser-based sensors for addressing climate change. In Proceedings of the CLEO: Applications and Technology, San Jose, CA, USA, 14-19 May 2017; p. AM3B-1.

109. Frish, M.; Wainner, R.; Green, B.; Laderer, M.; Allen, M. Standoff gas leak detectors based on tunable diode laser absorption spectroscopy. In Proceedings of the Infrared to Terahertz Technologies for Health and the Environment, Boston, MA, USA, 23-26 October 2005; p. 60100D.

110. Wainner, R.T.; Green, B.D.; Allen, M.G.; White, M.A.; Stafford-Evans, J.; Naper, R. Handheld, battery-powered near-IR TDL sensor for stand-off detection of gas and vapor plumes. Appl. Phys. B Lasers Opt. 2002, 75, 249-254. [CrossRef]

111. van Well, B.; Murray, S.; Hodgkinson, J.; Pride, R.; Strzoda, R.; Gibson, G.; Padgett, M. An open-path, hand-held laser system for the detection of methane gas. J. Opt. Soc. Am. A 2005, 7, S420. [CrossRef]

112. Gao, X.; Fan, H.; Huang, T.; Wang, X.; Bao, J.; Li, X.; Huang, W.; Zhang, W. Natural gas pipeline leak detector based on NIR diode laser absorption spectroscopy. Spectrochim. Acta A Mol. Biomol. Spectrosc. 2006, 65, 133-138. [CrossRef]

113. Wang, T.; Zhou, T.; Jia, X. Remote sensing with laser spectrum radar. In Proceedings of the Hyperspectral Remote Sensing Applications and Environmental Monitoring and Safety Testing Technology, Beijing, China, 9-11 May 2016; p. 101560C.

114. Lwin, M.; Corrigan, P.; Gross, B.; Moshary, F.; Ahmed, S. Mid-infrared backscattering measurements of building materials using a quantum cascade laser. In Proceedings of the Infrared Technology and Applications XXXVI, Orlando, FL, USA, 5-9 April 2010; p. 766043.

115. Basistyy, R.; Genoud, A.; Diaz, A.; Moshary, F.; Thomas, B. Active standoff mixing-ratio measurements of $\mathrm{N}_{2} \mathrm{O}$ from topographic targets using an open-path quantum cascade laser system. In Proceedings of the Lidar Remote Sensing for Environmental Monitoring XVI, Honolulu, HI, USA, 24-25 September 2018; p. 107790G.

116. Basistyy, R.; Genoud, A.; Thomas, B. Backscattering properties of topographic targets in the visible, shortwave infrared, and mid-infrared spectral ranges for hard-target lidars. Appl. Opt. 2018, 57, 6990-6997. [CrossRef]

117. Frish, M.B.; Wainner, R.T.; Laderer, M.C.; Green, B.D.; Allen, M.G. Standoff and Miniature Chemical Vapor Detectors Based on Tunable Diode Laser Absorption Spectroscopy. IEEE Sens. J. 2010, 10, 639-646. [CrossRef] 
118. Frish, M.B.; Wainner, R.T.; Laderer, M.C.; Allen, M.G.; Rutherford, J.; Wehnert, P.; Dey, S.; Gilchrist, J.; Corbi, R.; Picciaia, D. Low-cost lightweight airborne laser-based sensors for pipeline leak detection and reporting. In Proceedings of the Next-Generation Spectroscopic Technologies VI, Baltimore, MD, USA, 29-30 April 2013; p. 87260C.

119. Yang, S.T.; Talbot, R.W.; Frish, M.B.; Golston, L.M.; Aubut, N.F.; Zondlo, M.A.; Gretencord, C.; McSpiritt, J. Natural Gas Fugitive Leak Detection Using an Unmanned Aerial Vehicle: Measurement System Description and Mass Balance Approach. Atmosphere 2018, 9, 383. [CrossRef]

120. Golston, L.M.; Aubut, N.F.; Frish, M.B.; Yang, S.T.; Talbot, R.W.; Gretencord, C.; McSpiritt, J.; Zondlo, M.A. Natural Gas Fugitive Leak Detection Using an Unmanned Aerial Vehicle: Localization and Quantification of Emission Rate. Atmosphere 2018, 9, 333. [CrossRef]

121. Phillips, M.C.; Brumfield, B.E. Standoff detection of turbulent chemical mixture plumes using a swept external cavity quantum cascade laser. Opt. Eng. 2017, 57, 011003. [CrossRef]

122. Phillips, M.C.; Brumfield, B.E.; Harilal, S.S. Real-time standoff detection of nitrogen isotopes in ammonia plumes using a swept external cavity quantum cascade laser. Opt. Lett. 2018, 43, 4065-4068. [CrossRef] [PubMed]

123. Diaz, A.; Thomas, B.; Castillo, P.; Gross, B.; Moshary, F. Active standoff detection of $\mathrm{CH}_{4}$ and $\mathrm{N}_{2} \mathrm{O}$ leaks using hard-target backscattered light using an open-path quantum cascade laser sensor. Appl. Phys. B Lasers Opt. 2016, 122, 121. [CrossRef]

124. Takeuchi, E.B.; Rayner, T.; Weida, M.; Crivello, S.; Day, T. Standoff detection of explosives and chemical agents using broadly tuned external-cavity quantum cascade lasers (EC-QCLs). In Proceedings of the Optics and Photonics for Counterterrorism and Crime Fighting III, Florence, Italy, 18-20 September 2007.

125. Bauer, C.; Sharma, A.K.; Willer, U.; Burgmeier, J.; Braunschweig, B.; Schade, W.; Blaser, S.; Hvozdara, L.; Muller, A.; Holl, G. Potentials and limits of mid-infrared laser spectroscopy for the detection of explosives. Appl. Phys. B Lasers Opt. 2008, 92, 327-333. [CrossRef]

126. Bauer, C.; Willer, U.; Schade, W. Use of quantum cascade lasers for detection of explosives: Progress and challenges. Opt. Eng. 2010, 49, 7. [CrossRef]

127. Schade, W.; Orghici, R.; Mordmüller, M.; Willer, U.J.H.o.B. Detection of Explosives. In Handbook of Biophotonics; Wiley: Hoboken, NJ, USA, 2013; pp. 195-218. [CrossRef]

128. Breshike, C.J.; Kendziora, C.A.; Furstenberg, R.; Yoon, Y. Rapid detection of infrared backscatter for standoff detection of trace explosives. In Proceedings of the Chemical, Biological, Radiological, Nuclear, and Explosives (CBRNE) Sensing XXI, Online, 27 April-8 May 2020; p. 114160W.

129. Pacheco-Londono, L.C.; Warren, E.; Galan-Freyle, N.J.; Villarreal-Gonzalez, R.; Aparicio-Bolano, J.A.; Ospina-Castro, M.L.; Shih, W.C.; Hernandez-Rivera, S.P. Mid-Infrared Laser Spectroscopy Detection and Quantification of Explosives in Soils Using Multivariate Analysis and Artificial Intelligence. Appl. Sci. 2020, 10, 19. [CrossRef]

130. Wang, Z.; Sanders, S.T. Toward single-ended absorption spectroscopy probes based on backscattering from rough surfaces: $\mathrm{H}_{2} \mathrm{O}$ vapor measurements near $1350 \mathrm{~nm}$. Appl. Phys. B Lasers Opt. 2015, 121, 187-192. [CrossRef]

131. Wang, Z.; Sanders, S.T.; Robinson, M.A. Spatially resolved concentration measurements based on backscatter absorption spectroscopy. Appl. Phys. B Lasers Opt. 2016, 122, 176. [CrossRef]

132. Peng, W.Y.; Goldenstein, C.S.; Mitchell Spearrin, R.; Jeffries, J.B.; Hanson, R.K. Single-ended mid-infrared laser-absorption sensor for simultaneous in situ measurements of $\mathrm{H}_{2} \mathrm{O}, \mathrm{CO}_{2}, \mathrm{CO}$, and temperature in combustion flows. Appl. Opt. 2016, 55, 9347-9359. [CrossRef]

133. Zhou, Y.; Mathews, G.C.; Goldenstein, C.S. Compact, fiber-coupled, single-ended laser-absorption-spectroscopy sensors for high-temperature environments. Appl. Opt. 2018, 57, 7117-7126. [CrossRef]

134. Ding, W.; Sun, L. Calibration-free Handheld sensor based on Tunable Diode Laser Absorption Spectroscopy for Remote Detection of Methane. In Proceedings of the Optics and Photonics for Energy and the Environment 2015, Suzhou, China, 2-5 November 2015; p. ETu4A-2.

135. Ding, W.; Sun, L.; Yi, L.; Zhang, E. 'Baseline-offset'scheme for a methane remote sensor based on wavelength modulation spectroscopy. Meas. Sci. Technol. 2016, 27, 085202. [CrossRef] 
136. Frish, M.B.; Scherer, D.R.; Wainner, R.T.; Allen, M.G.; Shankar, R.; Loncar, M. Monolithic integrated-optic TDLAS sensors. In Proceedings of the Next-Generation Spectroscopic Technologies V, Baltimore, MD, USA, 23-24 April 2012; p. 83740I.

137. Hernández Bennetts, V.M. Mobile Robots with In-Situ and Remote Sensors for Real World Gas Distribution Modelling. Ph.D. Thesis, Örebro University, Örebro, Sweden, 2015.

138. Neumann, P.P.; Kohlhoff, H.; Hüllmann, D.; Lilienthal, A.J.; Kluge, M. Bringing Mobile Robot Olfaction to the next dimension-UAV-based remote sensing of gas clouds and source localization. In Proceedings of the 2017 IEEE International Conference on Robotics and Automation (ICRA), Singapore, 29 May-3 June 2017; pp. 3910-3916.

139. Harris, M.; Pearson, G.N.; Willetts, D.V.; Ridley, K.; Tapster, P.R.; Perrett, B. Pulsed indirect photoacoustic spectroscopy: Application to remote detection of condensed phases. Appl. Opt. 2000, 39, 1032-1041. [CrossRef] [PubMed]

140. Perrett, B.; Harris, M.; Pearson, G.N.; Willetts, D.V.; Pitter, M.C. Remote photoacoustic detection of liquid contamination of a surface. Appl. Opt. 2003, 42, 4901-4908. [CrossRef] [PubMed]

141. Li, J.S.; Yu, B.; Fischer, H.; Chen, W.; Yalin, A.P. Contributed review: Quantum cascade laser based photoacoustic detection of explosives. Rev. Sci. Instrum. 2015, 86, 031501. [CrossRef] [PubMed]

142. Chen, X.; Cheng, L.; Guo, D.; Kostov, Y.; Choa, F.S. Quantum cascade laser based standoff photoacoustic chemical detection. Opt. Express 2011, 19, 20251-20257. [CrossRef] [PubMed]

143. Chen, X.; Guo, D.K.; Choa, F.S.; Wang, C.C.; Trivedi, S.; Snyder, A.P.; Ru, G.Y.; Fan, J.Y. Standoff photoacoustic detection of explosives using quantum cascade laser and an ultrasensitive microphone. Appl. Opt. 2013, 52, 2626-2632. [CrossRef]

144. Choa, F.-S.; Wang, C.-C.; Khurgin, J.; Samuels, A.; Trivedi, S.; Gupta, D. Standoff photoacoustic detections with high-sensitivity microphones and acoustic arrays. In Proceedings of the Chemical, Biological, Radiological, Nuclear, and Explosives (CBRNE) Sensing XVII, Baltimore, MD, USA, 18-20 April 2016; p. 98240M.

145. Gupta, D.; Wang, C.-C.; Khurgin, J.; Samuels, A.; Trivedi, S.; Choa, F.-S. Acoustic array beam-forming for standoff chemical detection. SPIE News Room 2016. [CrossRef]

146. Gupta, D.; Chen, X.; Wang, C.-C.; Trivedi, S.; Choa, F.-S. Stand-off chemical detection using photoacoustic sensing techniques-From single element to phase array. Chemosensors 2018, 6, 6. [CrossRef]

147. Sharma, R.C.; Kumar, S.; Kumar, S.; Mann, M.; Sharma, M. Photoacoustic remote sensing of suspicious objects for defence and forensic applications. Spectrochim. Acta A Mol. Biomol. Spectrosc. 2020, 224, 117445. [CrossRef]

148. Cooper, J.K.; Grant, C.D.; Zhang, J.Z. Experimental and TD-DFT study of optical absorption of six explosive molecules: RDX, HMX, PETN, TNT, TATP, and HMTD. J. Phys. Chem. A 2013, 117, 6043-6051. [CrossRef]

149. Zrimsek, A.B.; Bykov, S.V.; Asher, S.A. Deep Ultraviolet Standoff Photoacoustic Spectroscopy of Trace Explosives. Appl. Spectrosc. 2019, 73, 601-609. [CrossRef]

150. Holthoff, E.L.; Pellegrino, P.M. Development of photoacoustic sensing platforms at the Army Research Laboratory. Appl. Opt. 2017, 56, B74-B84. [CrossRef] [PubMed]

151. Marcus, L.S.; Holthoff, E.L.; Pellegrino, P.M. Standoff Photoacoustic Spectroscopy of Explosives. Appl. Spectrosc. 2017, 71, 833-838. [CrossRef] [PubMed]

152. Marcus, L.S.; Holthoff, E.L.; Pellegrino, P.M. Standoff photoacoustic spectroscopy for hazard detection. J. Acoust. Soc. Am. 2015, 138, 1940. [CrossRef]

153. Holthoff, E.L.; Marcus, L.S.; Pellegrino, P.M. Photoacoustic spectroscopy for trace vapor detection and standoff detection of explosives. In Proceedings of the Chemical, Biological, Radiological, Nuclear, and Explosives (CBRNE) Sensing XVII, Baltimore, MD, USA, 18-20 April 2016; p. 98240R.

154. El-Sharkawy, Y.H.; Elbasuney, S. Novel laser induced photoacoustic spectroscopy for instantaneous trace detection of explosive materials. Forensic Sci. Int. 2017, 277, 215-222. [CrossRef]

155. Hu, Q.; Lim, J.S.K.; Liu, H.; Fu, Y. Photo-vibrational spectroscopy of solid and liquid chemicals using laser Doppler vibrometer. Opt. Express 2016, 24, 19148-19156. [CrossRef]

156. Fu, Y.; Liu, H.; Hu, Q.; Xie, J. Photo-vibrational sensing of trace chemicals and explosives by long-distance differential laser Doppler vibrometer. In Proceedings of the Chemical, Biological, Radiological, Nuclear, and Explosives (CBRNE) Sensing XVIII, Anaheim, CA, USA, 11 April 2017; p. 101830B. 
157. Fu, Y.; Hu, Q.; Liu, H. Standoff photoacoustic sensing of trace chemicals by laser Doppler vibrometer. In Proceedings of the Chemical, Biological, Radiological, Nuclear, and Explosives (CBRNE) Sensing XVII, Baltimore, MD, USA, 18-20 April 2016; p. 98240O.

158. Fu, Y.; Liu, H.; Xie, J.C. 100-m standoff detection of a QCL-induced photo-vibrational signal on explosives using a laser vibrometer. Opt. Laser Eng. 2018, 107, 241-246. [CrossRef]

159. Kosterev, A.A.; Bakhirkin, Y.A.; Curl, R.F.; Tittel, F.K. Quartz-enhanced photoacoustic spectroscopy. Opt. Lett. 2002, 27, 1902-1904. [CrossRef]

160. Ma, Y. Review of recent advances in QEPAS-based trace gas sensing. Appl. Sci. 2018, 8, 1822. [CrossRef]

161. Van Neste, C.W.; Senesac, L.R.; Thundat, T. Standoff photoacoustic spectroscopy. Appl. Phys. Lett. 2008, 92, 234102. [CrossRef]

162. Van Neste, C.W.; Senesac, L.R.; Thundat, T. Standoff spectroscopy of surface adsorbed chemicals. Anal. Chem. 2009, 81, 1952-1956. [CrossRef]

163. Liu, N.W.; Zhou, S.; Zhang, L.; Yu, B.L.; Fischer, H.; Ren, W.; Li, J.S. Standoff detection of VOCs using external cavity quantum cascade laser spectroscopy. Laser Phys. Lett. 2018, 15, 085701. [CrossRef]

164. Sun, J.; Ding, J.; Liu, N.; Yang, G.; Li, J. Detection of multiple chemicals based on external cavity quantum cascade laser spectroscopy. Spectrochim. Acta A Mol. Biomol. Spectrosc. 2018, 191, 532-538. [CrossRef] [PubMed]

165. Kumar, D.; Gupta, S.; Kumar, S.; Sharma, R.C.; Soni, R.K. Open-path measurement of ozone and methane gases using quartz-enhanced photoacoustic spectroscopy. Spectrosc. Lett. 2016, 49, 469-476. [CrossRef]

166. Li, J.S.; Liu, N.W.; Ding, J.Y.; Zhou, S.; He, T.B.; Zhang, L. Piezoelectric effect-based detector for spectroscopic application. Opt. Laser Eng. 2019, 115, 141-148. [CrossRef]

167. Sharma, R.C.; Kumar, D.; Bhardwaj, N.; Gupta, S.; Chandra, H.; Maini, A.K. Portable detection system for standoff sensing of explosives and hazardous materials. Opt. Commun. 2013, 309, 44-49. [CrossRef]

168. Zhang, Z.Q.; Jia, S.H.; Ma, B.S.; Chen, H.L.; Wei, Y. Dynamics of quartz tuning fork force sensors used in standoff photoacoustic detection. J. Mech. Sci. Technol. 2015, 29, 3091-3096. [CrossRef]

169. Udem, T.; Holzwarth, R.; Hansch, T.W. Optical frequency metrology. Nature 2002, 416, 233-237. [CrossRef]

170. Vodopyanov, K.L. Broadband mid-IR frequency comb source for standoff chemical detection. In Proceedings of the Micro-and Nanotechnology Sensors, Systems, and Applications VII, Baltimore, MD, USA, 20-24 April 2015; p. 94672N.

171. Boudreau, S.; Levasseur, S.; Perilla, C.; Roy, S.; Genest, J. Chemical detection with hyperspectral lidar using dual frequency combs. Opt. Express 2013, 21, 7411-7418. [CrossRef]

172. Truong, G.W.; Waxman, E.M.; Cossel, K.C.; Baumann, E.; Klose, A.; Giorgetta, F.R.; Swann, W.C.; Newbury, N.R.; Coddington, I. Accurate frequency referencing for fieldable dual-comb spectroscopy. Opt. Express 2016, 24, 30495-30504. [CrossRef]

173. Villares, G.; Hugi, A.; Blaser, S.; Faist, J. Dual-comb spectroscopy based on quantum-cascade-laser frequency combs. Nat. Commun. 2014, 5, 5192. [CrossRef]

174. Coddington, I.; Newbury, N.; Swann, W. Dual-comb spectroscopy. Optica 2016, 3, 414-426. [CrossRef]

175. Millot, G.; Pitois, S.; Yan, M.; Hovhannisyan, T.; Bendahmane, A.; Hänsch, T.W.; Picqué, N. Frequency-agile dual-comb spectroscopy. Nat. Photon. 2016, 10, 27. [CrossRef]

176. Schliesser, A.; Brehm, M.; Keilmann, F.; van der Weide, D. Frequency-comb infrared spectrometer for rapid, remote chemical sensing. Opt. Express 2005, 13, 9029-9038. [CrossRef] [PubMed]

177. Ideguchi, T.; Poisson, A.; Guelachvili, G.; Picque, N.; Hansch, T.W. Adaptive real-time dual-comb spectroscopy. Nat. Commun. 2014, 5, 3375. [CrossRef]

178. Coburn, S.; Alden, C.B.; Wright, R.; Cossel, K.; Baumann, E.; Truong, G.W.; Giorgetta, F.; Sweeney, C.; Newbury, N.R.; Prasad, K.; et al. Regional trace-gas source attribution using a field-deployed dual frequency comb spectrometer. Optica 2018, 5, 320-327. [CrossRef]

179. Waxman, E.M.; Cossel, K.C.; Truong, G.W.; Giorgetta, F.R.; Swann, W.C.; Coburn, S.; Wright, R.J.; Rieker, G.B.; Coddington, I.; Newbury, N.R. Intercomparison of Open-Path Trace Gas Measurements with Two Dual Frequency Comb Spectrometers. Atmos. Meas. Tech. 2017, 10, 3295-3311. [CrossRef]

180. Truong, G.-W.; Waxman, E.; Cossel, K.C.; Giorgetta, F.; Swann, W.C.; Coddington, I.; Newbury, N.R. Dual-comb spectroscopy for city-scale open path greenhouse gas monitoring. In Proceedings of the CLEO: Science and Innovations, San Jose, CA, USA, 5-10 June 2016; p. SW4H-2. 
181. Cossel, K.C.; Waxman, E.M.; Giorgetta, F.R.; Cermak, M.; Coddington, I.R.; Hesselius, D.; Ruben, S.; Swann, W.C.; Truong, G.W.; Rieker, G.B.; et al. Open-path dual comb spectroscopy to an airborne retroreflector. Optica 2017, 4, 724-728. [CrossRef]

182. Ycas, G.; Giorgetta, F.R.; Cossel, K.C.; Waxman, E.M.; Baumann, E.; Newbury, N.R.; Coddington, I. Mid-infrared dual-comb spectroscopy of volatile organic compounds across long open-air paths. Optica 2019, 6, 165-168. [CrossRef]

183. Schroeder, P.J.; Wright, R.J.; Coburn, S.; Sodergren, B.; Cossel, K.C.; Droste, S.; Truong, G.W.; Baumann, E.; Giorgetta, F.R.; Coddington, I.; et al. Dual frequency comb laser absorption spectroscopy in a $16 \mathrm{MW}$ gas turbine exhaust. Proc. Combust. Inst. 2017, 36, 4565-4573. [CrossRef]

184. Hensley, J.M.; Brown, J.M.; Allen, M.G.; Geiser, M.; Allmendinger, P.; Mangold, M.; Hugi, A.; Juoy, P.; Faist, J. Standoff detection from diffusely scattering surfaces using dual quantum cascade laser comb spectroscopy. In Proceedings of the Ultrafast Bandgap Photonics III, Orlando, FL, USA, 16-19 April 2018; p. 1063820.

185. Hayden, T.R.S.; Malarich, N.; Petrykowski, D.; Nigam, S.P.; Christopher, J.D.; Lapointe, C.; Wimer, N.T.; Hamlington, P.E.; Rieker, G.B. OH radical measurements in combustion environments using wavelength modulation spectroscopy and dual-frequency comb spectroscopy near $1491 \mathrm{~nm}$. Appl. Phys. B Lasers Opt. 2019, 125, 226. [CrossRef]

186. Westberg, J.; Teng, C.C.; Chen, Y.; Liu, J.; Patrick, L.; Soskind, M.; Shen, L.; Wysocki, G. Field deployment of a mid-IR dual-comb spectrometer based on quantum cascade lasers. In Proceedings of the OSA Optical Sensors and Sensing Congress, Vancouver, BC, Canada, 22-26 June 2020.

187. Giorgetta, F.; Rieker, G.; Sinclair, L.; Baumann, E.; Coddington, I.; Swann, W.; Newbury, N. Phase Spectroscopy of Atmospheric Gases across a 2-km Open-Air Path by Dual-Comb Spectroscopy. In Proceedings of the Applications of Lasers for Sensing and Free Space Communications, Arlington, VA, USA, 7-11 June 2015; p. LT2F-3.

188. Okubo, S.; Iwakuni, K.; Inaba, H.; Hosaka, K.; Onae, A.; Sasada, H.; Hong, F.-L. Ultra-broadband dual-comb spectroscopy across 1.0-1.9 $\mu \mathrm{m}$. Appl. Phys. Express 2015, 8, 082402. [CrossRef]

189. Suh, M.G.; Yang, Q.F.; Yang, K.Y.; Yi, X.; Vahala, K.J. Microresonator soliton dual-comb spectroscopy. Science 2016, 354, 600-603. [CrossRef] [PubMed]

190. Fdil, K.; Michaud-Belleau, V.; Hebert, N.B.; Guay, P.; Fleisher, A.J.; Deschenes, J.D.; Genest, J. Dual electro-optic frequency comb spectroscopy using pseudo-random modulation. Opt. Lett. 2019, 44, 4415-4418. [CrossRef] [PubMed]

191. Ycas, G.; Giorgetta, F.R.; Baumann, E.; Coddington, I.; Herman, D.; Diddams, S.A.; Newbury, N.R. High-coherence mid-infrared dual-comb spectroscopy spanning 2.6 to $5.2 \mu \mathrm{m}$. Nat. Photonics 2018, 12, 202. [CrossRef]

192. Shen, X.L.; Yan, M.; Hao, Q.; Yang, K.W.; Zeng, H.P. Adaptive Dual-Comb Spectroscopy With 1200-h Continuous Operation Stability. IEEE Photon. J. 2018, 10, 1-9. [CrossRef]

193. Link, S.M.; Maas, D.; Waldburger, D.; Keller, U. Dual-comb spectroscopy of water vapor with a free-running semiconductor disk laser. Science 2017, 356, 1164-1168. [CrossRef] [PubMed]

194. Westberg, J.; Sterczewski, L.A.; Kapsalidis, F.; Bidaux, Y.; Wolf, J.M.; Beck, M.; Faist, J.; Wysocki, G. Dual-comb spectroscopy using plasmon-enhanced-waveguide dispersion-compensated quantum cascade lasers. Opt. Lett. 2018, 43, 4522-4525. [CrossRef]

195. Martin-mateos, P.; Genner, A.; Moser, H.; Lendl, B. Implementation and characterization of a thermal infrared laser heterodyne radiometer based on a wavelength modulated local oscillator laser. Opt. Express 2019, 27, 15575-15584. [CrossRef]

196. Menzies, R.T.; Shumate, M.S. Air-Pollution-Remote Detection of Several Pollutant Gases with a Laser Heterodyne Radiometer. Science 1974, 184, 570-572. [CrossRef]

197. Weidmann, D.; Reburn, W.J.; Smith, K.M. Retrieval of atmospheric ozone profiles from an infrared quantum cascade laser heterodyne radiometer: Results and analysis. Appl. Opt. 2007, 46, 7162-7171. [CrossRef]

198. Weidmann, D.; Tsai, T.; Macleod, N.A.; Wysocki, G. Atmospheric observations of multiple molecular species using ultra-high-resolution external cavity quantum cascade laser heterodyne radiometry. Opt. Lett. 2011, 36, 1951-1953. [CrossRef]

199. Weidmann, D.; Hoffmann, A.; Macleod, N.; Middleton, K.; Kurtz, J.; Barraclough, S.; Griffin, D. The Methane Isotopologues by Solar Occultation (MISO) Nanosatellite Mission: Spectral Channel Optimization and Early Performance Analysis. Remote Sens. 2017, 9, 1073. [CrossRef] 
200. Tsai, T.R.; Rose, R.A.; Weidmann, D.; Wysocki, G. Atmospheric vertical profiles of $\mathrm{O}_{3}, \mathrm{~N}_{2} \mathrm{O}, \mathrm{CH}_{4}, \mathrm{CCl}_{2} \mathrm{~F}_{2}$, and $\mathrm{H}_{2} \mathrm{O}$ retrieved from external-cavity quantum-cascade laser heterodyne radiometer measurements. Appl. Opt. 2012, 51, 8779-8792. [CrossRef] [PubMed]

201. Smith, F.; Havemann, S.; Hoffmann, A.; Bell, W.; Weidmann, D.; Newman, S. Evaluation of laser heterodyne radiometry for numerical weather prediction applications. Q. J. R. Meteorol. Soc. 2018, 144, 1831-1850. [CrossRef]

202. Hoffmann, A.; Macleod, N.A.; Huebner, M.; Weidmann, D. Thermal infrared laser heterodyne spectroradiometry for solar occultation atmospheric $\mathrm{CO}_{2}$ measurements. Atmos. Meas. Tech. 2016, 9, 5975. [CrossRef]

203. Shang-lu, Z.; Yin-bo, H.; Xing-ji, L.; Zhen-song, C.; Cong-ming, D.; Qiang, L.; Xiao-ming, G.; Rui-zhong, R.; Ying-jian, W. Retrieval of Atmospheric $\mathrm{H}_{2} \mathrm{O}$ Column Concentration Based on Mid-Infrared Inter-Band Cascade Laser Heterodyne Radiometer. Spectrosc. Spect. Anal. 2019, 39, 1317-1322. [CrossRef]

204. Wilson, E.; McLinden, M.; Miller, J.; Allan, G.; Ott, L.; Melroy, H.; Clarke, G. Miniaturized laser heterodyne radiometer for measurements of $\mathrm{CO}_{2}$ in the atmospheric column. Appl. Phys. B Lasers Opt. 2014, 114, 385-393. [CrossRef]

205. Wilson, E.L.; McLinden, M.L.; Georgieva, E.M.; Miller, J.H. Low-cost miniaturized laser heterodyne radiometer for highly sensitive detection of $\mathrm{CO}_{2}, \mathrm{CH}_{4}$, and $\mathrm{CO}$ in the atmospheric column. In Proceedings of the 2011 NASA Carbon Cycle and Ecosystems Joint Science Workshop, Alexandria, VA, USA, 3-7 October 2011.

206. Melroy, H.; Wilson, E.; Clarke, G.; Ott, L.; Mao, J.; Ramanathan, A.; McLinden, M. Autonomous field measurements of $\mathrm{CO}_{2}$ in the atmospheric column with the miniaturized laser heterodyne radiometer (Mini-LHR). Appl. Phys. B Lasers Opt. 2015, 120, 609-615. [CrossRef]

207. Wilson, E.; DiGregorio, A.; Villanueva, G.; Grunberg, C.; Souders, Z.; Miletti, K.; Menendez, A.; Grunberg, M.; Floyd, M.; Bleacher, J. A portable miniaturized laser heterodyne radiometer (mini-LHR) for remote measurements of column $\mathrm{CH}_{4}$ and $\mathrm{CO}_{2}$. Appl. Phys. B Lasers Opt. 2019, 125, 211. [CrossRef]

208. Deng, H.; Yang, C.; Wang, W.; Shan, C.; Xu, Z.; Chen, B.; Yao, L.; Hu, M.; Kan, R.; He, Y. Near infrared heterodyne radiometer for continuous measurements of atmospheric $\mathrm{CO}_{2}$ column concentration. Infrared Phys. Technol. 2019. [CrossRef]

209. Martín-Mateos, P.; Bonilla-Manrique, O.E.; Gutiérrez-Escobero, C. Wavelength modulation laser heterodyne radiometry. Opt. Lett. 2018, 43, 3009-3012. [CrossRef] [PubMed]

210. Sonnabend, G.; Wirtz, D.; Vetterle, V.; Schieder, R. High-resolution observations of Martian non-thermal $\mathrm{CO}_{2}$ emission near $10 \mathrm{~m}$ with a new tuneable heterodyne receiver. Astron. Astrophys. 2005, 435, 1181-1184. [CrossRef]

211. Nakagawa, H.; Aoki, S.; Sagawa, H.; Kasaba, Y.; Murata, I.; Sonnabend, G.; Sornig, M.; Okano, S.; Kuhn, J.R.; Ritter, J.M. IR heterodyne spectrometer MILAHI for continuous monitoring observatory of Martian and Venusian atmospheres at Mt. Haleakalā, Hawaii. Planet. Space Sci. 2016, 126, 34-48. [CrossRef]

212. Macleod, N.A.; Rose, R.; Weidmann, D. Middle infrared active coherent laser spectrometer for standoff detection of chemicals. Opt. Lett. 2013, 38, 3708-3711. [CrossRef] [PubMed]

213. Macleod, N.A.; Molero, F.; Weidmann, D. Broadband standoff detection of large molecules by mid-infrared active coherent laser spectrometry. Opt. Express 2015, 23, 912-928. [CrossRef]

214. Killinger, D.K.; Mooradian, A. Optical and Laser Remote Sensing; Springer: Berlin, Germany, 2013; Volume 39.

215. Razavipour, S.G.; Gupta, J.A.; Sabiston, G.; Sabourin, N.; Bezinger, A.; Lapointe, J.; Poitras, D. Pressure-dependent sensitivity of a single-pass methane detection system using a continuous-wave distributed feedback laser at $3270 \mathrm{~nm}$. Appl. Opt. 2019, 58, 6906-6911. [CrossRef]

216. Wei, W.; Chang, J.; Huang, Q.J.; Wang, Q.; Liu, Y.Y.; Qin, Z.G. Water vapor concentration measurements using TDALS with wavelength modulation spectroscopy at varying pressures. Sens. Rev. 2017, 37, 172-179. [CrossRef]

217. Reimann, P.; Schutze, A. Fire detection in coal mines based on semiconductor gas sensors. Sens. Rev. 2012, 32, 47-58. [CrossRef]

218. Du, Z.H.; Yan, Y.; Li, J.Y.; Zhang, S.; Yang, X.T.; Xiao, Y.H. In situ, multiparameter optical sensor for monitoring the selective catalytic reduction process of diesel engines. Sens. Actuators B Chem. 2018, 267, 255-264. [CrossRef] 
219. Li, J.Y.; Zhang, C.G.; Wei, Y.Y.; Du, Z.H.; Sun, F.S.; Ji, Y.; Yang, X.T.; Liu, C. In situ, portable and robust laser sensor for simultaneous measurement of ammonia, water vapor and temperature in denitrification processes of coal fired power plants. Sens. Actuators B Chem. 2020, 305, 127533. [CrossRef]

220. Deguchi, Y.; Kamimoto, T.; Kiyota, Y. Time resolved 2D concentration and temperature measurement using CT tunable laser absorption spectroscopy. Flow Meas. Instrum. 2015, 46, 312-318. [CrossRef]

221. Wang, Z.; Deguchi, Y.; Kamimoto, T.; Tainaka, K.; Tanno, K. Pulverized coal combustion application of laser-based temperature sensing system using computed tomography-Tunable diode laser absorption spectroscopy (CT-TDLAS). Fuel 2020, 268. [CrossRef]

222. Wang, Z.; Kamimoto, T.; Deguchi, Y.; Zhou, W.; Yan, J.; Tainaka, K.; Tanno, K.; Watanabe, H.; Kurose, R. Two dimensional temperature measurement characteristics in pulverized coal combustion field by computed tomography-tunable diode laser absorption spectroscopy. Appl. Therm. Eng. 2020, 171. [CrossRef]

223. Liu, C.; Cao, Z.; Lin, Y.; Xu, L.; McCann, H. Online Cross-Sectional Monitoring of a Swirling Flame Using TDLAS Tomography. IEEE Trans. Instrum. Meas. 2018, 67, 1338-1348. [CrossRef]

224. Cai, W.W.; Kaminski, C.F. Tomographic absorption spectroscopy for the study of gas dynamics and reactive flows. Prog. Energy Combust. Sci. 2017, 59, 1-31. [CrossRef]

225. Liu, C.; Tsekenis, S.A.; Polydorides, N.; McCann, H. Toward Customized Spatial Resolution in TDLAS Tomography. IEEE Sens. J. 2019, 19, 1748-1755. [CrossRef]

226. Liu, C.; Xu, L.; Chen, J.; Cao, Z.; Lin, Y.; Cai, W. Development of a fan-beam TDLAS-based tomographic sensor for rapid imaging of temperature and gas concentration. Opt. Express 2015, 23, 22494-22511. [CrossRef]

227. Wen, P.; Amin, M.; Herzog, W.D.; Kunz, R.R. Key challenges and prospects for optical standoff trace detection of explosives. TrAC Trends Anal. Chem. 2018, 100, 136-144. [CrossRef]

228. Sigrist, M.W. Mid-infrared laser-spectroscopic sensing of chemical species. J. Adv. Res. 2015, 6, 529-533. [CrossRef]

229. Schunemann, P.G.; Zawilski, K.T.; Pomeranz, L.A.; Creeden, D.J.; Budni, P.A. Advances in nonlinear optical crystals for mid-infrared coherent sources. J. Opt. Soc. Am. B 2016, 33, D36-D43. [CrossRef]

230. Hou, C.C.; Chen, H.M.; Zhang, J.C.; Zhuo, N.; Huang, Y.Q.; Hogg, R.A.; Childs, D.T.; Ning, J.Q.; Wang, Z.G.; Liu, F.Q.; et al. Near-infrared and mid-infrared semiconductor broadband light emitters. Light Sci. Appl. 2018, 7, 17170. [CrossRef] [PubMed]

231. Jung, D.; Bank, S.; Lee, M.L.; Wasserman, D. Next-generation mid-infrared sources. J. Opt. UK 2017, 19, 123001. [CrossRef]

232. Razeghi, M.; Zhou, W.; Slivken, S.; Lu, Q.-Y.; Wu, D.; McClintock, R. Recent progress of quantum cascade laser research from 3 to $12 \mu \mathrm{m}$ at the Center for Quantum Devices. Appl. Opt. 2017, 56, H30-H44. [CrossRef] [PubMed]

233. Curl, R.F.; Capasso, F.; Gmachl, C.; Kosterev, A.A.; McManus, B.; Lewicki, R.; Pusharsky, M.; Wysocki, G.; Tittel, F.K. Quantum cascade lasers in chemical physics. Chem. Phys. Lett. 2010, 487, 1-18. [CrossRef]

234. Hugi, A.; Maulini, R.; Faist, J. External cavity quantum cascade laser. Semicond. Sci. Technol. 2010, $25,083001$. [CrossRef]

235. Lyakh, A.; Barron-Jimenez, R.; Dunayevskiy, I.; Go, R.; Tsvid, E.; Patel, C.K.N. Progress in rapidly-tunable external cavity quantum cascade lasers with a frequency-shifted feedback. Photonics 2016, 3, 19. [CrossRef]

236. Rauter, P.; Capasso, F. Multi-wavelength quantum cascade laser arrays. Laser Photon. Rev. 2015, 9, 452-477. [CrossRef]

237. Zhou, W.J.; Wu, D.H.; McClintock, R.; Slivken, S.; Razeghi, M. High performance monolithic, broadly tunable mid-infrared quantum cascade lasers. Optica 2017, 4, 1228-1231. [CrossRef]

238. Bizet, L.; Vallon, R.; Parvitte, B.; Brun, M.; Maisons, G.; Carras, M.; Zeninari, V. Multi-gas sensing with quantum cascade laser array in the mid-infrared region. Appl. Phys. B Lasers Opt. 2017, 123, 145. [CrossRef]

239. Giglio, M.; Patimisco, P.; Sampaolo, A.; Zifarelli, A.; Menduni, G.; Elefante, A.; Blanchard, R.; Pfluegl, C.; Witinski, M.; Vakhshoori, D. Quartz-enhanced photoacoustic spectroscopy employing a distributed feedback-quantum cascade laser array for nitrous oxide and methane broadband detection. In Proceedings of the Novel In-Plane Semiconductor Lasers XVIII, San Francisco, CA, USA, 4-7 February 2019; p. 109391Q.

240. Vurgaftman, I.; Weih, R.; Kamp, M.; Meyer, J.; Canedy, C.; Kim, C.; Kim, M.; Bewley, W.; Merritt, C.; Abell, J. Interband cascade lasers. J. Phys. D Appl. Phys. 2015, 48, 123001. [CrossRef] 
241. Jayaraman, V.; Segal, S.; Lascola, K.; Burgner, C.; Towner, F.; Cazabat, A.; Cole, G.; Follman, D.; Heu, P.; Deutsch, C. Room temperature continuous wave mid-infrared VCSEL operating at $3.35 \mathrm{um}$. In Proceedings of the Vertical-Cavity Surface-Emitting Lasers XXII, San Francisco, CA, USA, 27 January-1 February 2018; p. 105520B.

242. Röpcke, J.; Davies, P.B.; Hamann, S.; Hannemann, M.; Lang, N.; Van Helden, J.-P.H. Applying quantum cascade laser spectroscopy in plasma diagnostics. Photonics 2016, 3, 45. [CrossRef]

243. Hübner, M.; Gortschakow, S.; Guaitella, O.; Marinov, D.; Rousseau, A.; Röpcke, J.; Loffhagen, D. Kinetic studies of NO formation in pulsed air-like low-pressure dc plasmas. Plasma Sources Sci. Technol. 2016, 25, 035005. [CrossRef]

244. Marinov, D.; Lopatik, D.; Guaitella, O.; Ionikh, Y.; Röpcke, J.; Rousseau, A. Surface deactivation of vibrationally excited $\mathrm{N}_{2}$ studied using infrared titration combined with quantum cascade laser absorption spectroscopy. J. Phys. D Appl. Phys. 2013, 47, 015203. [CrossRef]

245. Rieker, G.B.; Jeffries, J.B.; Hanson, R.K. Calibration-free wavelength-modulation spectroscopy for measurements of gas temperature and concentration in harsh environments. Appl. Opt. 2009, 48, 5546-5560. [CrossRef]

246. Li, J.Y.; Yang, S.; Du, Z.H.; Gao, H.; Wei, Y.Y. Resolving multiple combustion parameters from a single transition using degraded deconvolution of Voigt lineshape. Infrared Phys. Technol. 2018, 92, 6-12. [CrossRef]

247. Qi-Xing, T.; Yu-Jun, Z.; Dong, C.; Kai, Z.; Ying, H.E.; Kun, Y.; Guo-Hua, L.; Yi-Bing, L.U.; Bo-Qiang, F.; Dong-Qi, Y.U. Laser absorption spectroscopy data processing method based on co-frequency and dual-wavelength and its application. Opt. Express 2018, 26, 4459-4469. [CrossRef]

248. Tang, Q.X.; Zhang, Y.J.; Chen, D.; Zhang, K.; He, Y.; You, K.; Liu, G.H.; Lu, Y.B.; Fan, B.Q.; Yu, D.Q. Research on the spectral phase correction method for the atmospheric detection in open space. Opt. Express 2018, 26, 19328-19340. [CrossRef]

249. Krzempek, K.; Dudzik, G.; Abramski, K.; Wysocki, G.; Jaworski, P.; Nikodem, M. Heterodyne interferometric signal retrieval in photoacoustic spectroscopy. Opt. Express 2018, 26, 1125-1132. [CrossRef]

250. Jarvis, J.; Haertelt, M.; Hugger, S.; Butschek, L.; Fuchs, F.; Ostendorf, R.; Wagner, J.; Beyerer, J. Hyperspectral data acquisition and analysis in imaging and real-time active MIR backscattering spectroscopy. Adv. Opt. Technol. 2017, 6, 85-93. [CrossRef]

251. Breshike, C.J.; Kendziora, C.A.; Furstenberg, R.; Nguyen, V.; Kusterbeck, A.; McGill, R.A. Infrared backscatter imaging spectroscopy of trace analytes at standoff. J. Appl. Phys. 2019, 125, 104901. [CrossRef]

252. Hashmonay, R.A.; Yost, M.G. Innovative approach for estimating fugitive gaseous fluxes using computed tomography and remote optical sensing techniques. J. Air Waste Manag. 1999, 49, 966-972. [CrossRef] [PubMed]

253. Martin-Mateos, P.; Acedo, P. Heterodyne phase-sensitive detection for calibration-free molecular dispersion spectroscopy. Opt. Express 2014, 22, 15143-15153. [CrossRef] [PubMed]

254. Giorgetta, F.R.; Rieker, G.B.; Baumann, E.; Swann, W.C.; Sinclair, L.C.; Kofler, J.; Coddington, I.; Newbury, N.R. Broadband Phase Spectroscopy over Turbulent Air Paths. Phys. Rev. Lett. 2015, 115, 103901. [CrossRef] [PubMed]

(C) 2020 by the authors. Licensee MDPI, Basel, Switzerland. This article is an open access article distributed under the terms and conditions of the Creative Commons Attribution (CC BY) license (http://creativecommons.org/licenses/by/4.0/). 